\title{
Geschichtliche Einleitung.
}

Der Durstende, der an einem aus einer Bergesspalte hervortietenden Quell niederknieet und mit dem Munde das Wasser aufsaugt oder der mit gehöhlter Hand dasselbe aus einem Wasserlaufe schöft, begeht wohl kaum eine Thätigkeit, die man künstliche Wasserversorgung nennen wird. Diese beginnt vielmehr erst da, wo eine uber den momentanen Gebrauchszweck hinausgehende vorbereitende Handlung zu der demnächstigen Wasserversorgung vorliegt, wie solches eines der ältesten chinesischen Sprichwörter "Grabe einen Brunnen, ehe du durstig bist" bezeichnend ausdrückt.

Die alteste Art solcher Wasserversorgungen. werden anfänglich Cisternen, in Form von Hỏblungen im Boden hergestellt, in denen Regenoder Tageswasser gesammelt wurde, gewesen sein. Später vertiefte man diese Cisternen und kam so zu den Brunnen, die das in den Boden eingedrungene Wasser sammelten und der Bentitzung zugänglich machten. Die Entstehung der ersten Brunnen reicht gewiss in die vorgeschichtliche Zeit zurück.

Die Brunnen oder Cisternen zum Sammeln von Oberflächenwasser sind bei fast allen wilden Völkerstämmen vorgefunden. Ueber tiefere Brunnen für Grundwasser finden wir die erste schriftliche Nachricht im 1. Buche Mose, wonach Abraham dem Abimelech Land mit einem Brunnen darauf verkaufte. Da die Entdeckung der Metalle der siebenten Generation der Erdbewohner zugeschrieben wird, so besass man sehr fruh die Mittel, die Brunnen in die Tiefe durch die Felsen treiben zu können. Der Mangel an Regen und an Flussläufen zwang die östlichen Völkerschaften, den Brunnen grossen Werth beizulegen, und mancher derselben hat Veranlassung zur Ansiedlung und späteren Entstehung von Städten gegeben, die oft ihren Namen von dem Brunnen ent- 
nommen haben. An den Brunnen spielte sich als Vereinigungspunkt der Eingesessenen manche Scene der biblischen und weltlichen Geschichte ab. Sie wurden auch mitunter als Raum zum Verstecken sowohl als zum Umbringen von Feinden und Verbergen von Leichen benützt.

In der Nähe der Pyramiden finden sich theilweise noch Brunnen vor, welche mit diesen Bauwerken gleichzeitig entstanden sein werden und von denen der bei den Pyramiden von Gizeh heute noch in Benützung ist. Unter den Ruinen von Ninive ist ein heute noch brauchbarer Brunnen aufgefunden, der von Assur, dem Sohne eines vorgeschichtlichen Herrschers, hergestellt ist. Der Sohn des Pharao baute einen Brunnen bei Wadee Jasous, der noch, heute für den Hafen von Aennum am rothen Mecre benützt wird. Heliopolis, die Stadt der Sonne, in der die griechischen Philosophen die Weisheit der Aegypter erforschten, ist verschwunden; aber der jetzt noch wassergebende Brunnen und ein einzelner Obelisk zeigt heute noch die Spuren derselben Ephesus ist nicht mehr und der Tempel der Artemis, an dem 220 Jahre gebaut u urde, ist verschwunden: aber die Brunnen, die die Bürger mit Wasser versorgten, fliessen heute noch so frisch und voll wie fruher. Als die Juden aus Egypten heimkehrten, fanden sie in Eli m zwólf Brunnen, die heute noch Wasser geben. Der Davids Brunnen zwischen Bethlehem und Jerusalem, der den Durst Davids gestillt, dient heute noch den Reisenden in Palästina zu gleichem Zwecke. Die Einwohner von Ko s trinken das Wasser desselben Quelles, welches 2300 Jahre früher dem Hippokrates gedient hat.

Die Orte im alten Grichenland hatten sehr zahlreiche Brunnen und es soll dort nach Plinius der erste Brunnen yon $\mathrm{D}$ a $\mathrm{n}$ a u $\mathrm{s}$ gebaut sein. Attika wurde hauptsächlich durch.Brunnen versorgt. Sol on bestimmte in seinen Gesetzen einen gewissen Kreis der zur Benützung der öffentlichen Brunnen berechtigten Einwơhner. Wer darüber hinaus wohnte, musste selbst einen Brunnen, aber in $2 \mathrm{~m}$. Entfernung vom Nachbar, abteufen. Fand er in $20 \mathrm{~m}$. Tiefe kein Wasser, so war er berechtigt, täglich 54 Liter Wasser von seinem Nachbar zu holen.

Die Römer stellten in allen Ländern, die sie erobert, wenn Wassermangel vorhanden war, Brunnen her und bei ihren Belagerungen spielte die Wasserversorgung eine grosse Rolle. Bei Chartres in Frankreich besteht noch ein als heilig bezeichneter Brunnen, in welchen die Römer einen Märtyrer geworfen haben sollen.

Durch das Graben eines Brunnens wurde Herculaneum entdeckt, nachdem es 1630 Jahre begraben gewesen. Ilier deckte man nach 
dieser Zeit einen zugewölbten Brunnen wieder auf, der völlig unversehrt das schönste Wasser enthielt. In dem 40 Jahre später aufgefundenen Pompeji sind Brunnen, Regenwassercisternen und Fontainen in grosser $\mathrm{Zahl}$ vorgefunden. Sie finden sich fast in jeder Strasse, und in jedem Hause oft mehrere derselben. 1832 ist dort nahe dem Pantheon ein $35 \mathrm{~m}$. tiefer Brunnen mit $4,5 \mathrm{~m}$. Wasserstand entdeckt.

Von den Brunnen der Phönicier und von denen in Karthago sind heute noch Reste erhalten. Die, Chinesen waren besonders erfahren in der Erbohrung von Brunnen. Sie haben solche his zu $500 \mathrm{~m}$. Tiefe hergestellt. Persien war ebenso wie Aegypten bei der Wasserarmuth fast ganz auf Brunnen angewiesen. Die Engländer fanden bei der Besitzergreifung von $\mathrm{Hindustan}$ hier allein 50000 Brunnen vor.

Trotzdem bei den Phöniciern, den Aegyptern und spater auch bei den Israeliten ein Gesetz bestand, dass ein Brunneneigenthümer ein in seinen offen gelassenen Brunnen gefallenes Thier bezahlen musste, wofür er jedoch dessen Leiche erhielt, findet man bei den asiatischen Völkern sehr viele Brunnen ohne eine über das Terrain sich erhebende Schutzmauer. Dieselben wurden vielmehr mit hölzernen Deckeln zugedeckt und darüber Erde geschtittet, um sie besser vor der feindlichen Absicht des Vergiftens oder des Zuschuttens zu sichern, sowie auch, um sie vor Wasserentwendung zu schützen; denn schon im alten Testamente ist verschiedentlich vom Bezahlen und Stehlen von Wasser die Rede. Man deckte die Brunnen auch wohl mit grossen, schwer zu beseitigenden Steinen ab. Es ist daraus zu schliessen, dass man hier keine bleibende maschinenartige Einrichtungen zum Heben des Wassers angewendet. Welchen Werth man auf die Erhaltung der Brunnen legte, geht aus verschiedenen Angaben hervor, wonach man, namentlich bei den Aegyptern, an den Brunnen zu ihrem Schutze constante Wachen errichtet hatte. Bei den Griechen und Römern sind die Brunnen fast stets in den Umfassungswänden hoch über das Terrain hinaufgeführt und häufig sind diese Schutzmauern reich decorirt.

In der Nähe von Sichem, auf dem Wege von Galiläa nach Jerusalem, liegt ein beruhmter Brunnen, der Jakobs-Brunnen, welcher vor über 3500 Jahren dem Erzvater Jakob diente und heute noch seine Nachkommen speist. $\operatorname{Er}$ ist $30 \mathrm{~m}$. tief, hat $3 \mathrm{~m}$. Durchmesser, hält $6 \mathrm{~m}$. Wasser und ist völlig durch festen Felsen gebohrt. Hier fand die Begegnung von Christus mit der Samariterin statt. Heute noch wird dieser Brunnen von allen nach Palästina wallfahrtenden Pilgern besucht. 
Der Brunnen Zemzem in Mekka bildete, ebenso wie die Moschee Kaaba, in welcher er sich befand, und der schwarze Stein schon lange vor Muhamed eines der drei grössten Heiligthümer der Araber, weshalb Muhamed diese drei Gegenstände auch in seine Religionslehre aufnahm. Er war der einzige. Brunnen in Mekka, dessen Wasser getrunken werden konnte. Derselbe hatte $65 \mathrm{~m}$. Tiefe, $2,5 \mathrm{~m}$. Durchmesser und es stand das Wasser in $\mathrm{ihm}$ bis auf $17 \mathrm{~m}$. hoch unter der Terrainfläche. Eine 1,5 m. hohe Einfriedigungsmauer von Marmor schloss ihn oben ein.

Das grossartigste Bauwerk, welches sich allen auf irgend einem Gebiete ausgeführten bedeutenden Leistungen alter Zeiten würdig zur Seite stellen kann, ist der Josephs-Brunnen in Kairo. Ueber die Zeit der Erbauung desselben fehlen alle zuverlässigen Angaben. $O b$ è seine Entstehung den Babyloniern oder dem Soliman verdankt, oder wer ihn sonst erhaut hat, ist unbekannt. Derselbe besteht aus zwei Brunnenscháchten von rechteckigem Querschnitte, die unter einander liegen und durch eine grosse Kammer mit einander verbunden sind. Er ist ganz in Felsen ausgearbeitet. Dic Solle des unteren Brunnenschachtes reicht bis in den Kies, aus dem das Wasser entnommen wird. In jedem der beiden Schächte befindet sich unabhängig von einander je ein Eimerwerk, welches aus Thongefässen, die an einer Kette ohne Ende aufgehängt waren, bestand. Diese Ketten wurden durch Göpel, die von Ochsen oder Pferden gedreht wurden, bewegt. Das Eimerwerk des unteren Schachts hatte in der erwähnten Kammer zwischen beiden Schächten seinen Göpel und goss das Wasser hier in ein Reservoir aus, aus welchem es das Eimerwerk des oberen Schachtes, dessen Göpel uber Tage aufgestellt war, entnahm. Der obere Schacht hat einen rechteckigen Querschnitt von $7,7 \mathrm{~m}$. mal 5,6 m., der untere von 4,6 m. mal 2,8 m. Ersterer ist $50 \mathrm{~m}$., letzterer $40 \mathrm{~m}$. tief. Um die Thiere in die $\mathrm{zwischen}$ beiden Schächten liegende Kammer zur Bewegung des unteren Göpels bringen zu können, ist spiralförmig um den oberen Schacht in dem Felsen ein Kanal von $2 \mathrm{~m}$. Breite und 2,2 $\mathrm{m}$. Höhe hergestellt, der eine solche Steigung hat, dass man auf diesem Wege bequem reiten kann. Dabei ist der lichte Raum des Schachtes durch eine stehengebliebene $15 \mathrm{~cm}$. starke Wand des natirlichen Felsens, in welcher sich Lichtöffnungen befinden, von dem Kanal getrennt.

Wenngleich die im Vorstehenden geschilderten Brunneuanlagen sehr häufig öffentliche waren und somit der allgemeinen Benutzung anheim fielen, so wurde durch sie allein doch nicht das erreicht, was 
hier speciell aus dem grossen Rahmen ausgeschieden als ktustliche Wasserversorgung behandelt werden soll, nämlich:

die Anlagen, welche, über die Grenzen des Bedürfnisses der einzelnen Familie oder des einzeluen Grundbesitzers hinausgehend, es sich zur Aufgabe machen, eine grössere Zahl von Menschen, die Einwohner einer ganzen Ortschaft oder von Theilen derselben in mehr oder weniger grosser Vollkommenheit gemeinschaftlich mit allem erforderlichon Wasser zu versorgen.

Bei den Brunnen bedarf es zur Wassergewinnung noch der künstlichen Hebung, auf welche später zurlickgekommen werden wird. Vorab sollen hier jedoch die für die in Frage stehenden $Z$ wecke zulässigen Wassergewinnungsal ten, welche ausser der Erschliessung durch Brunnen möglich sind, verfolgt werden.

Wenn die eigentlichen Brunnen aus der nicht befriedigten Aufstauung des Oberflächenwassers entstanden sind, so hat ebenfalls die Verfolgung der Idee dieser Ansammlungen auf der anderen Seite schon früh zu bedeutenden mit Erfolg gekrönten Anlagen gefuhrt. Es lag zu nahe, dass man zur Zeit des Wassertiberflusses, bei Regenwetter oder grosser Elgiebigkeit von Quellen und Wasserläufen das Wasser in grosseren Cisternen, Teichen oder Reservoiren ansammelte, um dasselbe während der Zeit der Trockenheit zu benützen.

So war Jerusalem, welches nur zwei Brunnen, den Brunnen Rogel und den Mariẹnbrunnen besass, hauptsächlich auf Regenwasser angewiesen, welches in vielen Tausenden von unterirdischen Cisternen von den Dächern der Häuser gesammelt wurde. In der Stadt befanden sich ausserdem eine grosse Zahl von kunstlich hergestellten Teichen, z. B. der Hiskiasteich, der obere und der untere Gihonteich und der Teich Siloah. Aehnliche Reservoire lagen vor dem Jaffathore und dem Stephansthore. Der durch seine Wunderwirkungen bekannte Teich Bethesda lag vor dem Schaafthore und ist jetzt verschuittet. Am grossartigsten waren die Reservoire zwischen Bethlehem und Hebron, die Teiche des Salomo, die zum Theil heute noch existiren. Das Wasser wurde von hier durch eine theils in die Felsen eingehauene, theils aus 2 ausgehohlten Steinen gebildete Leitung dem Tempel in Jerusalem zugeführt. Die Leitung hatte im Lichten $250 \mathrm{~mm}$. Durchmesser. Wo sie künstlich aus Steinen hergestellt ist, sind dieselben in eine Art Beton eingeschlossen und in den Boden versenkt verlegt. Diese Leitung soll unter Pontius Pilatus ausgefuhrt sein. Es wird ferner von Gibeon berichtet, dass dort zwei grosse unterirdische 
Bassins gewesen seien, die an der nördlichen Seite des Hugels in den Felsen eingehauen waren.

Der Mörissee in Aegypten, im Thale von Fayum einige Meilen oberhalb von Memphis gelegen, ist künstlich für Bewàsserungszwecke von dem Aegypterkönige, den die Griechen Möris nanuten und der 2200 oder 3000 vor $\mathrm{Chr}$. gelebt haben soll, hergestellt. Der Boden dieses Sees ist ausgegraben und kinstliche Dámme von $50 \mathrm{~m}$. Breite und $5 \mathrm{~m}$. Höhe begrenzten seine Seiten. Die Oberflache des Sees hat nach einigen Angaben $12240 \mathrm{Ha}$., nach anderen sogar noch zehnmal mehr betragen. Der See wurde von grossen Schiffen befahren. Als Wasserstandszeiger dienten zwei in demselben erbaute Pyramiden, jede $165 \mathrm{~m}$. hoch. Durch ein von hier ausgehendes Kanalnetz, welches durch Schleusen mit dem See verbunden war, fand die Bewässerung der Ebene von Memphis statt. Die Schleusenverwaltung allein kostete im Jahre 216000 Mk. Aber schon die Fischerei auf dem See brachte jährlich funfmal mehr ein. Der See wurde aus einem sich von Oberàgypten herab parallel dem Nile entlang ziehenden Kanale gespeist, der ausserdem noch viele Landstrecken bewassserte. Jetzt ist der Mórissee ausgetrocknet und die Kanäle sind verschuttet.

Aehnliche Anlagen finden sich in dem ganzen ubrigen Theile von Aegypten, welcher in Alterthume bewohnt war. Trotzdem 8 Monate eine furchtbare Hitze war, und ferner zwei Monate Ueberschwemmungen im Jahre stattfanden, also nur zwei kurze Monate fur ein Emporblühen der Vegetation blieben, so hat dennoch zu jener Zeit eine Fläche von $750 \square$ Meilen 8 Millionen Menschen ernährt. Wohin durch Stauung der Hochfluthen des Nils das Wasser nicht zu leiten möglich war, dienten zahllose Maschinen zum Schöpfen desselben, von denen später die _Rede sein wird.

Von gleicher Bedeutung waren die Bewässerungsanlagen in $\mathrm{As}$ syrien. Die Königin Nitocris liess den Nitocris-See herstellen, der durch einen Kanal yom Euphrat aus gespeist wurde. Derselbe war so gross, dass er 22 Tage lang die ganze Wassermasse des Euphrat aufnehmen konnte. 1200 Jahre später wurde durch den See, welcher halb versandet war, Babylon ins Verderben gebracht, indem der die Stadt belagernde Kyros den Euphrat nach hier leitete und damit in der Stadt eine grosse Ueberschwemmung verursachte. Eine von Semiramis herruhrende Denkschrift, welche von Alexander aufgefunden ist, lautet: "Ich habe alle Ströme gezwungen dahin zu fliessen, wo jch wollte, und ich wollte sie nur da, wo es nützlich war. Ich habe 
die dürre Erde fruchtreich gemacht, indem ich sie durch meine Ströme bewässerte "

In ähnlicher Lage der Wasserbedurftigkeit befand sich Indien, zu dessen Bewässerung das ganze Land mit Kanälen durchzogen war. Hier ist in der Anlage von Teichen das Unglaublichste geleistet. In der Präsidentschaft Madras allein befanden sich 53000 Sammelteiche oder Reservoire ausser den kleinen bei den Dörfern gelegenen, zu der Zeit, als die Englander das Land eroberten und es soll die Länge sämmtlicher zur Eindeichung der Teiche vorhandenen Erdwälle $4800 \mathrm{Q}$ Kilom. betragen haben. Bei und in diesen Teichen befinden sich mehr als 300000 Kunstbauten, als Brücken, Schleusen etc. Obgleich viele der besten Reservoire zerfallen oder zerstört sind, bringt das aus denselben abgegebene Wasser der Präsidentsclaft Madras jetzt noch eine jährliche Einnahme von 30 Millionen Mk., ein Sechstel der Gesammteinnahmen aus diesem Landestheile. Der Teich von Poinaris im District Trichinopolis hat $20000 \mathrm{Ha}$. Oberfläche und seine Ufer sind $48 \mathrm{Kilom}$. lang. Der Teich von Veranum hat $8000 \mathrm{Ha}$. Oberfläche und Dämme von 16 Kilom. Lànge. In Ceylon befindet sich ein Reservoir mit einem Damme von 20 Kilom. Linge, welches eine Wasserfläche von 64 Kilom. Umfang abschliesst. Ein anderes Reservoir hat einen 1,6 Kilom. langen künstlichen Damm und einen Umfang von 30 Kilom. Der Cummum-'Teich in der Präsidentschaft Madras ist $8 \mathrm{Kilom}$. lang und hat eine Maximalbreite von ذّ Kilom. Die Wasserfläche beträgt circa 2000 Ha. und es hat der künstliche Damm eine Höhe von $30 \mathrm{~m}$. Der Teich von Caverykaupum hat $1685 \mathrm{Ha}$. Oberfläche, der von Dschumprumkaupum $2550 \mathrm{Ha}$. und der von Ussuda $9690 \mathrm{Ha}$. bei 12 Millionen $\mathrm{kbm}$. Inhalt.

Die Dimensionen dieser Wasserbehälter übersteigen wesentlich die der in England fur Wasserversorgungen erbauten und unterscheiden sich in der Construction der Dámme dadurch, dass die Hindus niemals Thon für die wasserdichtende Schicht bei denselben benützt haben.

Die Zuleitung des Wassers, soweit sie ohne künstliche Hebung von den Quell- oder Sammelgebieten zu den Verbrauchsorten möglich war, geschah durch offene oder verdeckte Kanäle, die theils uber oder in der Terrainoberfläche hergestellt, theils auf künstlichem Unterbau uber Thäler oder Niederungen hinweggefübrt oder durch Berge und Höhenzüge in Form von Tunneln hindurchgetrieben wurden. Man leitete das Wasser, nur dem naturlichen Gefälle folgend, weiter. Diese Rücksicht verlangte, nicht immer die directesten Wege zu wählen, 
sondern den zulässigen Gefällen und vorhandenen Terrainverhältnissen Rechnung zu tragen, wodurch der Bestimmungsort oft erst auf langen Umwegen zu erreichen war.

Die für solche $\mathrm{Zwecke}$ geschaffenen Bauwerke, von welchen einzelne noch völlig erhalten sind und welche zum Theil aus den Ruinen und Beschreibungen zu unserer genauen Kenntniss gelangten, müssen unsere grosste Hochachtung hervorrufen sowohl wegen der Grossartigkeit der Conception, als auch wegen der Aufwendung von Mitteln, die unter unseren jetzigen Verhältnissen uns unerschwinglich erscheinen.

Vielleicht eine der altesten Leitungen, die wahrscheinlich von den Phöniciern erbaut ist, diente zur Versorgung des alten Karthago und es sind einzelne Theile derselben noch so weit brauchbar geblieben, dass diese, nachdem sie 2000 Jahre brach gelegen, in den 60 er Jahren zur Wasserversorgung von Tunis wieder in Gebrauch genommen werden konnten, wobei die zerstörten Theile durch gusseiserne Leitungen ersetzt wurden. Die ganze Leitung war circa $100 \mathrm{Kilom}$. lang und so hoch und breit in dem Kanale, dass ein Mann dieselbe durchschreiten konnte. Wo sie die Felsen durchdringt, sind in circa $20 \mathrm{~m}$. Entfernung Ventilationsschächte von $2 \mathrm{~m}$. Durchmesser hergestellt. Der Aquaduct selbst besteht aus 2 Reihen Bogeustellungen über einander und hat eine Höhe von bis $39 \mathrm{~m}$. Die Pfeiler desselben sind theils ganz von Mauerwerk, theils von Lehm, der früher mit grossen Steinplatten bekleidet war, hergestellt.

Auch in Griechenland finden sich Ueberbleibsel von alten Aquaducten in verschiedenen Theilen des Landes. Die grossen Bevölkerungen Athens und Korinths machten eine künstliche Wasserzuführung jedenfalls nothig. Denn dass man dort von dem Wasser reichlichen Gebrauch machte, beweisen die Schilderungen Homers von den Gartenanlagen des Alkínoos.

Den ältesten Bericht über eine grössere Leitung verdanken wir Herodot. Dieselbe war nach ihm von Eupalinos, einem Architekten von Magaera, für die Stadt $S$ amos erbaut und bestand aus einem Kanale von fast $1 \mathrm{~m}$. Breite und einem Tunnel von 1,6 Kilom. Länge.

Ein eigenthümlicher, sehr primitiver Aquaduct ist bei Pataza aufgefunden. Er uberschreitet eine Schlucht von $62 \mathrm{~m}$. Weite und $78 \mathrm{~m}$. Maximaltiefe. Eine im Grundrisse nicht geradlinig, sondern in einer Curve gebaute kräftige Mauer hat eine Durchlassöffnung für den das Thal durchfliessenden Wasserlauf und trägt oben Steioblöcke von fast $1 \mathrm{~m}$. Seite in Würfelform, die mit Löchern von $300 \mathrm{~mm}$. Durch- 
messer durchbohrt sind und mit runden $70 \mathrm{~mm}$. hohen und ebenso tiefea Falzen und Nuthen in einandergreifen. An den Stössen sind sie mit schmiedeeisernen Klammern, die mit Blei vergossen sind, verbunden. In je circa $6 \mathrm{~m}$. Entfernung befinden șich Ventilationsöffnungen von $175 \mathrm{~mm}$. Durchmesser.

Die grossartigsten derartigen Bauten sind von den Römern und zwar für Rom selbst mit der Zeit der. Censur des Appius Claudius beginnend ( 312 v. Chr.) und in den folgenden Jahren ausgefuhrt. Bis zu dieser Zeit würde diese Stadt fast ausschliesslich aus dem Tiber, sowie dürch Brunnen kleiner Quellen versorgt. Kein Volk gleicht den Römern in der immensen Ausdehnung dieser offentlichen Banten, durch welche solche übermässige Wassermengen mit solch erstaunlichen Werken zugeführt wurden. Diese auf den-ersten Blick unerklärliche Aufwendung von Mitteln wird begreiflich, wenn man die derzeitigen Verhältnisse etwas näher betrachtet.

Die römischen Bauten waren keine stältische, sondern solche, welche von der Regierung des Reiches, das die Welt beherrschte, für ihren Sitz hergestellt wurden. Sie dienten dem Wohlleben der Stadt. in riesigem Maasstabe und fur den, der die Herrschaft besass oder erstrebte, war ibre Schopfung das Mittel, sich die Gunst des Volkes zu erhalten oder zu erringen. Die $\mathrm{H}$ andwerksleistungen waren durch die grosse Zahl der Gilden in den kleinsten Detaillirungen von einander getrennt. Dadurch war aber eine Theilung der Arbeit und damit eine Vollkommenheit und Fertigkeit in der einzelnen Arbeitsleistung erreicht, die uns heute noch, trotzdem uns ihnen unbekannte theoretische Kenntnisse und mechanische Einrichtungen zu Hülfe stehen, in Erstaunen setzen müssen. Die wachsende Maclt dieser Handwerkergilden zwang die Regierung, ihnen zablreiche Concessionen und Begünstigungen zu ertheilen; sie besass aber die Klugheit, als Gegenleistung dafür von ihnen die Verpflichtung zu erlangen, der Regierung stets eine grosse Zahl von Handwerkern gegen festgestellten Lohn nach Bedürniss zur Verfügung zu stellen. Diese wurden entweder in Rom bei Bauten beschäftigt oder mussten die auf Eroberungen ausziehenden Legionen als Nichtcombattanten begleiten. Wo neue Colonien gegrundet wurden, hatten sie die nöthigen Wege- und Wasserbauten auszuführen und es standen denselben als Hülfskräfte die Sclaven und Kriegsgefangenen, welche man $\mathrm{ja}$ an jeder Stelle in jeder Zahl concentriren konnte, zur Verfügung. Dadurch besass man ein Heer geschulter Arbeiter, die die schnellste und beste Ausführung von 
Bauten ermöglichten. Es sollen beispielsweise durch solche Kräfte die beruhmten Bäder des Caracalla in zwei Jahren ausgeführt sein.

Die Arbeitsleistungen wurden zu jener Zeit auch nicht schlecht bezahlt. So erhielt bei freier Kost pro Tag ein freier Arbeiter 85 Pf., ein Maurer, Zimmermann, Schmied 3 Mk., ein Maler $3 \mathrm{Mk}$. 75 Pf., ein.Stuckarbeiter und Decorateur 7 Mk. 50 Pf., während damals z. B. das Rindfleisch $60 \mathrm{Pf}$. und das Schweinefleisch $1 \mathrm{Mk}$. pro Pfund kostete.

An der Spitze eines durch solche Kräfte auszuführenden baulichen Unternehmens stand der Vertreter des Bauherrn, der "Curator operis", der die Interessen des Stantes zu vertreten hatte. Die Ausführung leitete der Baumeister, welcher oftmals zugleich als Unternehmer für die Lieferungen der Materialien auftrat; die Arbeiter wurden aberstets von der Behörde selbst bezahlt. Unter dem Baumeister standen Inspectoren, Werkfuhrer, Aufseher und Geometer, "mensores aedificorum“. Von den von dem Baumeister ursprünglich in Zeichnungen festgelegten und gebilligten Plane durfte ohne hóhere Genebmigung nicht abgewichen werden. Zur Erlangung der nothigen Baumaterialien war der Staat berechtigt, alles für ihn brauchbar erscheinende Material, als Erde, Thon, Steine, Ziegel, Sand, Holz etc., welches sich in Privatbesitz befand, durch Schiedsrichter abschätzen zu lassen und in Besitz zu nehmen. Für die nöthigen Transportwege musste während des Baues das nöthige Terrain unentgeldlich uberlassen und die erforderlichen Spanndienste mussten auf Requisition geleistet werden.

Ueber den Zustand der Rom versorgenden Wasserleitungen im ersten Jahrhundert uach Christo finden sich in einer von Sextus Frontinus, der unter Nerva und Trajan als curator die Oberleitung der Wasserversorgung in Händen hatte, eine sehr interessante Denkschrift: "Commentarius de Aquaeductibus Urbis Romae", die 1820 von Rondelet in französischer Uebersetzung unter dem Titel „Commentaire de S. J. Frontin sur les Aqueducs de Rome" und 1844 von A. Dederich in deutscher Uebersetzung unter dem Titel ,Frontinus, Ueber die Wasserleitungen der Stadt Rom" herausgegeben, hinterlassen.

Rom wurde zu dieser Zeit durch 9 Leitungen versorgt: nämlich durch die Appia Claudia seit 313 v. Chr., die alte Anio seit 273 v. Chr., die Marcia seit 146 v. Chr., die Tepula seit 127 v. Chr., die Julia seit 33 v. Chr., die Virgo und die Alsietina seit 19 v. Chr. und endlich durch die Claudia und die neue Ánio seit $39 \mathrm{n}$. Chr.

Die Aqua Alsietina, auch Aqua Augusta genannt, wurde aus dem 
Lago Martignano gespeist, wahrend die ubrigen Leitungen Quellenwasser aus 3 verschiedenen Bezirken zufuhrten. Die Appia und die Virgo entnahmen das Wasser den in der Nähe der Stadt an Ufer des Anio entspringenden Quellen. Die Quellen der Tepula und der Julia lagen in der Nähe des Lago di Castel Gandolfo zwischen Marino und Frescati. Diese beiden Quellgebiete befinden sich in vulkanischem Gestein, während die ùbrigen vier Leitungen, die Marcia, die Claudia, die Anio novus und die Anio vetus, den Zufluss aus dem Kalkgebirge erhalten, welches zwischen Tivoli, Agosta und Subraco liegt.

Die A qua Appia Claudia ist, wie bemerkt, von dem Censoren Appius Claudius Crassus vollendet, während Gajus Plautius, der dafur den Beinamen Venox (von vena, Wasserader) erhielt, sie begonnen hat. Sie nahm ihren Anfang bei Praenste und hatte eine Länge von 26,03 Kilom. Die Quellen lagen $62 \mathrm{~m}$. ủber dem Meere und es mündete das Wasser in Rom 53,63 m. tiefer, als es entsprang, ein. Das täglich zugeführte Quantum betrug $61300 \mathrm{kbm}$. Der Kanal hatte $0,80 \mathrm{~m}$. Breite und $1,60 \mathrm{~m}$. Hỏe. $\mathrm{Er}$ ist auf $88 \mathrm{~m}$. Länge von Bogenstellungen getragen.

Die Aqua Anio vetus ist von dem Censoren Papirius Cursor begonnen und von Fluvius Flaccus vollendet. Das Geld zu ibrer Herstellung ist durch Verkauf der dem Könige Pyrrhus abgenommenen Siegesbeute beschafft. Diese Leitung entnahm das Wasser dem Flusse Anio bei Tibur und war $63,7 \mathrm{Kilom}$. lang, wovon $329 \mathrm{~m}$. Länge Aquaducte sind. Die Quelle entspringt $183 \mathrm{~m}$. über dem Meere und es mündete das Wasser in Rom 35,17 m. über dem Meere ein. Die Leitung bestand aus einem Kanale von $1,10 \mathrm{~m}$. Breite und 2,48 m. Hỏhe, der täglich $272600 \mathrm{kbm}$. Wasser zufuhhrte.

Die Aqua Marcia ist von dem Prätor Quintus Marcius erbaut und führte das Wasser der Peligner und Marsischen Berge zu. Plinius äussert sich uber dieses Wasser, „dass unter den durch die Gute der Götter der Stadt gewàhrten Segnungen das Wasser der Marcia, welches klar, kalt und gesund sei, als eine der ausgezeichnetsten gelte ${ }^{4}$. Trotzdem die Quellen 53 Kilom. von Rom entfernt und $312 \mathrm{~m}$. über dem Meere entspringen, hat die Leitung eine Länge von 100,6 Kilom. Der Kanal ist $1,7 \mathrm{~m}$. breit und 2,50 m. hoch und ist mit einem Halbkreisgewölbe geschlossen, während die beiden vorhergehenden Leitungen in der Decke einen giebelförmigen Abschluss haben. Die Marcia wurde unter Augustus in ihrem Quantum durch Einmündung der unterirclisch erschlossenen Aqua Augusta, die $3000 \mathrm{~m}$. lang war, verstärkt. Die. Leitung mundete in Rom $37,48 \mathrm{~m}$. hoch über dem Meere ein $\mathrm{nnd}$ 
lieferte $95400 \mathrm{kbm}$. Wasser pro Tag. Auf $10108 \mathrm{~m}$. Länge war der Kanal durch, Bogenstellungen getragen. Auf der ganzen Länge der Leitung vertheilt finden sich in derselben in gewissen Zwischenräumen Schlammfänge.

Die Aqua Tepula hatte 18,8 Kilom. Länge, wovon $610 \mathrm{~m}$. auf Aquäducte entfallen. Sie mundete $38,23 \mathrm{~m}$. hoch über dem Meere in Rom und lieferte pro Tag $2300 \mathrm{kbm}$. Der Kanal ist $0,80 \mathrm{~m}$. breit und $1,00 \mathrm{~m}$. hoch. Die Leitung führte das Wasser der Tepula aus dem Lucullischen Gebiete nach dem Capitol.

Die A qu a Julia, von Agrippa erbaut, war 19,5 Kilom. lang und ruhte $9588 \mathrm{~m}$. lang auf Bogenstellungen. Sie mlindete $39,71 \mathrm{~m}$. hoch über dem Meere in die Stadt und lieferte pro Tag $45400 \mathrm{kbm}$., welches in dem Quellgebiete der Tepula gesammelt wurde. Der Kanal hatte $0,70 \mathrm{~m}$. Breite und $1,40 \mathrm{~m}$. Hohe. Die zuletzt aufgeführten drei Leitungen wurden auf einer Strecke durch einen gemeinschaftlichen Aquäduct getragen, die eine uber der anderen liegend.

Die A qua Virgo ist gleichfalls von Agrippa erbaut. Sie kommt aus dem Lucullischen Gebiete und nimmt auf ihrem Laufe noch einige andere Quellen auf. Sie hatte eine Lange von $25,2 \mathrm{Kilom}$., wovon $1037 \mathrm{~m}$. aus einem Aquäducte und $800 \mathrm{~m}$. aus einem Tunnel bestehen. Sie entspringt $70 \mathrm{~m}$. über dem Meere und mündete in Rom $10,43 \mathrm{~m}$. darüber. Das täglich zugefuhrte Quantum betrug $59000 \mathrm{kbm}$. Der Kanal hat $0,50 \mathrm{~m}$. Breite und $2,00 \mathrm{~m}$. Höle.

Die Aqua Alsietina ist von Augustus selbst erbaut. Sie wurde auch Aqua Augusta genannt und diente hauptsächlich für die Versorgung von Teichen fur die Schauspiele von Seeschlachten (naumachiae), sowie ausserdem zur Gartenbewässerung für Private. Sie war 34,0 Kilom. lang und ruhte in einer Länge von $530 \mathrm{~m}$. auf einem Aquäducte. Sie führte $25000 \mathrm{kbm}$. Wasser pro 24 Stunden zu und entsprang $56 \mathrm{~m}$. und mundete $5 \mathrm{~m}$. úber dem Meere.

Die Aqua Claudia ist unter der Regierung des Caligula begonnen und unter der des Claudius vollendet. Sie hat, trotzdem sie neben der Marcia entspringt, nur 68,7 Kilom. Länge gegenüber der Länge der Marcia von 100,6 Kilom. Von der Aqua Claudia entfallen $803 \mathrm{~m}$. auf einen Tunnel und $14173 \mathrm{~m}$. auf Aquäducte. Das Wasser entsprang an der Sublacensischen Strasse 25う m. über dem Meere und floss $47,42 \mathrm{~m}$. hoch uber dem Meere in Rom aus. Das täglich zugeführte Quantum betrug $109000 \mathrm{kbm}$. Der Kanal ist $1,00 \mathrm{~m}$. breit, $2,00 \mathrm{~m}$. hoch und scheidrecht abgedeckt. 
Die Aqua Anio novus, gleichfalls unter der Regierung des Caligula begonnen und von Claudius vollendet, ist 88,9 Kilom. lang, wovon $802 \mathrm{~m}$. auf Tunnel und $13023 \mathrm{~m}$. auf Aquäducte entfallen. Sie entspringt $250 \mathrm{~m}$. über dem Meere und mündete $48,12 \mathrm{~m}$. darüber in Rom ein. Sie lieferte täglich $109000 \mathrm{kbm}$. Wasser und entnahm dasselbe dem Flusse Anio. Der Kanal ist $1,00 \mathrm{~m}$. breit und $2,70 \mathrm{~m}$. hoch mit Halbkreisgewölben geschlossen.

Von diesem gesammten zugefuhrten $W$ a s s e $r q$ u a n $t u$ m ron 947200 kbın. täglich entfielen, der verschiedenen Qualität wegen für verschiedene Verbrauchszwecke gesondert: für den allgemeinen Gebrauch, zum Strassenwaschen etc. $636100 \mathrm{kbm}$., nämlich das Wasser der Appia, der Anio vetus und novus und der Alsietina; ferner als Bade- und Trinkwasser die ubrigen $311100 \mathrm{kbm}$., von welchen das Wasser der Virgo $59000 \mathrm{kbm}$. als das reinste bezeichnet wird. Nach einer Berechnung Rondelet's würde dieses Wasserquantum durch ein Flussbett von circa $10 \mathrm{~m}$. Breite und $2 \mathrm{~m}$. Tiefe bei $0,6 \mathrm{~m}$. Geschwindigkeit pro Secunde abfliessen. Derselbe giebt als die Hohe der Leitungen bei ihrem Eintritte in die Stadt, tuber dem Quai der Tiber bei der Mündung der Cloaca Maxima gemessen, an: für die Claudia 47,42 m., die Anio nova 47,32 m., die Julia 39-71 m., die Tepula 23-38 m., die Marcia 37,28 m., die Anio vetus 25,17 m., die Virgo 10,43 m. und die Appia $8,37 \mathrm{~m}$. Die ganze Länge der Leitungen betrug 443,4 Kılom., von welcher $240 \overline{\mathrm{m}}$. auf verschiedene Tunnel und $49537 \mathrm{~m}$. auf Aquäducte mit Bogenstellungen, welche bis zu $32 \mathrm{~m}$. Hohe hatten, entfallen.

Das Wasser der verschiedenen Leitungen ergoss sich in Rom, nachdem es vorher kleine Behälter, piscinae, zum Absetzen von Sand etc. passirt hatte, in sogen. castella, Wasserschlösser (franz. Chateau d'eaux), auch receptacula, da sie zur Aufnc.bme u.ld Ansammlung, und anch dividicula, da sie als Vertheiler dienten, genannt. Frontinus giebt ihre Zahl auf 247 an. Sie bildeten drei verschiedene Arten von Reservoiren, aus denen das Wasser für die verschiedenen Zwecke getrennt abgegeben wurde. Ein directer Anschluss an die Hauptzuleitungen zur Stadt war auf das Strengste ausgeschlossen. Der eine Theil dieser Wasserschlösser versorgte die Privatconsumenten, der andere die öffentlichen Teiche, die Fontainen, die offentlichen Bäder und die Tempel und der dritte endlich die Paläste und sonstigen Gebäude des kaiserlichen Dienstes. Von diesen Reservoiren aus, die im Ganzen vielleicht $20060 \mathrm{kbm}$. Wasser fassten, also nicht als 
eigentliche Vorrathsbassins, sondern hauptsächlich zum Ausgleich und zur Reguliruıg dienten, wurde das Wasser einer grossen Zahl von über die ganze Stadt vertheilten runden, gemauerten Cisterneu oder Wasserthürmen durch Leitungen zugeführt. Aus diesen Cisternen fand die eigentliche Abgabe statt.

Welche Mittel auf die Wasserverwendungseinrichtungen für öffentliche Zwecke verausgabt wurden, beweist, dass Agrippa im Laufe eines Jahres 70 Teiche, 105 Fontainen und 130 Reservoire in Rom bauen liess, alle mit ehernen und mamornen Statuen und Säulen geschmückt. Die Zahl der ersteren wird von Plinius auf 300 , die der letzteren auf 400 als überhaupt vorhanden angegeben. Zur "Zeit des Trajan sollen 590 Bassins mit fliessenden Rohrbrunnen und ferner 38 plastisch geformte Kunstwerke als Fontainen vorhanden gewesen sein.

Unter Augustus entfiel in Rom auf den Kopf der gesammten Bevölkerung von 350000 Seelen circa $2,7 \mathrm{kbm}$. Wasser pro Tag; es sollen aber auch damals in der Stadt 1350 offentliche fliessende Brunnen und 591 Fontainen mit springendem Strable mit Wasser gespeist sein. Ferner wurden 19 immense befestigte Lager, 95 grosse offentliche Badeanstalten, 39 grosse Theater und Kampfplätze (arenae), alle mit uberschwenglicher, Tag und Nacht stattindender Wasserbenützung unterhalten. Die Zahl der offentlichen Bäder wird zur Zeit des Valentinian ausser den 12 Thermen auf 856 Stück angegeben. Ein solcher Wasserverbrauch ist, wenn es sich nur um reelle Verwendung gehandelt hätte, undenkbar, wenn auch, trotzdem ein Wasserverbrauch für technische $Z$ wecke kaum in heutigem Maasse existirte, die Verwendung des Wassers zur Kühlung der Luft sowohl, als auch zum Baden - im Tage 7 mal zu baden war nichts Ungewohnliches in einem unsere Gẹbräuche weit übersteigendem Maasse, begründet auf der Verschiedenheit des Klimas, stattfand. Nach Angabe des Frontinus sollen von Einer Leitung allein 13594 Privatleitungen von je $20 \mathrm{~mm}$. Durchmesser aus den entsprechenden Cisternen gespeist sein. Die künstlichen Teiche hatten in Rom eine solche Ausdehnung, weil man darauf Seegefechte auffuhrte, ein Schauspiel, das die Römer in so hohem Grade interessirte, dass Augustus, wie schon bemerkt, die Aqua Alsietina von 34 Kilom. Länge ursprünglich nur für diesen Zweck erbaute und dass Claudius den See Fucinus dafür durch an den Ufern hergestellte Zuschauerplätze einrichten liess.

Dem Frontinus verdanken wir ferner noch einige Einzelheiten uber die Verwaltung der Wasserversorgung. Unter der Republik 
hatteń die Censoren und Aedilen dieses Geschäft wahrzunehmen. Während der Kaiserzeit wurden vom Kaiser dazu Personen ernannt, die vom Senat bestätigt werden mussten. Welche Wichtigkeit dem-Posten dieser Curatoren der Wasserleitungen zugeschrieben wurde, geht daraus hervor, dass Frontinus vor seiner Ernennung zum Director der Wasserleitungen alle burgerlichen Ehrenstellen Roms erreicht, vor Agricola den militäı ischen Oberbefehl in Britannien gehabt und daselbst Wales unterworfen hatte. Diese Curatoren wurden überhaupt aus dem Kreise der angesehensten und bewälırtesten Männei genommen. Von Amtswegen führten sie in der Stadt Architekten, Schreiber, Buchführer und ferner einen Ausrufer und drei Staatssclaven mit sich, denen sich ausserhalb der Stadt noch zwei Lictoren zugesellten. Die Curatoren hatten zu sorgen, dass das Wasser bei Tag und Nacht ununterbrochen fur die Benützuug des Volkes floss.

Während zur Zeit der Republik für die Privaten nur der Ueberfluss aus den Bassins bestinmt war und auch dieser nur für Bäder und Walkcranstalten, die als gemeinnützlich angesehen wurden, benützt werden durfte und es nur den Grossen der Stadt zugestanden wurde, Wasser in ihre Häuser zu leiten, ging man zur Zeit des Kaiserreiches darin weiter. Damals konnte Jedermann um dieses Privilegium anhalten. Aber nur die Curatoren konnten den Privaten die Benützung und Einleitung von Wasser bewilligen und eq war diese Bewilligung ein Benificium, eine Gunst oder eine Belohnung für die Verdienste, während der kleine Mann in der Regel nur an den öffentlichen Brunnen, in den öffentlichen Bädern und in den Waschhäusern das Wasser benützte. Es wurde das Quantum für Private durch ein Messrohr von bestimmtem Querschnitte, welches diesen Querschnitt auf eine Lange von 16 m., von der Eintrittsöffnung ab gerechnet, haben musste, volgeschrieben. Der Anschluss von Privatleitungen konnte sur an den Cisternen erfolgen. Die Concession für Private wurde nur auf ein bestimmtes Quantum einer bestimmten Person auf Lebenszeit ertheilt und es war die Einheit des Maasses der quinarius d. i. ein Maass, welches durch ein Rohr von Bronce von $3 \mathrm{~cm}$. Durchmesser urid $30 \mathrm{~cm}$. Länge, der calix genannt, das vertical stand und uber dessen Eintrittsöffnung das Wasser sich in der Cisterne $33 \mathrm{~cm}$. hoch erhob, bestimmt wurde. Es giebt das 420 Liter pro 24 Stunden. Für öffentliche Gebäude und Bäder fanden Messrohre von grösserem Querschnitte Verwendung. Der Wa s ser z oll, Pouce d'eau, welcher früher als Maasseinheit für die Pariser Wassermessungen diente und auch heute noch 
nicht ausser Gebrauch ist, stammt aus der Zeit des Julian und ist ähnlich wie der quinarius bestimmt. Zu jedem Privathause führte eine besondere Leitung, welche oft mehrere $100 \mathrm{~m}$. lang war, und es ist daher klar, dass die höher und weiter abgelegenen Wohnungen viel weniger Wasser als die näher liegenden durch gleiche Messrohre erhielten. Dieser Unterschied soll nach den Berechnungen von Belgrand oft wie 1:10 sich verhalten haben. Es haftete die Concession, wie gesagt, an der Person und konnte weder durch Erbe noch durch Kauf übertragen werden.

Die Instandhaltung der Leitungen wurde von einer grossen Zahl theils in der Stadt, theils ausserhalb wohnender Arbeiter besorgt, deren Namen und Stationen auf öffentlichen Tafeln in den einzelnen Bezirken verzeichnet waren. Dieselben theilten sich nach den verschiedenen Obliegenheiten in Castellarier, die die Reservoire zu beaufsichtigen hatten, in Controleure, die die Leitungen zu begehen hatten, in Pflasterer, die die Wege wieder herzustellen hatten, in Tüncher, die die Beschädigungen an den Aquärlucten zu repariren hatten etc. Unter Agrippa bestand diese Schaar aus 240 Personen und wuchs unter Claudius auf 700 Personen an, die theils vom Staate, theils vom Kaiser besoldet wurden. Dieser Kaiser fuhrte zur Verwaltung der Wasserwerke ausser dem Curator, der die Staatsinteressen wahrzunehmen hatte, zuerst einen Procurator, dem speciell die kaiserlichen Interessen oblagen, ein. Innerhalb bebauter Orte mussten die Gebäude, Bäume etc. sowohl von den oherirdischen als den unterirdischen Leitungen $1,62 \mathrm{~m}$. und im freien Felde $4,87 \mathrm{~m}$. abstehen. Hohe Geldstrafen wurden über diejenigen verhängt, welche eine Beschädigung dieser öffentlichen Anlagen ausfuhıten oder beabsichtigten. Die Vergeudungen und böswilligen Beschädigungen, sowie das Stehlen von Wasser muss aber ungeheuer gewesen sein, da Frontinus angiebt, dass das Wasserquantum würde verdoppelt werden könncn, wenn man diesen Ungesetzlichkeiten mit Erfolg entgegentreten könnte. Fur die Ausdehnung dieser Vergeudungen spricht auch ein Gesetz vom Jahre 404, welches für jede Unze unrechtmässig entnommenes Wasser eine Geldstrafe von ein Pfund Gold bestimmt.

Es ist später in der That durch Messung der verschiedenen Quellen an ihrem Ursprunge nachgewiesen, dass sie uber $1200000 \mathrm{kbm}$. pro Tag liefern mussten, dass also wirklich nur ein Theil davon Rom erreichte. Dieses ist daraus zu erklärén, dass Kaiser und Staat geringe Verdienste mit der Berechtigung der Verwendung des Leckwassers aus den Zuleitungen, des durch die Ueberfallrohre der Reservoire und 
Fontainen abgehenden Wassers, sowie endlich des durch Undichtigkeiten der Rohrleitungen entweichenden Wassers belohnten. Wie ausgiebiger Gebrauch hiervon gemacht und wie die Leckage unterstützt wurde, beweist, dass die Aqua Tepula mehrere Jahre ohne Wasser war. Ztur Vergrösserung dieses Quantums trug ferner die Leichtigkeit der Beschädigung der Bleirohre, 'die- nur einem geringen Drucke widerstanden, bei. Auch wurde es dadurch vergrössert, dass viele Leitungen, die nur aus Prunksucht oder zur Befriedigung der Eitelkeit des Erbauers hergestellt waren, nach dessen Tode lieber dem Verfall ubberlassen, als im Stande gehalten wurden; denn der Nachfolger erreichte häufig seine $Z$ wecke billiger durch die Herstellung neuer, als durch die Reparatur alter Anlagen.

Der Preis fur das abgegebene Wasser muss sehr billig gewesen sein, da die Gesammteinnahme von Privaten unter Augustus nur $60000 \mathrm{Mk}$. betragen hat.

Später sind für Rom noch eine grössere Zahl anderer Leitungen ausgeführt, von denen die Hadriana, die Alexandrina, die Neroniana, die Trajana die bedeutendsten gewesen sein sollen, uber welche jedoch genauere Daten nicht vorliegen.

Auf einige Punkte über die im Vorstehenden beschriebenen Bauausfihrungen mag hier noch kurz aufmerksam gemacht werden. Aus der Vergleichung der in den verschiedenen Zeiten erbauten Leitungen ist zu ersehen, dass das wachsende Bedürfniss eive stete Steigerung des Druckes, mit dem das Wasser in Rom ankam, durch bessere Leitung erreichen liess, sowie dass man, vielleicht durch Verbesserung der Messinstrumente und vervollkommneten Kenntniss in der Bauweise, die neueren Leitungen den alten gegenüber wesentlich abzukürzen lernte. Für die Wahl der Kanalquerschnitte fehlten alle wissenschaftlichen Grundlagen und ihre Grösse scheint hauptsächlich durch die Rücksichten auf innere Reparaturbedurftigkeit bedingt zu sein.

Das Mauerwerk wurde aus Quadern, die stellenweise sehr schón bearbeitet und fast ohne Mörtel verlegt werden konnten, ja wie bei dem opus revinctum hakenblattformig in einander griffen, oder auch nur mit Quadern verblendet und im Innern mit kleinen Steinen ausgefüllt, das op us reticulatum, oder ferner aus gewöhnlichen unregelmässigen Bruchsteinen, das opus incertum, hergestellt. Wo solche Steine fehlten, bediente man sich der Ziegel, die 15 bis $20 \mathrm{~cm}$. im Quadrat und 2,5 bis $5 \mathrm{~cm}$. dick hergestellt wurden. Zu Verblendungen benutzte man auch solche in dreseckiger Form. Endlich wandte man sehr 
viel den Beton an, der jedoch nicht, wie jetzt geschieht, vorher aus Steinen und Mörtel gemischt wurde, sondern bei dem man auf eine Mörtelschicht die Steine, dann wieder Mortel etc. brachte und danach zi demselben eine bedeutend grossere Menge Mortel als wir verbrauchte. Der Mangel an $\mathrm{Holz}$ führte bei der Construction der Gewòlbe zur Frsparung der Lehrbögen zu verschiedenen Hulfsmitteln, z. B. zur Anwendung concentrischer Bögen über einander, zur Ausführung von Bögen aus Quadérn in $Z$ wischenräumen, welche mit Beton ansgefüllt wurden etc. Roman-Cement und Portland-Cement waren ebenso wie hydraulischer Kalk den alten Römern unbekannt. Zu hydraulischem Mörtel wurde Puzizolanerde, zu gewohnlichem Mortel Ziegelsand verwendet, und mit einem Theile Kalk und zwei Theilen reinem Flussande oder drei Theilen scharfem gegrabenen Sande gemischt. Den Kalk liess man sich, an der Luft ohne Anwendung von Wasser in dünnen Lagen ausgebreitet, löschen und verwandte ihn meistens erst ein Jahr später. Den Sand, sowie die Puzzolanerde bewahrte man gehörig ausgesiebt unter Dach vor den Einflutssen des Wetters auf. Der Putz der Kanäle, Reservoire und Cisternen wurde in der Weise hergestellt, dass erst eine Putzschicht mit grobem Sand, dann eine solche mit feinem Sand und darüber eine solche mit breiartigem Mórtel aufgetragen wurde. Uñ dem Putze Zeit zum Abbinden zu geben, ehe das Wasser daraus entwichen war, wurde schliesslich die ganze Fläche mit einer Mischung überzogen, die aus Leinöl, in Rothwein gelöschtem Kalk, Wachs und Theer bestand und nach Plinius auch noch zerstossene Feigen enthielt. Dieselbe wurde so eingerieben, dass die Oberfläche so glatt wie Marmor wurde. Die alten Leitungen, die Appia, die Anio vetus und die Marcia sind mit Ausnahme des inneren, vom Wasser berührten Theiles trocken in Bruchstein gemauert, während die spateren Leitungen in vollkommenster Weise in Mörtelmauerwerk hergestellt sind.

Die verschiedenen Bogenstellungen bei den Aquäducten uber einander werden von einer Seite durch die erstrebte Erzielung einer höheren Stabilität der Bauwerke erklärt. Von anderer Seite sucht man die Erklärung darin, dass man die Aquäducte zugleich zur Herstellung von in geringerer Höhe von ihnen gleichfalls getragenen Wegen benützt habe. Bei Beurtheilung dieses Punktes ist es zu beachten, dass auch das Bedưrfniss nach höherer Zuführung des Wassers, sowie die nachherige Erstellung solcher höherer Leitungen dazu geführt haben kann, wie es die Marcia, die Tepula und die Julia zeigen.

Die Frage, ob die Römer zu jener Zeit schon die Möglichkeit, das 
Wasser durch Siphons zu leiten, -gekannt haben, ist vielfach aufgeworfen und verschieden beantwortet. Jedenfalls spricht die günstige Höhenlage der Rom zugeführten Quellen, indem das Kalkgebirge $210 \mathrm{~m}$. übcr dem höchsten Punkte Roms liegt, sowie die gefährliche Lage einer in der so bevölkerten Ebene der Roma Vecchia liegenden Leitung nicht für die Anwendung von Siphons und es ist um so weniger anzunehmen, dass solche unterirdische Leitungen bestanden, weil die Erbauer bestrebt waren, sichtbare Denkmale zur Verherrlichung ihres Namens in den Aquäducten zu errichten, aber nicht das Gold in der Erde zu vergraben.

Ueber die Herstellungsk osten der Leitungen liegen nur wenige Anhaltspunkte vor. Es hat die Aqua Claudia, wohl die billigste von allen, $6000000 \mathrm{Mk}$. oder circa $80 \mathrm{Mk}$. pro lfd. m., die Aqua vetus $12000000 \mathrm{Mk}$. oder $130 \mathrm{Mk}$. pro lfd. m. gekostet, während die Wiener Hochquellenleitung sich auf circa $160 \mathrm{Mk}$. pro lfd. m. gestellt hat.

Dieselbe Thätigkeit, die die Römer auf die Herstellung guter Wasserversorgungen für Rom aufwandten, verfolgten sie auch in den verschiedenen von ihnen unterjochten Ländern und es finden sich hier noch manche redende Beispiele davon vor. Nicht nur Italien und Sicilien weisen solche Sparen auf, sondern auch Griechenland, Spanien, Frankreich und Deutschland sind reich daran. In Spanien werden die Städte Segovia in Alt-Castilien und Sevilla in Andalusien noch heute durch römische Leitungen versorgt. Der Aquäduct von Segovia ist $750 \mathrm{~m}$. lang und $3 \dot{1} \mathrm{~m}$. hoch. Er ist von zwei Reihen Bogenstellungen über einander gebildet, von denen die untere aus 42 , die obere aus 119 Bögen besteht.

Die Leitung zu Nîmes im südlichen Frankreich steht unter den gallischen Bauten obenan, wenngleich die Qualität des zugeführten Wassers sehr ungenügend war. Die Leitung hatte 49,75 Kilom. Länge. Der Kanal hat unten 1,20 m., oben 1,30 m. Breite bei 1,80 m. Höhe und ist mit einem Halbkreingewölbe geschlossen. Er nahm $76 \mathrm{~m}$. über dem Meere die Quellen der Eure und der Airan, die bei der Stadt d'Usez im Kalkgebirge entspringen, auf und führte dieselben, die ein tägliches Quantum von $29530 \mathrm{kbm}$. lieferten, einem Reservoire in der Stadt, 59,04 m. über dem Meere gelegen, zu. Die ganze Länge der Aquäducte betrug $3220 \mathrm{~m}$. Der eine derselben bei Vert ist $2000 \mathrm{~m}$. lang und $2 \mathrm{~m}$. bis $15 \mathrm{~m}$. hoch. Er besteht aus 256 Bögen von verschiedenen Spannweiten. Ein anderer, Pont du Gard genannt, unter welchem der Fluss Gardon durchfliesst, ist einer der schönsten Reste von den Bauwerken 
der Römer in Gallien. Derselbe ist mit Ausnahme des oberen Kanales aus bearbeiteten Steinen ohne Anwendung von Mörtel hergestellt. Die grösste Höhe beträgt $54 \mathrm{~m}$. und die ganze Lànge $269 \mathrm{~m}$. Drei Bogenstellungen befinden sich uber einander und in der unteren Etage 6, in der mittleren 11 und in der oberen 35 Bögen neben einander. Die grösste der unteren Oeffnungen hat $34 \mathrm{~m}$. Spannweite. Die Erbauung wird dem Agrippa, dem Schwiegersohne des Augustus, in der Zeit zugeschrieben, als er nach der Ruckkehr. des Augustus aus Aegypten (17 v. Chr.) mit der Verwaltung von Gallien betraut wurde.

In Lyon finden sich noch Reste einer $50 \mathrm{n}$. Chr. angeblich von Marcus Antonius erbauten Wasserleitung, die das Wasser vom Mont d'Or nach der Stadt brachte. Fine zweite Leitung ist von Tiberius gebaut; sie führt das Wasser der Loire von Feurs aus der Stadt zu. Die dritte und prachtvollste Leitung hat der Kaiser Claudius dieser seiner Geburtsstadt errichtet. Dieselbe hatte 52 Kilom. Länge und führte die $170 \mathrm{~m}$. ther dem Meere entspringenden Quellen vom Berge Pila in einer Hohe von 53,06 m. über dem Meere der Stadt zn. Sie nahm in ihrem Laufe ferner die Wasser des Gien, des Jaunon und des Furand, Nebenflissse der Rhône und Loire, auf. Das täglich gelieferte Wasserquantum betrug $22700 \mathrm{kbm}$. und es hatte der Kanal eine untere Breite von $0,55 \mathrm{~m}$. und eine obere Breite von $0,75 \mathrm{~m}$. bei einer Höhe von $1,60 \mathrm{~m}$. Oben war er halbkreisförmig geschlossen. Vierzehn hohe Aquäducte führten uber Abgrunde von $60 \mathrm{~m}$. bis $90 \mathrm{~m}$. Tiefe.

Die Ueberschreitung des Thales zwischen Soucieux und Chaponost hätte einen Aquäduct von $65 \mathrm{~m}$. Höhe und $760 \mathrm{~m}$. Länge, sowie die zwischen Chaponost und Sainte Foy einen solchen von $97 \mathrm{~m}$. Höhe und bedeutender Länge verlangt. Aehnliche Bauten waren für das Thal zwischen Sainte Foy und Fourvier nöthig. Der enormen Kosten dieser Bauten wegen legte man daher durch diese Thäler Siphonleitungen aus Bleirohren, die von der einen Seite des Thales abfielen, auf einem weniger hohen Aquäduct, aus einer Bogenreihe bestehend, durch das Thal geführt wurden, auf der andern Seite zu der entgegengesetzten Höhe anstiegen und hier sich wieder in den Kanal ergossen. An den Abhängen liegen parallel 9 Rohre von $21 \mathrm{~cm}$. Durchmesser, die sich auf der Mitte der Abhänge in je 2 Rohre theilen und hier und über den Aquäduct als 18 Rohre fortgeführt sind. Sie bestanden aus $27 \mathrm{~mm}$. dicken Bleiplatten, die nach oben zusammengebogen und in einer scharfen Kante zusammengelöthet waren, wie später näher mitgetheilt werden wird. 
Eine $130 \mathrm{n}$. Chr. von den Römern in Metz zur Zuleitung des Wassers von der Gorze hergestellte Leitung ist $18 \check{\mathrm{a}}+$ zum Theil wieder restaurirt und liefert der Stadt jetzt täglich $40000 \mathrm{kbm}$. Wasser. Ihre Länge beträgt 22,16 Kilom. Der Kanal hat 0,97 m. Breite und 1,95 m. Tiefe; er hat $1 \mathrm{~m}$. Gefälle auf 1 Kilom. Länge. Von dem alten Aquiducte, der über die Mosel fuhrte und aus 118 Bögen bestand, stehen noch 5 auf dem linken Ufer und noch 17 auf dem rechten Ufer des Flusses bei dem Dorfe Lony, unter welchen die Landstrasse $18 \mathrm{~m}$. tief hindurch führt.

Die Leitung von Arcueil, die das Wasser von Rungis nach Paris führt, ist während des kurzen Aufenthaltes des Julian (360) in Paris ausgefübrt. Sie bestcht aus einem überwölbten Kanale von $1,00 \mathrm{~m}$. Breite und 2,00 m. Höhe und ist auf einem Aquäducte über die Bièvres geführt. Eine andere unterirdische Leitung für diese Stadt nahm ihren Anfang bei den Mineralquellen auf den Höhen von Chaillot, durchkreuzte die Champs Élysées und einen Theil der Tuileries-Gärten und lief in dem Garten des Palais-Royal aus. 1781 hat man hier ein Reservoir von 6,5 m. Seite entdeckt, in welchem sich Medaillen von Aurelian bis zu Valentinian I. hinauf befanden, so dass unter dessen Regierung (375) die'Leitung ausgefuhrt sein wird.

Eine aus der Romerzeit stammende Leitung fur An tibes ist 1770 restaurirt und liefert noch heute der Stadt täglich $2700 \mathrm{kbm}$. Wasser. Die Leitung ist 6 Kilom. lang und es befindet sich in ihr ein Tunnel von $4940 \mathrm{~m}$. Länge. Der Kanal ist $0,65 \mathrm{~m}$. breit und $1,25 \mathrm{~m}$. hoch.

Zwischen Trier und Cỏn finden sich noch Ruinen eines Aquärluctes aus der Römerzeit. Eine aus dem Eifelgebirge bergeführte Leitung versorgte beide Städte mit Wasser - nach einer deutschen Sage sogar mit Moselwein.

Nachdem 330 Constantinopel zur Hauptstadt erwählt war, begannen die Romer für dieses zweite Rom grosse Wasserversorgungsanlagen herzustellen. Die Stadt besass die Wasserläufe Barbyses und Cydares, welche jedoch häufig sehr wasserarm waren. Sie nahm daher ihre 'Zuflucht zur Aufsammlung von Regenwasser in unterirdischen Cisternen. Da diese Versorgung jedoch eine ungenügende wáar, so wurde auf den Höhen am schwarzen Meere 24 Kilom. von Constantinopel entfernt eine Reihe von Sammelbassins angelegt, deren Dämme künstlerisch schön mit weissem Marmor bekleidet waren. Von diesen Reservoiren wurde das Wasser mittelst verschiedener Kanäle durch vier Hauptleitungen durch das Thal Burgos geführt. Die grösste dieser Leitungen soll 
527 von Justinian ausgefuhrt sein. In diesen Leitungen befinden sich eine Zahl schöner Aquäducte. Einer derselben ist $140 \mathrm{~m}$. lang und $32 \mathrm{~m}$. hoch und besteht aus 2 Bogenstellungen über einander. Fin anderer im Innern der Stadt soll aus den Steinen, die durch die Zerstörung der Mauern von Chalcedon gewonnen wurden, erbaut sein.

Vielfach hat man für Constantinopel statt der Aquäducte Siphons angewendet, die aus Rohrleitungen, die den Conturen des Thales folgen, bestehen. Wurden die Leitungen zu lang, so errichtete man in den Thälern Thürme und führte auf der einen Seite die Leitung am Thurme in die Höhe, liess das Wasser sich hier in ein kleines, auf dem Thurme aufgestelltes Reservoir ergiessen und leitete es auf der andern Seite wieder hinunter. Es sind dies die sogen. Suterazi, uber deren Zweck man sich vielfach nicht einig ist. Er kann jedoch nur dex gewesen sein, als Luftauslass zu dienen und dafür war es allerdings eine sehr kostspielige Construction, welche nicht nur die Druckhohe, welche der in der Leitung erlangten Geschwindigkeit entspricht, sondern auch die durch die Reibung in dem aufsteigenden und abfallenden Rohre consumirte Hohe verlieren lässt. Der Zweck hätte viel billiger erreicht werden konnen.

Im Inuern der Stadt waren grosse Reservoire hergestellt, um im Falle einer Belagerung den nöthigen Wasservorrath zu besitzen. Eins derselben ist nach dex Beschreibung des Procopius in der Basilica von Justinian erbaut. Es ist eine grosse viereckige Cisterne mit Pfeilern, welche auf einem Felsen in grosser Hohe' errichtet ist. Sie ist uber $100 \mathrm{~m}$. lang und $45 \mathrm{~m}$. breit. Es stehen darin 336 Marmorsäulen von $12,5 \mathrm{~m}$. Hōhe, die die überwölbte Decke tragen. Dieselben sind in 12 Reihen aufgestellt, deren jede aus 28 Stuck besteht. Die Seitenwände, die Gewolbe und die Decke sind von Ziegelsteinen hergestellt und über derselben befinden sich Terrassen. Bei einem andern grossen Reservoire, welches von dem Senator Philoxenos erbaut ist, wurde die Decke von 424 Marmorpfeilern getragen und uber 212 derselben war nochmāls dieselbe Zahl von Säulen aufgestellt. Die Türken nannten das Bauwerk "Tausend und eine Säule". In einer andern Cisterne befanden sich 32 korinthische Sáulen in 4 Etagen über einander, deren jede aus 8 Säulen in $3 \mathrm{~m}$. Entfernung bestand. Die Cisterne St. Benedict endlich hat ihr Dach verloren; aber 300 Pfeiler sind noch vorhanden, die die Decke getragen haben.

Dass in früheren Zeiten ausser den Römern auch andere Völker grossantige Wasserwerksbauten errichtet haben, beweist der Aquäduct 
von Spoleto, der von Theodorich ausgefthrt sein soll. Er befindet sich in einem Thale. neben dieser einst so wichtigen Stadt und besteht aus 7 Bögen von $22 \mathrm{~m}$. Spannweite und $31 \mathrm{~m}$. Höhe; derselbe kann sich den römischen Bauten an die Seite stellen.

Es mögen hier, um die Aquäducte mit Ausnahme der für Paris später gemachten Anlagen bis zum Ende des 18. saec. zum Abschluss zu bringen, noch einige Notizen über die spätere Versorgung von Rom, sowie über die Aquäducte von Caserte, Montpellier und Genua folgen.

Aus den alten Leitungen, die vormals $R$ o $m$ versorgten, sind drei neue, von den Päpsten wieder restaurirt, entstanden und dienen noch heute den täglichen Bedurfnissen. Die A qua Vergine, unter Nicolaus V. und Sixtus IV. begonnen, ist 1568 von Pius IV. vollendet und war eine Restauration der Aqua Virgo. Ihr Wasser wird in der Stadt durch 7 Hauptleitungen an 50 theils ganz, theils halb öffentliche Brunnen vertheilt. Sixtus V. legte den Grund zur Aqua Felice, indem er die Claudia und Marcia mit mehreren anderen Quellen auf dem Gebiete von Pontano zusammenführte. Urban VIII. vereinigte diese Wasser in einem kolossalen Reservoire, von wo sie in dem alten Aquaduct der Claudia der Stadt zufliessen. Paul V. endlich liess durch Johann Fontana die alte Alsietina unter dem Namen Paola wiederherstellen und Clemens X. führte durch Karl Fontana 1694 derselben das Wasser aus dem See Bracciano zu. Das Rom jetzt noch durch diese drei Leitungen zugefuhrte Wasser ist nach den 1809 von Vici, dem Director der römischen Wasserwerke, vorgenommenen Messungen zu täglich $150000 \mathrm{kbm}$. festgestellt. Die Aqua Vergine versorgt die Fontaine von Trevi und die Aqua Felice führt das Wasser auf den Berg Quirinal nach der Fontaine des Moses.

Karl III. von Neapel liess den Aquäduct von Caserte ausführen, der seinem Schlosse in Caserte, einer $8 \mathrm{Kilom}$. von Neapel entfernten Stadt, das Wasser zufuhrte, wo es sich in ein $130 \mathrm{~m}$. hoch liegendes Reservoir ergoss. Die Leitung war uber 14 Kilom. lang und durchschnitt tiefe Thäler und hohe Gebirge.

Montpellier wird seit 1752 durch eine von Pitot projectirte Leitung versorgt. Dieselbe ist 14 Kilom. lang und fuhrt das Wassér von den Quellen Saint Clément zu. Der Kanal ist aus $1 \mathrm{~m}$. langen mit Falzen ineinanderfassenden steinernen Rinnen gebildet, die $0,27 \mathrm{~m}$. im Lichten hoch und $0,32 \mathrm{~m}$. breit oben entweder mit Decksteinen dicht geschlossen sind oder über welchen ein begehbarer Kanal von 1,62 m. Breite und 2,65 m. Höhe in Mauerwerk hergestellt ist. Die Leitung endet 
mit einem Aquäducte von $880 \mathrm{~m}$. Länge auf dem Place de Peyrou in einem Wasserschlosse, welches mit einer auf Säulen ruhenden Kuppel überdacht ist. Der Aquäduct besteht aus zwei Reihen Bögen und hat eine Höhe von $28 \mathrm{~m}$. Die untere Reihe hat 33 Bögen von $8 \mathrm{~m}$. Spannweite, die auf Pfeilern von $4 \mathrm{~m}$. im Quadrat ruhen. Die obere Reihe ist aus 133 Bögen von 2,78 m. Spannweite auf 1,36 m. starken Pfeilern gebildet. Der letzte Theil des Aquäductes besteht aus drei einfachen Bogen, von denen der mittlere 19,5 m. Spannweite und die beiden äusseren $10 \mathrm{~m}$. Spannweite haben. Vielfache Beschädigungen durch den Frost haben dazu geführt, den Theil des Kanales, in dem das Wasser fliesst, mit Bleiplatten zu bekleiden. Die Leitung führt der Städt täglich $973 \mathrm{kbm}$. Wasser zu und hat circa 950000 Livres gekostet.

Genua wird seit 1293 durch eine Leitung von urspringlich 8 Kilom. Länge mit Wasser versorgt. Dieselbe ist durch Hinzuziehen anderer Quellen weiter ausgedehnt und hatte 1782 eine Länge von 28 Kilom. In derselben ist 1782 eine Siphonleitung, delle A rcate genannt, die das Thal des Flusses Geivato uberschreitet und das Wasser von dem Hügel Mollasana dem Pino zufuhrt, hergestellt. Die Länge dieses Siphons betragt in der Horizontalen gemessen $668,65 \mathrm{~m}$. Für den Eintritt, sowie für den Austritt des Wassers in und aus dem Siphon sind Reservoire hergestellt. Das Eintrittsreservoir liegt 7,43 m. hoher als das Austrittsreservoir und der tiefste Punkt des Siphons liegt $50,02 \mathrm{~m}$. tiefer als der Eintritt und $42,49 \mathrm{~m}$. tiefer als der Austritt. Die Leitung besteht aus gusseisernen Rohren von $370 \mathrm{~mm}$. Durchmesser und $20 \mathrm{~mm}$. Wandstärke. Die einzelnen Rohre sind $0,8 \mathrm{~m}$. lang. Im tiefsten Punkte befindet sich ein Wasserauslass, im hochsten ein Luftauslass. Das Rohr liegt in 2 tiefen Senkungen des Thales auf Aquäducten, deren einer $150 \mathrm{~m}$. lang und aus 9 Bogen besteht, während der andere $240 \mathrm{~m}$. lang ist und aus 14 Bógen gebildet ist. Am höchsten Punkte misst letzterer $22 \mathrm{~m}$. Höhe.

Nähere Mittheilungen äber die grossartigen Leitungen für Marseille, Dijon, Paris, Newyork, Wien. Frankfurt a. M. etc., sowie uber die grosse Zahl der englischen Gravitationsleitungen zu machen, die dem jetzigen Jahrhundert angehören, wird sich spiter Gelegenheit bieten.

Ich benütze diesen Ruhepunkt, noch einen Rückblick auf die Wasserversorgungen bis zum Beginn des Mittelalters, sowie in der ferneren Zeit und speciell auf die romischen Leitungen im Allgemeinen zu werfen. 
Wenn wir die Lage der verschiedenen Theile Asiens, sowie die von Aegypten und ton anderen Theilen Afrika's betrachten. so zeigt sich, dass das durch die Natur gelieferte Wasser hier ungemein sparsam ist, da selten Regen fältt, dass aber in dem dortigen Klima das Bedurfniss nach Wasser uberhaupt ein ungemeines ist. Das Wasser selbst war somit nur mit Schwierigkeiten und durch ununterbrochene Arbeit zu erlangen. Daraus erklärt sich die eigenthümliche Kraft und Schónheit all der Verherrlichungen des Wassers, die dasselbe bei den dortigen Schriftstellern und im Alterthume uberhaupt gefunden hat. Mubamed verspricht in seinem Paradiese Quellen lebendigen Wassers, während in der Hölle schmutziges kochendes Wasser vorhanden ist. Die Hochlaltung des Wassers war bei diesen Völkerı durch das Bedürfniss geboten und daher auch durch die Religion geheiligt.

Die römischen Bauten zeigen jedoch noch einen wesentlich anderen Charakter. Wenn sie auch in ihren ersten Anfängen nur aus dem Bedürfniss entstanden, so dienten sie in späterer Zeit in ihrer weiteren Entwicklung doch nicht unwesentlich mit zur Befriedigung der Ruhmsucht und des Ehrgeizes der Machthaber und sittigten und steigerten in ihrem Uebermaasse die Genusssucht des Volkes. Diese zu befriedigen und sie weiter zu reizen ist in Rom ein unverkennbares Bestreben der Machthaber gewesen. Die Herstellung solcher Riesenwerke war ja auch nur da möglich, wo sie, nicht ausschliesslich ntitzlichen Zwecken dienend, nicht von den Geniessenden allein hergestellt wurden, sondern wo sie der allmächtige Staat ausführte und mit seiner Gewalt zu erhalten bemüht war.

Als die römischen Kaiser des dritten Jahrhunderts durch die anstürmenden Barbaren und durch die Kämpfe mit Nebenkaisern in Anspruch genommen waren, verloreu sie das Interesse für die Stadt Rom und die Erhaltung von deren baulichen Anlagen. Seit der Verlegung des Kaisersitzes nach Constantinopel wendete sich ihre Thätigkeit hauptsächlich der Ausschmückung dieses Platzes zu und der Anblick Roms reizte die Machthaber nicht zur Erhaltung von dessen Pracht, sondern weckte nur den Wunsch, den neuen Herrschersitz ihm gleich zu machen. Das fünfte Jahrhundert brachte die Kämpfe in Italien und um Rom und da musste manches Werk des Friedens der Zerstörung anheimfallen. Und beim Austritte aus dem Mittelalter waren die Wasserwerke Roms nur noch Trümmer. Durch die Nachlässigkeit der Behörden, durch die Sorglosigkeit der Bürgerschaft, durch Erstur- 
mung durch auswärtige Feinde und durch Burgerkriege im Innern war die Stadt allmählich völliger Zerstörung anheimgefallen. Wie schon vorhin angeführt, begannen die Päpste des sechzehnten Jahrhunderts sich zu bemühen, das alte Rom und mit ihm die fruheren Wasserleitungen zu neuem Glanze zurückzuführen.

Zur Zeit des Mittelalters waren es nun ebenso für die ibrigen Machthaber andere Aufgaben, denen sie ihre Thätigkeit widmen mussten. Weniger den Arbeiten des Friedens, als denén des Krieges und der gegenseitigen Vernichtung, durch religiösen Fanatismus gesteigert, galt ihre fast ausschliessliche Thätigkeit.

Die Mönche, die im Mittelalter die Träger der Civilisation waren, hielten es für eine Tugend, ihre Kleider Jahr aus Jahr ein nicht zu wechseln und zogen zum Löschen des Durstes den Wein dem Wasser vor. Es war demnach in dieser Zeit, wie auch heute noch, ausschliesslich Sache des Bentutzenden oder der Benützenden selbst, für den nothigsten Wasserbedarf zu sorgen, und man entnahm das Wasser daher dem nächsten Flusslaufe, ohne sich eingehend um seine Qualität zu kummern, deren Prufung ja auch nur durch den Instinct erfolgen konnte, oder man suchte es durch neben den Wohnungen hergestellte Brunnen zu erlangen.

Nur wo Wasser in dieser Weise quantitatir zu beschaffen unmoglich oder wo solches mit zu vielen Kosten verbunden war, ferner wo die wachsende Bevòlkerung oder der Gewerbebetrieb Einzelner grössere Anforderungen stellte, ging man zu künstlichen Wasserzuführungen über. Dass man bei der ganzen wirthschaftlichen und socialen Lage hier natürlich zu dem am leichtesten Erreichbaren griff, kann nicht Wunder nehmen. Man führte das an den Bergen als Quellen zu Tage tretende Wasser durch gemauerte Kanäle oder Rohrleitungen (meistens von Holz, doch auch von 'Thon) den Orten zu, wo es sich in Bottiche frei ergoss, oder man musste sich, wenn dasselbe nicht zum Ausfluss kam, künstlicher Hebung bedienen. Die Fortschritte in der Mechanik brachten einzelne Genossenschaften, die grösserer Wassermengen bedurften, namentlich die Brauer, dazu, gemeinschaftlich durch ein Wasserrad bewegte Pumpwerke anzulegen und das Wasser von hier aus den einzelnen Interessenten zuzufuhren. Wir finden in manchen deutschen Stadten derartige Pumpenbruder-Gesellschaften aus dem 15. und 16. Jahrhundert. Aus diesen Gesellschaften oder mit diesen gleichzeitig entstanden bei weiterer Ausdehnung auch für öffentliche Zwecke von der Gesammtheit der Bürger hergestellte Anlagen, während die Mittel 
der Grossen, wenn sie sich dem Wasser zuwandten, meistens in. nutzlosen Spielereien vergeudet wurden. Wasserorgeln, Wasserubren, Schmuckfontainen und Cascaden, tanzende, durch Wasser bewegte Figuren, singende Vögel und alles Mögliche wurde von ihnen geschaffen, aber keine städtischen Wasservèrsorgungen.

Man darf bei Beurtheilung unserer alten städtischen Wasserversorgungen, namentlich in Deutschland, nicht aus dem Auge verlieren, dass die materielle Lage der Ortsbewohner diese zwang, sich auf das billigst Erreichbare zu beschränken, dass erst die Forschungen der Chemie und Medicin in diesem Jahrhundert unsere Augen in vieler Beziehung weiter geoffinet haben und wir eigentlich heute noch kaum im Stande sind, ein sicheres Urtheil über die Wasserqualität abzugeben, dass endlich die Technik in ihren Fortschritten namentlich durch die Kraft des Dampfes erst in diesem Jahrhundert in vollem Maasse die Moglichkeit allseitiger Wassererlangung geschaffen hat, und dann wird man mit Hochachtung vor dem Gemeinsinne unseres heutigen Bürgerthumes die in den letzten Jahrzehnten gemachten Anlagen betrachten, aber nicht, wie es von Manchem geschieht, auch heute noch mit Sehnsucht nach Rom zurückblicken. Ebenso wie für einen Theil des Volkes dort der Quell alleiniger Wahrheit entspringt, glauben manche Fachleute in der Art der römischen Wasserversorgungen den Quell des alleinig Gesunden zu sehen.

Es würde zu weit fubren, und es ist ja auch sehr schwierig, eine Wasserversorgungsgeschichte aller Städte zu schreiben, wenngleich -ich hoffe, fur unser Vaterland durch freundliche Unterstutzung meiner Fachgenossen in die Lage zu kommen, später vielleicht einen geringen Beitrag dazu noch liefern zu können. Ich will mich hier darauf beschränken, im Nachfolgenden eine Skizze der Entwicklung der Wasserversorgüng für die beiden grossten Stidte London und Paris zu geben. Sie unterscheiden sich beide in der Art der Wasserversorgung wesentlich dadurch von einander, dass in Paris die Sorge für das Wasser nicht nur anfangs, sondern auch heute noch der Regierung und der Stadtverwaltung anheim fiel, während in London diese sich im Laufe der Zeit rein als ein Privatgeschäft entwickelt hat, welches allerdings einer strengen obrigkeitlichen Aufsicht unterworfen ist.

So lange Paris aus den Inseln Cité und St. Louis bestand, bedurfte es keiner kunstlichen Wasserversorgung, da die- Seine der Menge nach genug Wasser und auch dieses bequem für den Gebrauch lieferte. Bei weiterer Ausdehnung an den Ufern der Scine und grösserer Elt- 
fernung von dem Flusse machte sich das Bedürfniss nach einer Veränderung geltend und es war Kónig Plilipp August, welcher 1183 eine mehrere Jahre vorher von den Monchen für das Kloster St. Laurent am Fusse des Montmartre angelegte Leitung für die Stadt annectirte. Dieselbe lieferte das von den Hoihen von Romainville, Bruyères und Ménilmontant in einem bei dem Dorfe Prés St. Gervais gelegenen Reservoire gesammelte Wasser durch eine Bleirohrleitung nach Paris. Die Leitung Prés St. Gervais existirt heute noch und liefert jetzt noch täglich $200 \mathrm{kbm}$. Wasser unter dem Namen Sources du Nord. Ausser für öffentliche Zwecke wurde dieses Wasser auch auf Privatgrundstücken verwendet, deren Besitzern es ursprünglich unentgeldlich als besondere Gunst, von 1598 ab aber nur gegen . Bezahlung abgegeben wurde.

Unter Heinrich IV. 1606 wurde bei der Pont-Neuf von einem Flamänder John Sintler eine hölzerne Pumpmaschine errichtet, die das Wasser in zwei guf den Brückenpfeilern aufgestellte Cisternen hob, von wo es dem Louvre, den Tuilerjen und verschiedenen öffentFontainen zugeführt wurde. Diese Maschine, die den Namen Pompe de la Samaritaine in Folge einer daran angebrachten Auschmuckung von vergoldeten Bleistatuen, Christus und die Samariterin darstellend, erhalten, ist bis zum Jahre $1 \times 13$ in Benützung gewesen und sie bewährte sich so vortrefflich, dass 1670 und 1671 zwei ähnliche Anlagen auf der Pont Notre-Dame errichtet wurden.

Schon Heinrich IV. fasste den Plan, den alten Aquäduct von Arcueil, der im 9. Jahrhundert von den Normannen zerstört war, wieder herzustellen. $\mathrm{Er}$ beschrrinkte sich jedoch auf die Zuleitung einer Quelle, die im Norden der Stadt bei Belleville entsprang. Unter Marie von Médicis erstand der neue Aquäduct von Arcueil nach 11 jähriger Bauzeit und wurde 1624 eröffnet. Wenn auch ursprünglich nur fur das Palais du Luxembourg bestimmt, so lieferte diese Leitung doch ausserdern noch Wasser für 12 offentliche Fontainen, deren Paris in Jahre 166953 Stïck besass. Die Leitung war 8 Kilom. lang und kostete $800000 \mathrm{Mk}$. Sie liefert heute noch $300 \mathrm{kbm}$. Wasser pro Tag. Zu Ende des 17. Jahrhunderts hatte Paris im Ganzen $1800 \mathrm{kbm}$. Wasser pro Tag oder circa $2 \frac{1}{2}$ Liter pro Kopf der derzeitigen Bevölkerung.

Unter der Regierung Ludwig XIV. wurden grossartige Anstrengungen zur Bewässerung von Versailles gemacht. Das Wasser wurde aus einem Gebiete von $15000 \mathrm{Ha}$. Ausdehnung in verschiedenen Teichen gesammelt und durch verschiedene Leitungen Reservoiren zu- 
geführt. Man hoffte bei $0,50 \mathrm{~m}$. Regenhöhe 75 Millionen kbm. im Jahre zu erhalten. Man hatte jedoch die Verdunstung etc. bei dieser Berechnung nicht berücksichtigt und hat heute kaum den funfzigsten Theil von dem erwarteten Quantum erlangt. Um den Bedarf der Wasserkünste, die, selbst wenn sie nicht alle gleichzeitig spielen, pro Secunde 751 Liter Wasser verbrauchten, decken zu können, arbeiteten Vauban und Lahire 1680 den Plan aus, das Wasser der Eure nach Versailles und Paris zu führen. Die Wasserentnahme bei Gouin liegt $35,73 \mathrm{~m}$. hüher als das Marmorschloss in Versailles und die Entfernung beträgt $155 \mathrm{Kilom}$. Zur Ueberschreitung des Thales von Maintenon musste ein Aquäduct von 3 Reihen Bögen über einander in einer Maximalhöhe von $71 \mathrm{~m}$. hergestellt werden und die ganze Länge der Aquäducte musste 7,7 Kilom. betragen. Die Leitung war in Form eines offenen Grabens projectirt und sollte täglich $113600 \mathrm{kbm}$. Wasser zuführen.

1684 würde mit diesem grossartigen Baue begonnen, der, wenn er durchgeführt wäre, vielleicht alle römischen Banten ubertroffen haben würde. Es wurde 4 Jahre mit grosser Energie an der Leitung gebaut. 40000 Soldaten, in einem eigens dafür hergestellten Lager untergebracht, waren daran thätig und es wurden allmählich 16 Millionen Mark dafür verausgabt. Dann wurde der ganze Bau aufgegeben, dessen Vollendung 64 Millionen Mark gekostet haben würde. Von dem Aquaducte, der den Namen Madame de Maintenon führte, wurde 65 Jahre später ein Theil abgebrochen und daraus die Villa Crécy für Madame de Pompadour erbaut. Es stehen heute noch 47 Bögen von $13 \mathrm{~m}$. Spannweite und $25 \mathrm{~m}$. Höhe als Erinnerung an dieses grossartige Project. Zur Versorgung von Versailles wurde an Stelle dieser Anlage 1682 von dem Holländer Rannquin mit einem Aufwande von $800000 \mathrm{Mk}$. in Marly ein Pumpwerk erbaut, welches durch die Wasserkraft der Seine betrieben wurde, ein Wunderwerk seiner Zeit, von welchem später die Rede sein wird.

Im 18. Jahrhundert tauchten verschiedene Pläne zur Versorgung von Paris aus der Seine auf; aber sie scheiterten an Unkenntniss in Ausführung und Behandlung.

1778 versuchte Perrier die Bildung einer Gesellschaft zur Wasserversorgung von Paris. Diese Gesellschaft setzte auch 1782 eine Dampfmaschine in Betrieb, die das Seinewasser, $34 \mathrm{~m}$. hoch gepumpt, dem Quartier St. Honoré zuführte. Diese Anlage, sowie eine zweite von derselben Gesellschaft geschaffene ging später in den Besitz der Stadt uber. 
1762 arbeitete de Parcieux einen Plan aus, der bezweckte, das Wasser des Flusses Yvette, dessen Quellen so hoch liegen, dass das Wasser der Stadt Paris $2 \mathrm{~m}$. löher als das der Leitung von Arcueil zugefuhrt werden konnte, zuzuleiten. Aber trotzdem Perronet und Chezy sich 1775 sehr günstig über den Plan aussprachen, war derselbenicht durchzusetzen. 1782 erhot sich de Fer de la Noverre, einen etwas modificirten Plan olne Zuschuss der Stadt auszuführen und drang nach vielen Widersprüchen endlich damit șo weit durch, dass er die Concession dafür erhielt. Der Bau begann, aber die ausbrechende Revolution hinderte seine Fortsetzung.

Der Plan der Zuführung des Wassers der Ourcq durch, einen K a nal, der zugleich der Schiffahirt dienen sollte, ist 1797 von Girard aufgestellt und der Kanal, 1801 in der Ausführung begonnen, $1822 \mathrm{dem}$ Betriebe übergeben. Derselbe fängt bei Mareuil an und hat bis zu dem Bassin von la Villette in Paris 94 Kilom. Länge. Der Kanal hat eine Breite am Boden von $3,50 \mathrm{~m}$. und bei 1,5 m. Wassertiefe $8 \mathrm{~m}$. Breite in der Oberfäche. Ausser dem Wasser der Ourcq nimnt er in seinem Laufe das der Grisette, der May Theronaime und der Benveonne auf und führt circa $60000 \mathrm{kbm}$. Wasser pro Tag nach Paris.

Mit dieser Anlage beginnt das 19. Jahrhundert und bis zum Jahre 1854 benutzte Paris ausser dem Canal de l'Ourcq, dem Ecau d'Arcueil und den Sources du Nord noch den artesischen Brumnen von Grenelle, welcher $900 \mathrm{kbm}$. pro 'T'ag lieferte.' Endlich noch wurde aus der Seine $19000 \mathrm{kbm}$. pro Tag entnommen, welch letzteres Wasser in den Pumpstationen zu Chaillot, zu Gros Caillou, am Quai d'Austerlitz und an der Brucke Notre Dame gefördert wurde. Hierüber, sowie über die weitere Entwicklung: die Leitungen der Dhuis und der Vanne, die Marne-Station und die neueren Seine-Pumpstationen werde ich an anderer Stelle berichten.

Einer von Genieys 1835 gemachten Bemerkung soll jedoch hier noch Erwähnung geschehen, weil sie einen Einblick gewährt, wie neu die heutige Art der Wasservertheilung eigentlich überhaupt noch ist: „Der Seine-Präfect Chabrol begab sich selbst zum Zwecke der Kenntnissnahme der in England ublichen Art der Wasservertheilung durch Rohrleitungen für die Privaten nach London und liess auch durch den Ingenieur Mallet 1824 umfassende Studien in ganz England machen, welcher die Wasserversorgungen in London, Manchester, Liverpool, Glasgow, Greenock und Edinburg besuchte." Das Wasser des Canal de l'Ourcq sollte nämlich nach dem Girard'schen Projecte von dem gemeinschaft- 
lichen Reservoire aus durch besondere Rohrleitungen für jede einzelne der öffentlichen Fontainen zugeleitet werden. Das aus der Seine entnommene Wasser war für den Privatgebrauch bestimmt und sollte nach dem englischen Rohrsysteme vertheilt werden. Genieys sagt nun bei derselben Gelegenheit ferner über diese Systeme: „Gegentber dem in Italien und in Frankreich fast allgemein eingefuhrten Systeme der Privatabgabe, wonach für jeden Abnehmer ein besonderes Rohr von dem Wasserschlosse abzweigt, hat man in England ein neues System eingeführt, bei welchem vom Maschinenháuse ein Hauptrohr ausgcht, welches möglichst der Mittellinie des zu versorgenden Districtes folgt. Von dem Hauptrohre zweigen Nebenrohre $a b$, die die volkreichsten und wichtigsten Strassen durchziehen. An diese Nebenrohre schliessen sich die Versorgungsrohre "tuyaux de service", die ein Netz durch alle Strassen des von der Maschine zu versorgenden Districtes bilden. Nur von diesen Versorgungsrohren zweigen die Privatleitungen ab, die die in den Häusern in verschiedenen Höhen aufgestellten Reservoire füllen. Die Vortheile dieses Systemes sind klar; dasselbe ist jedoch nur durchführbar bei Anwendung von Rohren, die einen grossen Druck aushalten können, also bei gusseisernen Rohren." -

Die Bewohner Londons entnahmen in alten Zeiten das nöthige Wasser aus der Themse und aus verschiedenen Brunnen. Auch wurden der Stadt vom Westen and Norden verschiedene Quellen mit herrlichem Wasser zugeführt.

Schon unter Heinrich II. 1180 wird in einer Beschreibung Londons der Quellen Hollywell, Clerkenwell und St. Clement's Well gedacht. Nach einem Berichte von John Stow, der zur Zeit der Regierung der Elisabeth (1580) lebte, wurde im Anfange des 12. Jahrhunderts der südliche Theil von London von der Themse, der westliche von dem. Flusse Wels und von dem Oldbourne und das Herz der City von dem Walbrooke mit Wasser versorgt. Für den östlichen Theil diente ein Bach, der die City bei Langbourne Ward durchfloss. Stow erwähnt auch der vorhin genannten drei Quellen oder Brunnen für die Vorstädte, sowie ferner anderer, neben Clerk Well gelegenen, als Skinners's Well, Fag's Well, Tode Well, Soder's Well und Rad Well. In West Smithfield war ein Teich, Horsepool genannt, und ein anderer neben der Kirche St. Giles, Cripplegate genannt, angelegt. Auch befanden sich nach seinen Mittheilungen vor allen Thoren, sowie auf dèn Strassen schöne Quellenausflüsse und Brunnen.

Das allmähliche Verderben und Versiegen eines Theiles derselben 
führte 1235 zur Herstellung der "Great Conduit". Durch sie wurde das Wasser dem ersten in der City in Westcheap errichteten Reservoire, welches aus Bleiplatten zusammengesetzt war, die man ummauert hatte, zugeführt. Das Wasser floss von Paddington nach Jameshead auf $2550 \mathrm{~m}$., von Jameshear on the Hill bis Newgate auf $510 \mathrm{~m}$. und von hier bis Crosse in Cheape auf $2420 \mathrm{~m}$. Entfernung zu. In dieselbe Zeit fällt die Ausführung der Zuleitung der Quellen von Tyborne, deren Leitung später (1432) bis Cheapside und 1438 bis Fleet Street und Cripplegate verlängert wurde.

Um das Wasser der Themse den Grundstucken selbst auf weitere Entfernung zuzuführen, war es Gebrauch, solches durch Gräben und Rinnen abzuleiten. Viele aus diesen Anlagen entspringende Streitigkeiten-führten dazu, dass 1342 gesetzlich jede derartige Ableitung verboten wurde. 1439 uberliess der Abt von Westminster dem derzeitigen Lord Mayor von London, Robert Large ein Reservoir und die Quellen von Paddington gegen eine jährliche Abgabe von zwei Pfefferkörnern. Im Jahre 1500 wurden Leitungen bei Stockes Market und London Wall, 1513 bei Bishopsgate, 1528 bei Coldgate und der Colman Street und 1535 von Hackney bis Aldgate hergestellt. 1544 erlangte die Stadt durch eine Parlamentsacte die Erlaubniss, Wasser ven Hampstead Heath, Marylobone, Hackney und Muswell Hill abzuleiten. Sie liess aber 50 Jahre verstreichen, ohne Gebrauch von diesem Rechte zu machen und verlor damit die Concession, welche 1692 einer Privatgesellschaft, der $\mathrm{Hampstead} \mathrm{Water} \mathrm{Company,} \mathrm{verliehen}$ wurde. Ueber eine Leitung aus der Themse bei Dowgate, die 1568 ausgeführt sein soll, fehlen nàhere Mittheilungen.

Der wachsende Mangel an Wasser fuhrte dazu, inmer neue Leitungen herzustellen und neue Wasserquellen zuzuführen. $15 \pm 4$ ertheilte Heinrich VIII. die Concession, in Umkreise von 8 Kilom. um die City herum von den benachbarten Dorfern und sonstigen Plätzen Wasser durch Rohre zuzuführen und dazu jedes Terrain, welches nicht durch Mauern oder Wälle eingeschlossen war, zu benützen, um hier Reservoire zu bauen, Rohre zu legen und Kanäle herzustellen. Ein 1546 erschienenes Gesetz bedrohte Jeden mit dem Tode, der Reservoire und Leitungen zerstörte.

Es fand in London schon früh das Geschäft des Wasserverkaufs statt. Dasselbe wurde den Leitungen entnommen und in Gefässen, ähnlich-wie heute die Milch, den Häusern zugetragen.

Als der Beginn einer Umwälzung in der Londoner Wasserversor- 
gung ist die 1582 von dem Deutschen Peter Maurice ansgeführte $P$ u mpenanlage unter dem eŕsten Bogen der Lond on Bridge, welche durch ein Wasserrad getrieben wurde, zu betrachten. Dieses Werk wird als das erste seiner Art in England bezeichnet und erregte grosses Aufsehen, während in verschiedenen Städten Deutschlands derartige Anlagen schon seit hundert Jahren und noch früher bestanden hatten. Maurice hatte einen Contract auf 500 Jahre wegen dieser Anlage mit dem Lord Mayor für die Stadt abgeschlossen und brachte 2 Jahre später einen gleichen Vertrag für eine ähnliche Anlage unter dem 2. Brückenhogen zu Stande Diese Maschinen bliebẹn bis 1701 in Besitz der Familie Maurice und gingen dann durch Kauf fur $1400000 \mathrm{Mk}$. in den Besitz ron Richard Soames tiber, der die, London Bridge Water Works Company zur Ausbeutung für diesen Zweck grunlete. 1701 wurde unter dem 4. Bogen der Brücke, 1761 unter dem 3. Bogen und 1767 endlich auch unter dem 5. Bogen je eine Maschine von der Gesellschaft aufgestellt und so die Anlage im Laufe der Zeit bis zu einer Leistungsfähigkeit von $18200 \mathrm{kbm}$. pro Tág gebracht. Es fiel der Gesellschaft jedoch sehr schwer, die Concurrenz der gleich zu erwähnenden, immer mächtiger sich ausdehnenden New River Water Works Company gegenüber auszuhalten, und sie trat daher ihre Concession endlich dieser gegen jährliche Zahlung von $75000 \mathrm{Mk}$. fur eine Reike von 260 Jahren ab. Der Southwark versorgende Theil dieser Anlage ging später in den Besitz der Borough Works gegen eine jährliche Entschädigung von $21200 \mathrm{Mk}$. uber. 1822 wurde die alte London Bridge und damit diese sämmtlichen früheren Anlagen beseitigt.

Die erste $\cdot$ Versorgung der Privathäuser durch Bleirohre fand in Folge der Maurice'schen ersten Anlage statt. 1583 wurden von den Kirchspielen St. Mary Magdalena und St. Nicolaus neben Fish Street Hill und 1610 für Aldersgate Leitungen ausgeführt, denen wahrscheinlich das Wasser künstlich gehoben zugefuhrt wurde. Ein Itąliener, Genebelli, bot 1591 dem Lord Burleigh für London eine Erfindung an, durch welche er das Wasser der Pfützen klären und zum Feuerauslöschen wirksamer machen wollte, ohne damit Gehör zu finden. 1594 errichtete Bulmer bei Broken Warf neben Blackfriars Bridge ein durch einen Pferdegöpel getriebenes Pumpwerk, welches aus 4 Pumpen bestand. Dasselbe war nach einer von 1725 datirten Notiz damals noch in Benützung. 1641 stellte ein Mr. Forde das Project auf, von Rickmansworth in Harfordshire einen schiffbaren Kanal bis St. 
Giles herzustellen, der zugleich zur Wasserversorgung dienen sollte, aber wegen Mangels an Geld nicht zur Ausführung kam. Zu gleicher Zeit proponirte Walter Roberts das Wasser von Hoddésdon in Herfordshire durch Thon- oder Steinrohre zu sammeln und nach einem bei Islington anzulegenden Reservoire zu leiten. Beide Projecte kamen nicht zur Ausführung.

1666 wurde nach dem grossen Brande die City in vier Districte getheilt. Jeder derselben musste 800 ledeine Eimer, 50 Leitern von $4 \mathrm{~m}$. bis $15 \mathrm{~m}$. Länge, jedes Kirchspiel ferner 2 Messing-Handspritzen, 24 Aexte und 40 Beile beschaffen. Ueber allen Brunnen mussten Pumpen aufgestellt and in den verschiedenen Leitungen, die der New River Company und den Thames Water Works gehorten, mussten als Entnahmestellen "Fire plugs" angebracht werden.

1691 wurden in der Nähe von Villiers Street am Ufer der Themse Anlagen zur Versorgung von Piccadilly, Corent Garden, Whitehall etc. von einer Gesellschaft hergestellt, deren Eigenthum 1818 in die Hände der New River Company überging. . Auch wird aus jener Zeit einer Gesellschaft, The Merchants' Waterwork, erwähnt, die drei Pumpenanlagen besass, von denen die eine vom Winde und die beiden andern von Wasser getrieben wurden.

1609 erhielt der Goldschmied Hugh Myddleton durch eine Parlamentsacte die Concession, die Quellen von Chadwell und Amwell durch einen herzustellenden Kanal, den New River, London zuzufuhren. Ursprünglich auf seine eigenen Mittel angewiesen, häuften sich für ihn jedoch die Schwierigkeiten so, dass er die Hulfe Jacob I. nachsuchen musste und auch fand. Und so gelang es denn, am 29. September 1613 das erste Wasser nach dem Reservoire New River Head zu fübren. Die Aquäducte waren aus hölzernen Gerüsten gebildet, über denen das Wasser in mit Blei ausgekleideten hölzernen Rinnen floss. Diese Gerüste sind später durch Dämme ersetzt. 1619 wurde die Gesellschaft New River Waterworks Company gegründet. Der New RiverKanal, dessen Quellen 32 Kilom. von London entfernt lagen, hatte ursprünglich $64 \mathrm{Kilom}$. Länge und ist später noch um circa $4 \check{5} \mathrm{Kilom}$. verlängert. $\mathrm{Da}$ die ursprünglichen Quellen nicht mehr genügten, so musste man zu dem dem New River Kanale benachbarten Flusse Lea seine Zuflucht nehmen, wozu 1737 das Parlament die Erlaubniss ertheilte.

Die Bewohner des östlichen Theiles von London wurden bis 1679 von der New River Company von Shadwell aus durch eine kleine 
Maschine versorgt, die, in diesem Jahre durch eine neue Anlage ersetzt, dem Theile Londons vom Tower bis Limehouse und von Whitechapel bis zur Themse das Wasser zuführte. Die 1745 gegründete West Ham Water Works Company versorgte den andern Theil von Whitechapel, Bow, Stratford, Bromley, Sepney, Bethnal Green etc. Das Eigenthum dieser Gesellschaft und die vorhin erwähnten dortigen Anlagen der New River Company gingen 1807 durch Kauf in die Hände der London Docks Company tiber, die daraus die East London Water Works Company mit anfänglich 2 Millionen Mark gründete. Aber schon in demselben Jahre wurde das Anlagecapital auf $5^{1 / 2}$ Millionen Mark vergrössert.

Die günstigen Erfolge der New River Company gahen 1723 Veranlassung zur Bildung der Chelsea Water Works Company, welche die Versorgung von Westminster und von den anliegenden Theilen der Stadt bezweckte. Das ursprüngliche Actiencapital von 800000 Mk. wurde einige Jahre später um 400000 Mk. erhöht. Die Wasserentnahme fand neben Victoria Bridge ausschliesslich aus der Themse statt.

Die Lambeth Water Works Company wurde durch Parlamentsacte 1785 incorporirt und bezweckte die Versorgung des Kirchspieles Lambeth und der anliegenden Theile der Grafschaft Surrey. Das Wasser wurde bei Waterloo Bridge, Hungerford Market gegenuber, der Themse entnommen. Zur Versorgung von Paldington und für die anliegenden Kirchspiele erhielt 1798 ein Mr. Hill für eine Gesellschaft, die später den Namen Grand Junction Water Works Company annahm, die Concession, trat jedoch damit erst 12 Jahre später in Thätigkeit. Das Wasser wurde zuerst aus dem Grand JunctionKanal entnommen, der dasselbe aus den Fltissen Colne und Brent, sowie aus einem grossen Teiche im Thale von Rinship im Nordwesten von Middlesex erhielt. Dieser Teich wurde durch verschiedene Wasserläufe gespeist. Da das Wasser jedoch sehr schlecht war, so musste die Anlage 1810 an die Themse in die Nähe von Chelsea verlegt werden.

Die West Middlesex Water Works Company wurde 1806 gegründet. Das Wasser wurde aus der Themse bei Barnes entnommen. Das ursprüngliche Actiencapital von $1600000 \mathrm{Mk}$. wurde 1810 auf $4800000 \mathrm{Mk}$. und 1813 auf $6811320 \mathrm{Mk}$. erhöht. Aus der 1805 gegründeten Vauxhall Company und der 1835 gegründeten Southwark Company wurde 1845 durch Verschmelzung die Southwark and Vauxhall Water Works Company. Die Kent Water Works 
Company wurde 1809 gegründet und nahm Besitz von den seit 1699 am Flusse Ravensbourne gelegenen Werken einer fruheren Gesellschaft.

Es wird auf die näheren Details des jetzigen Zustandes dieser 8 Gesellschaften, welche heute fast noch ausschliesslich die Wasserversorgung Londons besorgen, sowie auf die jetzige Versorgung Londons und die für die Zukunft für diese Versorgung ins Auge gefassten Projecte später speciell berichtet werden.

Ich schliesse hiermit die geschichtlichen Mittheilungen uber die Wasserversorgungen von einigen grösseren Städten bis zum Anfang dieses Jahrhunderts im Allgemeinen und will es versuchen, in dem Nachfolgenden einige geschichtliche Notizen über einzelne bei diesen Anlagen auftretende wichtigere Factoren zusammenzustellen. Es dürften als solche Theile, die nunmeht einer Besprechung zu unterziehen sind, in erster Linie die wissenschaftlichen Forschungen und speciell die Hydromechanik, dann ferner die Wasserleitungseinrichtungen, als Rohre, Hähne, Fontainen und Closets, und endlich die Wasserhebemaschinen zu bezeichnen sein.

Von Interesse ist es jedenfalls, hier zuerst die von den Römern angewendeten Messinstrumente kennen zu lernen, um daraus auf den Grad ihrer technischen Kenntnisse zu schliessen. Sie wandten bei ihren Messungen zur Bestimmung der Wege ihrer Leitungen nur das Nivellement an, welches von Vitruv das libramentum genannt wird. Als Messinstrumente benützten sie das dioptron, die Wasserwaage und den chorobates. Ersteres wird wohl eine Art Quadrant mit Visiren gewesen sein. Die Wasserwaage war ein Rohr, wahrscheinlich von Kupfer, circa $2 \mathrm{~m}$. lang und $3 \mathrm{~cm}$. im Durchsnesser, welches an beiden Euden $4 \mathrm{~cm}$. hoch aufgebogen war und so gestellt wurde, dass das Wasser in beiden Schenkeln gleich hoch stand. Der chorobates oder perumbulator war ein $3 \mathrm{~m}$. bis $6 \mathrm{~m}$. langes Holz, welches an beiden Enden Füsse von $1 \mathrm{~m}$. bis $1,5 \mathrm{~m}$. Höhe hatte. In der Mitte befand sich auf der oberen Fläche eine eingearbeitete prismatische Rinne, in welche Wasser geschüttet wurde. An beiden Enden waren seitlich an hölzernen Nägeln Bleilothe aufgehängt. Und mit Hülfe dieser einfachen Messinstrumente führten die Römer ihre grossartigen Bauten aus.

Die Erscheinungen der Bewegung und des A usflusses des W a ssers zu erklären, war den Römern nicht möglich und die ersten speculativen Betrachtungen darüber beschränkten sich nur auf die Statik des Wassers. A r chimede \& (gest. 212 v. Chr.) beschäftigte sich 
mit dem Schwimmen der Körper im Wasser. Er bestimmte die Eintauchung fester Körper, sowie den Auftrieb und die Lage, in welcher sich dieselben im Wasser ins Gleichgewicht setzen. Mit der Theorie dieses Gleichgewichts selbst hat er sich jedoch nicht beschäftigt und es scheint Simon Stevin (gest. 1568), ein Flamänder, der Erste gewesen zu sein, der sich mit der wissenschaftlichen Begrtindung und namentlich mit der Erklärung des hydrostatischen Paradoxons beschäftigt hat, dass nämlich von Flüssigkeiten auf die Böden von Gefässen ein grösserer Druck ausgeübt werden kann, als das Gewicht der in denselben eingeschlossenen Flùssigkeiten repräsentirt. A r is t o teles spricht schon die Vermuthung aus, dass die Luft, wenn sie nicht von Erde und Wasser umgeben ist; schwer sej. Die Peripatetiker suchten die ihnen wegen Unkenntniss des Luftdruckes unerklärlichen Erscheinungen durch eine unbekannte Kraft, die qualitas oculata, zu erklären, die den horror vacui besitzen sollte.

Galilaei (gest. 1624) entdeckte die Schwere der Luft und Toricelli (gest. 1647), der Erfinder des Barometers, bestätigte diese Entdeckung durch directe Versuche, die später durch Pa s \& \&l (gest. 1662) in vollständiger Weise wiederholt wurden. Pascal stellte an die Spitze seiner wissenschaftlichen Untersuchungen den Satz von der gleichförmigen Druckfortpflanzung eingeschlossener Flüssigkeiten und bewies, dass das Wasser in geneigten Rohren auf gleiche Höhe wie in senkrechten Rohren steigt. Dem Erfinder der Luftpumpe, Ot to v. Geri cke (gest. 1668), war es vorbehalten, die Mittel zur Erzeugung der Luftleere zu finden.. Toricelli entdeckte, dass, wenn das Wasser aus der Oeffnung in der Wand eines Gefässes ausfliesst, es dieselbe Geschwindigkeit annimmt, wie ein Korper; der, der Schwerkraft überlassen, aus der Höhe von der Oberflache des Wassers bis zur Ausflussöffnung frei herabfällt.

Mariotte (gest. 1684), welcher mit dem Engländer R. Boyle (gest. 1691) gleichzeitig das Gesetz, dass die Spannungen der Dämpfe in gleichem Verhältnisse wie die Dichten und im umgekehrten Verhältnisse wie die Volumina stehen, aufstellte, unterzog alle frühor festgestellten Sätze der praktischen Prüfung. Er begründete die Gesetze der Hydrostatik und untersuchte die Bewegung der Flüssigkeiten. Er fand, dass die wirklich bei dem Ausflusse von Flussigkeiten gemessenen Quantitäten immer etwas gegen die theoretisch berechneten zurückbleiben. Er entdeckte für die Ausflussmengen einen Zusammenhang zwischen dem Querschnitte des Gefässes und dem der Ausflussöffnung und stellte 
Versuche tuber die Höhe des springenden Strahles an, wobei er gleichfalls die Nichtübereinstimmung mit der Theorie entdeckte. Er wies zuerst auf die Nothwendigkeit hin, die auf Grund von Hypothesen gefundenen Formeln durch Experimente zu corrigiren.

Newton (gest. 1727), der Erfinder des Gravitationsgesetzes, schuf durch die Differential- und Integralrechnung gleichzeitig mit Leibniz (gest. 1716) neue Werkzeuge zu weiteren Studien. Mit diesen behandelte Maclaurin (gest. 1746) zum ersten Male die -Lehre von den Flussigkeiten. Die Bestrebungen zur Erforschung der Gestalt der Erde führte zur Vervollkommnung der Nivellirmethoden und zur Entdeckung neuer Instrumente für Längen und Hỏhenmessungen. Bouguer (gest. 1758) machte die erste Reise zur Erforschung der Gestalt der Erde nach Peru und Clairaut (gest. 1765) zu gleichem $Z$ wecke die zweite nach Lappland.

Daniel Bernoulli (gest. 1782) stellte die Theorie von Ebbe und Fluth auf und wandte zuerst das Princip von der Erhaltung der lebendigen Kräfte auf die Hydraulik an. Le onhard Euler (gest. 1782) und Lagrange (gest. 1813) forderten die Kenntniss der Hydraulik durch mathematische Calcule. Laplace (gest. 1827) behandelte zuerst die Capillaritatsfrage ausfubrlich. Segner (gest. 1777) beschäftigte sich mit der Érforschung der Obeı fläche der Flússigkeiten. Dr. Young (gest. 1829) hat ein vorzuggliches Werk über die Cohäsion der Flussigkeiten zurückgelassen. Ga uss (gest. 1855) schuf durch die Erfindung der Methode der kleinsten Quadrate dem Beobachter ein neues Hülfswerkzeug. Poisso n (gest. 1840) schrieb eine neue Theorie der Capillarkraft.

Borda (gest. 1766) bestimmte Ausfluss- und Contractionscoëfficienten und es folgten ihm auf diesem Gebiete der Experimentalhydraulik Bossut, Venturi, Bidone, Polini, Michelotti Vater und Sohn, Baileau, Poncelet, Lesbros, d Aubuisson, Navier und viele Andere. Der erste deutsche Forscher, der uns hier begeguet ist, Eytelwein (gest. 1849), dem viele unserer Landsleute später folgten, von denen nur die beiden ersten Grössen W e is s bach (gest. 1871) und $\mathrm{Hagen}$ hier genannt werden mögen.

Mit der Bewegung des Wassers in Kanälen und Flüssen und namentlich auch mit der Erfindung von Instrumenten zum Messen fliessenden Wassers beschäftigten sich Guilielmini, Guido Grandi, Mafredi, Lendrini, Borgna, Pil ot Ximenes etc. Eine wissengchaftliche Begrundung dieser Frage versuchte zuerst B r a h m s (175̆3) 
und später Dubuat (1779). Ihnen schliessen sich Cou lo a b (1800), Girard (1804), Belanger, d'Aubuisson, Dupuit und Prony an. Der Holländer Brüning, sowie die Deutschen Eytelwein, Weissbach, Hagen, Woltmann, Heinemann, Funk und Lahmeyer haben sich unter vielen Anderen hier einen hohen Namen erworben.

Um die Ergründung der Gesetze der Bewegung des Wassers in Rohrleitungen haben sich unter den Franzosen Couplet, Bossut, Dubuat, Gueymard, Prony, St. Venant, d'Aubuisson, Navier, Darcy und Dupuit, unter den Engländern Dr. Young und Provis und unter den Deutschen Gerstner, Eytelwein, Hagen, Woltmann und vor Allen Weissbach sehr verdient gemacht.

Dieses Heer von Namen, die zum Theil auch auf anderen Gebieten sich hohen Glanzes erfreuen, schafft eine Vorstellung von der geistigen Arbeit, an der sich Jahrhunderte hindurch die hervorragendsten Köpfe betheiligen mussten, um unsere heutige Hydraulik und damit die wissenschaftliche Basis für die Kenntniss der Leitung des Wassers zu schaffen. Die Fortschritte, die uns auf Grund dieser Geistesarbeit mogglich geworden, sind, wenn auch für uns, die wir in ilhrer Kenntniss herangewachsen, weniger uberraschend, aber doch darum gewiss nicht geringer anzuschlagen. Nichts ist geeigneter, als die Kenntniss der wissenschaftlichen Entwicklung der Grundlehren, auf denen unser Fach beruht, um den richtigen Maasstab für die Beurtheilung der römischen Bauten nach ihrem wahren Werthe, ohne sie im Entferntesten herabsetzen zu wollen, finden zu lassen und uns davor zu bewahren, dass wir unser Urtheil durch falsche Vorstellungen von ihrer Grosse und Erbabenheit, entsprungen aus der Massenwirkung ihrer Erscheinung, beirren lassen. Die Epoche der Alten fand ihren Glanzpunkt in der Gipfelung grossartiger Verbältnisse und verdient duich den Umfang der geleisteten Arbeit für einzelne Zwecke auch noch heute unsere ungetheilte Bewunderung, die wir nicht nur den Künstlern und Alterthumsforschern uberlassen wollen. Aber es kónnen dennoch die Ruinen des Aquäducts von Maiutenon sich ohne Furcht mit denen der verfallenen Werke des Claudius in der Campagna messen. Plinius konnte sagen: „Nihil magis mirandum est in toto orbe terrarum", indem er einen Rückblick auf die romischen Wasserversorgungen warf. Aber wir sind, gestutzt auf die Schätze, die die Forschungen und Beobachtungen des nicht rastenden menschlichen Geistes uns hinterlassen haben, in der Lage, unsere Arbeiten auf einem tieferen $W$ issen aufzubauen, das uns zu unvergleich- 
licheren Anstrengungen und $\mathrm{zu}$ grösseren Leistungen fähig macht und wir brauchen nicht zu befürchten, dass die Arbeiten dieses Jahrhunderts für Wasserversorgungszwecke dem Plinius weniger bewunderungswürdig erscheinen möchten.

Es dürfte hier am Platze sein, einige Bemerkungen über die Erkenntniss und Verbesserung der Qualität des Wassers zu machen. Die Furcht vor der Lösung des Bleies durch das Wasser und vor der dadurch hervorgerufenen schädlichen Einwirkung auf die Gesundheit ist eine sehr alte. Schon Hippokrates warnt davor, das zum Trinken bestimmte Wasser durch Cisternen oder durch Rohre von Blei zu leiten und Vitruv ermahnt Jeden, der gesund bleiben will, kein Wasser, das durch Blei geleitet ist, zum Trinken zu benützen. Trotzdem also schon Tausende von Jahren die Aufmerksamkeit auf diesen Punkt gerichtet und das durch Bleirohre geleitete Wasser zum Trinken benützt ist, tauchen heute noch immer wieder Stimmen auf, die davor

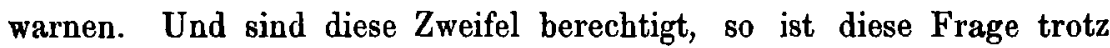
aller Fortschritte von Chemie und Medicin heute noch immer nicht als eine strenggelöste zu betrachten.

Wenngleich den Alten die Mittel zur Untersuchung des Wassers unbekannt waren, so wusste man dasselbe doch nach dem Grade der Klärheit, der Geschmacksreinheit und der Temperatur für die verschiedenen Verbrauchszwecke sehr wohl zu classificiren, wie es die Eintheilung der verschiedenen der Stadt Rom zugefuhrten Wasserarten fur die verschiedenen Verbrauchszwecke ausspricht, die von Frontinus angegeben ist.

Die Aeusserung des Plinius: "Quippe talis est aqua, qualis terra per quam fluit" beweist ferner, dass man sich schon damals, trotzdem man von der Chemie noch keine Idee hatte, darüber klar war, dass das Wasser eine löseńde Kraft auf den von ihm durchflossenen Boden ausübte. Wenn Seneca noch auf Grund seiner Beobachtungen, dass der Regen nicht tiefer als $3 \mathrm{~m}$. in die Erde eindringen könne, behauptete, die Quellen könnten unmöglich von atmosphärischen Niederschlägen herrühren, so haben doch schon Aristoteles und Vitruv die Ansicht ausgesprochen, dass die Mehrzahl der Quellen in Zusammenhang mit Regen, Schnee und Eis stehen. Plinius und später auch Vitrur geben die Mittel an, Quellen aus dem Feuchtigkeitszustande des Bodens zu erkénnen und bereits die alten Römer batten ihre Quellenfinder, aquillegi genannt. Die artesiscben Brunnen verdanken ihren Namen dem zuerst in del Grafschaft Artois im nordwestlichen Frankreich 1126 
abgebohrten Brunnen, obgleich sie in Aegypten und China schon unendlich viel fruher bekannt gewesen sind. Es ist nicht zu verkennen, dass, wenngleich maa nur in seltenen Fällen durch sie für grössere Wasserversorgungen zu einem befriedigenden Resultate gelangt ist, sie doch, aus dem Bedürnisse der Erschliessung guten Wassers entstanden, für die Anregung und Erweiterung unserer geologischen Kenntnisse von sehr grosser Bedeutung gewesen sind.

In der Person des Asklepiades (gest. 56 v. Chr.), dem Arzte des Cicero, finden wir den ersten Kaltwasserdoctor, wenngleich schon in fruherer Zeit die heilsame Wirkung des Wassers für Kranke, und Gesunde bekannt war, wie sie sich in den durch Religion und Sitte vorgeschriebenen und weitausgedehnten Anwendungen von Waschungen und Bädern ausspricht.

Einen Anfang der küstlichen Reinigung des Wassers begegnet uns auch schon bei fast sämmtlichen römischen Wasserleitungen, indem das Wasser meistens vor seinem Eintritt in die Stadt ein Reservoir zum Niederschlagen von Sand und Schlamm passirte. Wann die Benützung von Hausfiltern, zu deuen man jedenfalls anfänglich poröse Steine und später Sand benützt hat, begonnen, habe ich nicht erfahren können. Jedenfalls ist aber der pierre de Vergelet schon im vorigen Jahrhundert in Paris vielfach in Beniutzung gewesen. Im Anfange dieses Jahrhunderts machte Loowitz zuerst auf die filtrirende. Eigenschaft der Kohle aufmerksam und es gehören wohl fast alle weiteren Erfindungen auf dem Gebiete der Hausfilter unserem Jahrliundert an. 1806 tauchte in Paris eine Filtration nach dem Patent Schmith, Cuchet und Montfort und die Einführung von fontaines marchandes auf, aus welchen Seincwasser verkauft wurde, das zum Theil filtrirt war. 1833 finden wir bei einer derselben die Anwendung von feinem Kies und von siebartigen Sandsteinen, bei einer anderen von Sand und Kohle. 1835 erhielt Fonvielle cin Patent für die Compagnie française auf die Anwendung von Schwämmen, Sandstein, Kies und Kohle in kleinen, unter Druck arbeitenden Filterapparaten und 1839 nahm Souchon ein Patent auf die Anwendung von präparirter Scheerwolle zum Filtriren. Als neues Material fur diesen Zweck tauchte im Anfange dieses Jahrzehnts der Eisenschwamm, spongy irou des Professors Bischof in London, auf und das von Spencer 1866 in Wakefield angewendete magnetic proto carbide of irou, ein Magneteisenstein, welches dort zur Filtration im Grossen benützt wurde, erwies sich für diesen Zweck sehr bald als unbrauchbar. 
Für die mechanische Filtration im Grossen ist der erste mit Erfolg gekrönte Anfang 1839 für die Chelsea-Wasserwerke bei der Victoria Bridge in London von J. Simpson gemacht und es sind diesem Beispiele bis zum Jahre 1854 alle Londoner Wasserwerke und ausserdem noch eine grosse Menge anderer Städte, deren Zahl sich bis heute noch stets vermehrt, gefolgt. Die in verschiedenen schottischen und aueh in französischen Städten zeitweilig eingeführte Methode, wobei das Wasser bei seinem Durchgange durch das Filter den umgekebrten Weg machen muss, sowie die verticalen Filter haben es bis jetzt ebensowenig zu einem grösseren Erfolge bringen können, als die verschiedentlich versuchten abweichenden Reinigungsmethoden der Simpson'schen Filter.

Dass es mit unserer Kenntniss der $s \mathrm{chädlichen} \mathrm{Bestand-}$ theile des Wassers noch heute etwas unvollkommen aussieht, kann nicht überraschen, wenn man bedenkt, dass $L$ a voisier es 1783 zuerst direct aussprach, dass das Wasser eine Zusammensetzung des von Cavendish entdeckten Wasserstoffes und des von Priestley entdeckten Sauerstoffes sei. Die erste $W_{\text {asser unalyse scheint aus dem Jahre } 1799 \text { von }}$ Cavendish herzuruhren, der ein Ausscheiden von Kalk und Magnesia beim Kochen des Wassers nachwies. Es ist natbrlich, dass man sich bei den Wasseruntersuchungen, durch die Hand des Chemikers ausgeführt, auf die nach dem Stande seiner Wisseuschaft überall nachweisbaren Stoffe beschränkte und es ist zu entschuldigen, dass man den Resultaten des Befundes mitunter (inen grösseren Werth beilegte, als sie es verdienten. Es entstand ans dem berechtigten Wunsche der Erzielung brauchbarer Resultate, indem man dem, was man gefunden, eine Bedeutung beizulegen sich bemulte, die Theorie der Grenzzahlen, die hauptsächlich von Reichard und $\mathrm{Kubel}$ cultivirt, wohl bald verlassen werden wird. Trotz aller Fortschritte der organischen Chemie hat es sich aber bis jetzt gezeigt, dass nur ihre immer weitere Vervollkommnung uns wird in die Lage bringen konnen, die wirklich schädlichen Stoffe des Wassers zu entdecken, vorausgesetzt, dass gleichzeitig die Mediciner dazu im Stande sind, sie als solche bezeichnen zu können. Ob wir oder unsere Nachkommen diesen Zeitpunkt erleben werden, wer vermöchte das zu sagen!

Ich wende mich nunmelır wieder den speciell praktischen Fragen zu und zwar in erster Linie den Rohrleitungen.

Ausser der Benützung von Mauerwerk und von Steinen in ausgehöblter Form zur Herstellung von Wasserleitungen hat seit ältesten Zeiten das Blei wohl die Hauptverwendung für diesen Zweck gefunden: 
Namentlich war das der Fall, wenn es sich um geschlossene Leitungen bandelte, die einen inneren Druck aushalten sollten. Das Blei ist ja auch von allen Metallen das am frühesten und meisten verbreitete gewesen. Schon im 2. Buche Mose wird seiner erwähnt. Die Israeliten raubten den Midianitern Blei und schmolzen es ein. Die Phönicier überfuhrten Blei und Zinn aus Britannien. Die Römer betrieben in Frankreich, Spanien und Britannien Bergbau zur Gewinnung volı Blei und es sind 1741 in Yorkshire ausser. römischen Werkzengen für den Müblenbetrieb auch Bleiblöcke mit dem aufgegossenen Nameı des Kaisers Domitian aufgefunden.

Die Benützung des Bleies zur Herstellung von Statuen, Särgen etc. ist sehr alt. Noch älter ist jedoch das Giessen von Bleiplatten in Sand. Denn schon die Terrassen der hängenden Gürten der Semiramis waren zur Isolirung mit Bleiplatten, die zusammengelöthet waren, abgedeckt Man bediente sich zum lothen des Bleies nach Minues desselben Zinnlothes, wie heute. Die Benützung des Bleies zur Eindeckung der Dächer ist im Osten sehr früh gebräuchlich gewesen. Die Moschee von Aleppo, die grosse Halle des Divaus in Constantinopel etc. waren schon mit Blei eingedeckt. Auch benützte man Bleiplatten vielfach zum Schreiben sowohl in einzelnen Blättern, als auch in Buchern zusammengeheftet. Die Kunst des Walzens von Blei scheint im Alterthum eben so unbekannt gewesen zu sein, wie das Zusammenschweissen des im Erstarren befindlichen Bleies; jedenfalls aber sind alle alteren Spuren davon verloren.

Ausser dem Blei fand im Alterthum das $\mathrm{K}$ u p fer vielfach Verwendung zu Rohrleitungen. Leitungen aus Holz, Thon und Leder hergestellt standen diesen gegenüber weit zurïck. Wenn man auch Thonrohre bei geringem Drucke häufig gern anwandte, so griffen die alten Vỏlker in Aegypten, Griecheuland, Syrien und fast tiberall doch stets zu dem Blei, wenn es sich um die Herstellung von Leitungen für grösseren Druck handelte. In Aleppo sind Thonrohre und Bleirohre schon aus deu Zeiten gefunden, als dieser Stadt von den Griechen noch unter dem Namen Beroea und von den Juden unter dem Namen Zoba erwähnt wird. Wahrscheinlich werden die Rohre zur Bewässerung der Gürteı von Babylon, die einem sehr starken Drucke ausgesetzt waren, auch aus Blei hergestellt gewesen sein und es ist nachgewiesen, dass die von Archimedes zur Vertheilung des Wassers auf dem von ihm erbauten Schiffe IIiero verwendeten Rohre gleichfalls solche aus Blei waren.

Wenngleich die ersten Nachrichten über die Fabrikation dieser Bleirolure uns von den Römern uberbracht sind, so ist doch fast sicher 
erwiesen, dass sie pur die von den Babyloniern, Syriern, Aegyptern etc. erlernten Fabrikationsmethoden fortgepflanzt baben. Allé bis jetzt aus alten Zeiten aufgefundenen Bleirohre sind aus gegossenen Streifen, die mehr oder weniger vollkommen rund zusammengebogen und in den Stossflächen gelöthet waren, hergestellt. Die Bleistreifen wurden nach Vitruv in circa $3 \mathrm{~m}$. Länge und in verschiedener Dicke, dem Rohrdurchmesser entsprechènd, gegossen. In den verschiedensten Theilen Europas sind Reste römischer Rohre von $25 \mathrm{~mm}$. bis $300 \mathrm{~mm}$. Durchmesser aufgefunden, die im Querschnitt oft von der kreisrunden Form sehr abweichen und mehr eine umgekehrte Herzform haben. Auf diesen Rohren findet man haufig die Namen der Consuln, unter denen sie verlegt und die Namen der reichen Besitzer, welche sie sich iu ihren Wohnungen legen liessen, aber auch schon die Namen der Fabrikanten, die sie angefertigt haben, aufgegossen.

Der Verbrauch an Blei für Wasserleitungszwecke muss ein ganz enormer gewesen sein, wenn man bedenkt, dass das, was wir beute als gemeinschaftlich für alle Einwohner zum Anschluss der Privatleitungen haben, nämlich das städtische Rohrnetz, damals unbekannt war, wie sich aus der vorhin mitgetheilten Aeusserung von Genieys fur Paris noch in Jahre 1825 ergiebt. Mit Recht ist daraus wohl zu schliessen, dass es in anderen Orten ebenso gewesen ist. Man musste vielmehr, wie bemerkt, jede Privatleitung an die nächst gelegenen, aber oft Hunderte von Metern entfernteu Vertheilungscisternen anschliessen, wenn mau sich nicht ausnahmsweise mit einem oder mehreren anderen Abnehmern zur Anlage eines gemeinschaftlichen Rohres einigte. Wie schon frtiher mitgetheilt, betrug nach Frontiuus die Zahl der an eine der $9 \mathrm{Zu}$ leitungen Roms angeschlossenen Bleileitungen von $25 \mathrm{~mm}$. Durchmesser 13594. Pompeji war nur eine kleino Provinzialstadt und, trotzdem nur ein Drittel davon blosgelegt ist, hat man daraus schon eine grosse Zahl von Tonnen Bleirohre zu Tage gefördert.

Durch Bleirohre wurde der Stadt Cordova in Spanien im 9. Jahrhundert das Wasser unter dem Kalifen Abderrahman II. zugeführt und Damuscus leitete durch dasselbe Material das Wasser des Flusses Pharphar zur Bewässerung der Gärten und das des Flusses Abana für die Stadt und die Privathäuser zu.

Weil durch die Concession auf die Benützung des Leckwasser's aus den Leitungen, wie sie in Rom ertheilt wurde, viele bei der Natur des Materials und der Art der Herstellung und der Verbindung der Rohre sehr leicht zu bewirkende Beschädigungen und Betrtigereien 
stattfanden, so ersetzte man hier später diejenigen Bleileitungen, welche die Wasserschlösser mit den Vertheilungscisternen verbanden, durch solche aus $\mathrm{Thon}$, da solche weniger leicht unbemerkt ${ }^{-}$beschädigt werden konnten. Diese Rohre waren 0,6 m. lang und hatten an dem einen Ende einen Muff. Jedoch sind auch solche vorgefunden, die in einander geschroben sind.

In Jahre 1236 sind zur Wasserversorgung von London zuerst Bleirohre von $150 \mathrm{~mm}$. Durchmesser verlegt, die, ähnlich den römischen, aus gegossenen Platten zusammengelöthet waren. Sie wurden zu einer Leitung für die bei dem Dorfe Tyburn entspringenden Quellen benütat. Die Herstellung dieser Arbeit soll 50 Jahre in Anspruch genommen haben. Im Jahre 1539 sind in England die ersten Bleirohre stehend in Formen gegossen, allerdings nur in den kurzen Längen von circa $600 \mathrm{~mm}$. Die einzelnen Rohrstücke wurden in der Weise verbunden, dass man sie mit den Enden in einer Form zusammenlegte und durch Aufgiessen von flussigem Blei zusammenschweisste. Diese Erfindung ging von Robert Broke, einem Clerk Heinrich VIII., aus und wurde von einem Goldschmied Robert Cooper in die Praxis ubergeführt.

Unter der Regierung Heinrich IV. in Frankreich machte ein Einwohner von St. Germain die Erfindung, beliebig lange Rohre in der Weise herzustellen, dass man das gegossene kurze Rohr so weit aus der Giessform auszog, dass es nur einige Zoll in derselben stecken blieb und dann das Blei für das neue Rohr aufgoss. In dieser Weise wurden die beiden Enden zusammengeschweisst und es war die Herstellung beliebiger Rohrlängen leicht möglich. Auch wendete man zu jener Zeit das Schweissen des Bleies zur Herstellung von Rohren aus gegossenen Platten für die Langnähte vielfach an.

Das Walzen des Bleies zu Platten ist zuerst 1670 in Deptford von Thos. Hale ausgeführt. Das Ziehen von Bleirohren ist 1705 von dem Franzosen Dalesme und 1728 von Fayolle vorgeschlagen, aber zuerst von dem Engländer Wilkinson 1790 ausgefuhrt. Es muss um so mehr tiberraschen, dass diese Behandlung nicht fruher bekannt war, da nach den in Pompeji gefundenen Resten von Fensterblei man dieses schon in jener Zeit durch Walzen hergestellt hat. Das erste Patent für das Pressen von Bleirohren, ähnlich der Einrichtung, wie Thonrohre schon einige Zeit fruher gepresst wurden, hat 1820 der Engländer T. Barr erhalten, und es ist dieses jetzt ja noch die allgemein gebräuchliche Fabrikationsmethode. 
Die Möglichkeit der schädlichen Einwirkung des Bleies, auf die Gesundheit ist, wie früher erwähnt, schon im Alterthum, ebenso wie heute discutirt. Der Abneigung gegen das Blei, welches zu jener Zeit das einzige Material war, das für Siphonleitungen henützt werden konnte, schreiben es manche Kritiker zu, dass die Rìmer für Rom selbst nur Aquäducte bauten, da ibnen nach der $\Lambda$ nsicht derselben das Gesetz der billigeren Siphonleitung wohl bekannt gewesen sein soll, was jedoch von anderer Seite bezweifelt wird.

Schon im Anfange dieses Jahrhunderts, im Jahre 1804, also 14 Jahre nach der Erfindung des Ziehens von Bleirohren, wurde in England ein Patent auf die Fabrikation von $Z$ inn rohren mit Bleimantel genommen. Zur Ilerstellung eines solchen Rohres von $13 \mathrm{~mm}$. Durchmesser wurde ein Bleirohr von $26 \mathrm{~mm}$. lichtem Durchmesser und ebenso grosser Wandstärke gegossen, darauf der Dorn von $26 \mathrm{~mm}$. durch einen solchen von $13 \mathrm{~mm}$. Durchmesser ersetzt und nach Einstreuen von etwas Kolophonium das Zinn eingegossen. Ein solches $600 \mathrm{~mm}$. langes Rohr wurde dann in gewohnlicher Weise ausgezogen. Ein zweites englisches Patent von 1820 bezweckte eine innigere Verhindung beider Metalle. Und im letzten Jahrzehnt sehen wir vielfache, leider nicht immer mit Erfolg gekrönte neue Bemühungen zur Erreichung clerselben Aufgabe.

Es kann nicht uberraschen, dass bis jetzt von der Anwendung von Eisen für Rohrleitungen noch nicht die kiede gewesen, wenn man liedenkt, dass das Roheisen erst im Anfange des 15. Jahrhunderts entdeckt und nach authentischen Nachrichten im Jahre 1544 die ersten Sachen aus Gusseisen von Ralph. Hage und Peter Bawde in England hergestellt wurden. Im 17. Jahrhundert sind in Deutschland verschiedentlich gusseiserne Rohre benützt. Aher speciell für Wasserleitungen kamen sie in grösserem Umfange wohl zuerst 1672 bis 1682 in Versailles bei Paris für die Druckleitung der Maschinenanlage in Marly zur Anwendung. Die hier ver'wendeten Rohre hatten $200 \mathrm{~mm}$. und $150 \mathrm{~mm}$. Durchmesser bei $1 \mathrm{~m}$. Länge. Sechs Parallelstränge führten zur Erlangung des erforderlichen Querschnittes von den Pumpenanlagen fort und in dem Parke selbst war ein Bleirohr von $380 \mathrm{~mm}$. Durchmesser verlegt. Die Verbindung der eisernen Rohre fand durch Flahschen mit bleiernen oder ledernen Dichtungsscheiben statt.

Die Anwendung der eisernen Rohre war im vorigen Jahrhundert noch eine sehr beschränkte und man hatte wenig Vertrauen zu denselben, was beispielsweise daraus hervorgeht, dass man für die 1716 
in Herrenhausen bei Hannover von dem englischen Ingenieur Clifft erbauten Wasserkünste ausschliesslich Bleirohre verwendete.- Circa 150 Jahre später hat man dort zum guten Theil allein aus dem Verkaufe dieser Rohre ein bedeutend vergrössertes neues und vervollkommnetes Pumpwerk mit eisernem Rohrnetze hergestellt, von dem später die Rede sein wird.

Wenn man auch in der ${ }^{\circ}$ zweiten Hälfte des 18. Jahrhunderts anfing, die Rohre statt in Lehm in Sand zu giessen, um sie billiger herstellen zu können, so konnten sie sich doch kaum Eingang verschaffen und im Beginn dieses Jahrhunderts lagen in London fast noch ausschliesslich bölzerne Rohre in der Erde - die New River W. W. Comp. allein hatte deren $640 \mathrm{Kilom}$. liegen - und erst von 1809 an wurden in London gusseiserne Rohre in grösserem Umfange angewendet.

Die hölzernen Rohre, welche in den früheren Jahrhunderten auch fast ausschliesslich in Deutschland angewendet waren, wurden meistens aus den Stämmen der Fichten oder Föhren und der Rothtannen, mitunter auch aus denen der Ulmen angefertigt. Sie wurden mit der Hand gebohrt oder mit Bohrern, die durch Wasserkraft bewegt wurden, hergestellt. Von letzterer Finrichtung giebt schon de Caus eine Abbildung in seinem Werke "Von den gewaltsamen Bewegungen". Man stellte die Löcher stets durch Anwendung immer grösserer Bohrer nach einander her und erst in den fünfziger Jahren wurde ein Bohrer von Tottière Schweppe \& Comp. in Angers erfunden, der, ähnlich den Metallbohrern, einen vollen Kern herauşbohrte. Die Rohre wurden entweder nach dem Durchmesser ihrer Bohrung oder nach der Zahl der nöthigen Bohrungen bezeichnet; so war ein einbohriges Robr ein solches von $50 \mathrm{~mm}$., ein 4 bohriges ein solches von $100 \mathrm{~mm}$. und ein 9 bohriges ein solches von $150 \mathrm{~mm}$. Durchmesser. Selten wurde ein grösserer Durchmesser als $175 \mathrm{~mm}$. genommen und Rohre von 250 bis $300 \mathrm{~mm}$. Durchmesser wurden nur ausnahmsweise hergestellt. Die Rohre wurden entweder conisch in einander gesteckłt oder durch Ueberwürfe verbunden. Später sind vielfach dafur mit einer Schneide eingetriebene schmiedeeiserne Ringe, die etwas grösser als der lichte Durchmesser des Rohres waren, benützt. Die Dauer der Rohre war gewöhnlich 12 bis 15 und ausnahmsweise 20 Jahre. Sie verlangten in Folge davon sehr viele Reparaturen, so dass z. B. bei der New River W. W. Comp. jährlich 36 Kilom. alte Rohre durch neue ersetzt werden mussten, wenn dàmit, wie es wenigstens nöthig war, das ganze Rohrnetz in ausnahms- 
weise nur 20 Jahren erneuert werden sollte. Diese Gesellschaft hatte 1810 in èiner Strasse Lọndons noch 10 Leitungen hölzerner Rohre neben einander liegen und sie schätzte die Verluste an Wasser durch Leckage auf $25 \%$. Bis 1820 hatte sie sämmtliche hölzerne Rohre durch eiserne ersetzt, was einen Kostenaufwand von $6000000 \mathrm{Mk}$. verursacht hat.

Erst im zweiten Jahrzehnt dieses Jahrhunderts gewann die Verwendung der gusseisernen Robre und damit auch die Herstellungsmethoden derselben einen ungeahnten Aufschwung in Folge der allgemeineren Einfübrung der Gasbeleuchtung. Und nur durch diese Fortschritte ist es möglich geworden, die Einrichtungen der Gas- und Wasserversorgungen, sowie in neuerer Zeit auch die der Kanalisation in den Städten in solchem Maasse durchführen zu-können.

Von Tannebergsthal im sächsischen Voigtlande sollen die dort 1716 bis 1718 gegossenen Rohre in Deutschland zuerst Verwendung für Wasserleitungen gefunden haben. Das Gräflich Einsiedeln'sche Eisenwerk zu Lauchhammer lieferte seit 1787 nach damaligen Begriffen grosse Quantitäten eiserner Flanschenrohre von $75 \mathrm{~mm}$. Durchmesser und $2 \mathrm{~m}$. Länge für Stolpen und 1790 bis 1800 solche von $100 \mathrm{~mm}$. und $125 \mathrm{~mm}$. Durchmesser für Dresden, Leipzig und Torgau. 1796 lieferte dieses Werk eine $75 \mathrm{~mm}$. weite Leitung von $415 \mathrm{~m}$. Länge, die $65 \mathrm{~m}$. Wasserdruck auszuhalten hatte und mit Muffen, also ohne Schrauben, verbunden war. Als bester Beweis, wie es Anfangs dieses Jahrhunderts noch mit dor Anwendung des Gusseisens in Deutschland ausgesehen hat, mag der nachfolgende Titel einer 174 Seiten langen Druckschrift, welche 1820 von T. L. Hasse in Schneeberg erschienen ist, dienen. Er lautet: „Ueber Wasserleitungsrohre von Gusseisen nebst einem Vorworte, uber die mannigfaltigen nützlichen Anwendungen dieses Metalles". Es werden darin unter anderen die Firmen der Giessereien in Deutschland, welche wohl Rohre würden giessan können, mitgetheilt.

Betrachten wir nun, was heute in der Fabrikation dieses für unser Fach so wichtigen Artikels geleistet wird.

Während die Rohre früher liegend und in nassen Formen gegossen wurden, haben die Forderungen gleichmässiger und geringerer Wandstärke bei genügender Dichtigkeit schon seit einer Reihe von Jahren zu stehendem Guss in getrockneten Formen geführt. Die Rohrfabrikation ist durch die gesteigerten Anforderungen zu einer völligen Specialität geworden, die sehr umfangreiche maschinelle Einrichtungen verlangt und nur durch Massenfabrikation den Marktpreisen 
angemessene Selbsțosten erzielen kann. Die Methode, die Rohre liegend in getheilten Kästen mit vollem Modell zu formen, die Kästen zu trocknen, darauf den Kern einzulegen und sie dann stehend zu giessen, wird heute noch, wenn auch in geringerem Umfange, 'angewendet.

Die Benutzung von Maschinen zur Formerei scheint $1845 \mathrm{zu}$ beginnen und es wird der erste Versuch Harrison, der ohne Modell formte, zugeschrieben werden müssen. In einem zweitheiligen Kasten wurde annähernd je etwas mehr als die Hälfte des Rohres eingestampft, dann der Kasten geschlossen und die Form selbst mittelst einer Schablone eingedreht. Nach einer 1851 von Stewart mitgetheilten Methode wird der geschlossene Kasten ganz vollgestampft und dann mittelst einer Bobrvorrichtung die Rohrform eingeschnitten. Nach einer anderen Methode desselben Erfinders von 1847 soll das Rohrmodell in einem stehenden Kasten aufgestellt in den allmählich eingeschütteten Sand dadurch eingestampft werden, dass ein das Modellrohr umgebendes Blechrolır, welches sich mit dem Fortschritt der Arbeit hebt, in Drehung versetzt wird, welches unten spiralförmige Flügel hat. Die Einrichtung von Sheriff in Glasgow, der auch ähnlich die 1856 von Elder vorgeschlagene ist, verlangt nur ein kurzes Stück Modell, welches in dem stehend aufgestellten zweitheiligen Kasten allmählich aufsteigt, und es drücken daruberliegende conische Walzen den Sand fest. Der Muff wird nachher mit der Hand aufgesetzt. Newton schlug 1850 vor, nur ein halbes Modell auf einem Formbrette zu befestigen und dieses liegend in den mit Sand gefülten halben Kasten einzudrucken. Fairbairn und Hettrington (Manchester) legten die beiden Modellhälften oben und unten auf ein Formbrett und drückten sie gleichzeitig in die beiden Kastenhälften ein. Auch die 1857 von Waltjen in Bremen erfundene Maschine wollte ein Modellbrett mit halbem Modell, welches durch Excentriks zu heben war, liegend in den Kasten eindrücken. Downic schlug 1863 eine ähnliche Methode vor, mit dem Unterschiede, dass das volle Modell aus dem Modellbrett halb hervorragte und so befestigt war, dass es gedreht werden konnte.

Die Maschinenformerei, welche hiernach in England zuerst is Benützung gewesen, hat sich in den letzten Jahren auf dem Continente weiter entwickelt. Es sind hier drei Werke, die die eigentliche Maschinenstampferei, jede in etwas abweichender Weise, in grossem Umfange betreiben, nämlich die Giesserei in Marquise im Departement Pas de Calais in Frankreich, die Köln ische Maschinenbau-Actiengesellschaft in 
Bayenthal bei Kòln und die Duisburger Actiengesellschaft für Giesserei in Duisburg, letztere beiden hauptsächlich fur die grösseren Rolıre. Es soll ferner auch die Berliner Actiengesellschaft für Eisengiesserei, vormals Freund in Charlottenburg, Maschinenstampferei anwenden. Zwischen den beiden Methoden des liegenden Formens mit der Hand und des stehenden mit der Maschine steht die von Blaldy, Roechling \& Comp. in Pont à Mousson in Frankreich zuerst eingeführte Methorle, stehend mit der Hand zu formen, aber den geschlossenen Kasten stets an seiner Stelle zu belassen. Diese Art der Giesserei, selbstrersändlich mit verschiedenen Modificationen, ist in Deutschland von der Hannoverschen Eisengiesserei in Hannover und von der Friedrich Wilhelm'sHütte in Mullheim a. d. Ruhr, welche letztere unter den deutschen Rohrgiessereien die grösste Productionsfähigkeit hat, mit grossem Erfolge eingeführt. Dasselbe System sollen auch die Halbergerbitte bei Saarbrücken (R. Böcking \& Comp.), Wasseralfingen, Königin Marienhütte und Lauchha nnmer, vorm. Gräfl. Einsiedeln'scbe Werke zu Gröditz in Sachsen, sowie die bekannten Giessereien Adalberthütte in Kladno in Böhmen und endlich die L. v. Roll'schen Eisenwerke zu Choindez bei Solothurn (Schweiz) benützen. Die ubrigen deutschen Rohrgiessereien, als Peter Stühlen in Deutz, G. \& J. Jäger in Elberfeld, Daelen \& Burg in Heerdt bei Neuss und die Königin Marienhtitte in Cainsdorf in Sachsen haben liegende Formerei mit und ohne Naht bei stehendem Guss. Ueber die Art der Fabrikation der beiden Giessereien in Deutsch-Lothringen: Jahiet, Gorand, Lamotte \& Comp. in Oettingen und F. D. Wendel \& Comp. in Hayingen, ist mir nichts näheres bekannt. Die renommirtesten Rohrgiessereien in Schottland sind augenblicklich in Glasgow: Th. Edington \& Sons., R. Laidlaw \& Comp., D. G. Steward \& Gomp. und R. Maclaren \& Comp. und in England Cochrane, Grove \& Comp. in Midlesbro.

Nicht ohne Interesse dürfte die nachfolgende Gewichtstabelle pro $\mathrm{m}$. Wasserleitungsrohre sein. Sie enthalt die von dem Vereine deutscher Ingenieure und von dem Vereine von Gas- und Wasserfachmännern Deutschlands gemeinschaftlich aufgestellten Normalien und daneben die in Newbrigging's Gas Manager's Handbook (1874) in England für die Wasserleitungsrohre als üblich bezeichneten Gewichte. Ferner sind darin aufgenommen die Gewichte ron Marquise, Pont à Mousson, Gröditz, Cainsdorf und Roll nach den Angaben des Professors Durre in Aachen, von der Wiener Weltausstellung mitgetheilt, und auf der anderen Seite die Gewichte, welche einem neueren englischen 
Preiscourante entnommen sind, sowie diejenigen, welche schon 1819 in Philadelphia für die dortige Wasserversorgung Verwendung gefunden haben. (Siehe Tabelle pag. LXVIII.)

Die Hähne und Tentile sind gewiss sehr alten Trsprungs. Schon die Isis der alten Aegypter wurde mit dem Schlüssel, der die Schleussen des Xils offinete, abgebildet. Das Vorbild der Ventile sind jedenfalls die Thüren, vertical, horizontal oder geneigt drehbar, gewesen und es finden sich ja solche namentlich bei den musikalischen Instrumenten schon in frühester Zeit angewendet. Nach den aufgefundenen Mustern und den noch vorliegenden Beschreibungen haben die (xrriechen und Römer, ja selbst die Babylonier und Aegypter in Material und Arbeit eine viel reichere Auswahl für die Hähne, die sie sowohl aus Holz als aus Messing, ferner aus Blei und anderen Metallen herstelltei. in künstlerisch ausgebildeten Formen besessen. Der so vielfach angewandte Löwe als Wasserspeier ist auf die Aegypter zurückzuführen, die ihn häufig für geheiligte Quellen benützten. Die Ceberschwemmung des Nils fand nämlich statt, wenn die Sonne in das \%eichen des Löwen trat.

I)ie grossen Broncegefässe, deren aus der Zeit des Alterthums vielfach Erwähnung geschieht, hatten jedenfalls sämmtlich Hähne zu ihrer Entleerung. So das Broncebecken, dessen Bezaled erwähnt, welches aus dem Schmucke israelitischer Frauen hergestellt war, ferner der Bronce-See, welchen Salomon vou einem Tyrier herstellen liess etc. Dieses letztere ('efäss hatte die Form einer Halbkugel von $5 \mathrm{~m}$. Durchmesser und $2,5 \mathrm{~m}$. Tiefe. Es hatte $67 \mathrm{kbm}$. Inhalt und stand auf einem Piedestal, das von 22 Statuen getragen wurde, aus deren Munde sich das Wasser ergoss. In späterer Zeit ist dieser Bronce-See von Nebukadnezar nach Babylon entführt.

Ungemeinen Luxus trieben die Römer mit den Leitungen und Hähnen für ihre Bäder. Die Anwendung von reinem Silber für diese Gegenstände war nichts ungewöhnliches. In den Bädern des Caracalla waren sowohl die engen als die weiten Rohre von Silber. Doppelte Leitungen für warmes und für kaltes Wasser waren schon sehr früh in (Xebrauch. Selbst goldener Rohre wird von dem Propheten Zacharias erwähnt. In den Ruinen der Villa des Antoninus Pius ist ein Hahn von reinem Silber aufgefunden, der 35 Pfd. römisches Gewicht hatte.

Die früheren Hähne waren sämmtlich Kegelhähne und erst unser Jahrhundert hat die reiche Zahl von ('onstructionen gebracht, die zum grossen Theil aus dem Bedürfnisse hervorgegangen, den bei plötzlichem 
Gewichtstabelle für Muffenrohre.

\begin{tabular}{|c|c|c|c|c|c|c|c|c|c|}
\hline \multirow{3}{*}{$\begin{array}{c}\text { Roll } \\
\text { pro m. } \\
\text { Kilo }\end{array}$} & \multirow{3}{*}{$\begin{array}{c}\text { Gròddtz } \\
\text { und } \\
\text { Caingdorf } \\
\text { pro m. } \\
\text { Kilo }\end{array}$} & \multirow{3}{*}{$\begin{array}{c}\text { Pont } \\
\text { a } \\
\text { Monsson } \\
\text { pro m. } \\
\text { Kilo }\end{array}$} & \multirow{3}{*}{$\begin{array}{l}\text { Marquise } \\
\text { pro wi } \\
\text { Kilo }\end{array}$} & \multicolumn{4}{|c|}{ Normale Wasserrohre } & \multirow{3}{*}{$\begin{array}{c}\text { pro m. } \\
\text { Bllo } \\
\text { nach } \\
\text { Preis- } \\
\text { conarant }\end{array}$} & \multirow{3}{*}{$\begin{array}{c}1819 \\
\text { Phladel- } \\
\text { phra } \\
\text { pro m. } \\
\text { K1lo }\end{array}$} \\
\hline & & & & \multicolumn{2}{|c|}{ Deutsche } & \multicolumn{2}{|c|}{ Englische } & & \\
\hline & & & & $\begin{array}{l}\text { pro } \mathrm{m} . \\
\text { Kllo }\end{array}$ & $\begin{array}{l}\text { Durch- } \\
\text { messer }\end{array}$ & $\begin{array}{c}\text { pro m } \\
\text { Enlo }\end{array}$ & $\begin{array}{l}\text { Durch- } \\
\text { messer }\end{array}$ & & \\
\hline - & - & - & - & 10 & 40 & 10,5 & 37 & - & - \\
\hline 4,2 & 10 & 12 & 12 & 12 & 50 & - & - & - & - \\
\hline - & - & - & - & 15 & 60 & 14 & 51 & 一 & 一 \\
\hline 12,4 & 13 & 18 & 18 & 17 & 70 & 17,5 & 64 & - & - \\
\hline- & - & - & - & 20 & 80 & 18,5 & 76 & 20,5 & 26 \\
\hline 15 & - & - & 一 & 22 & 90 & - & - & 一 & 一 \\
\hline - & 21 & 25 & 28 & 24,5 & 100 & 一 & 一 & - & - \\
\hline - & $\left.25^{*}\right)$ & $\left.34^{*}\right)$ & 33*) & 32 & 125 & 28 & 102 & 28,5 & 36 \\
\hline 32 & 32 & 40 & 40 & 39 & 150 & 37 & 127 & - & - \\
\hline - & - & - & - & 48 & 175 & 48,5 & 152 & 48 & 59,5 \\
\hline 46 & 53 & 58 & 58 & 57 & 200 & 60 & 178 & - & - \\
\hline- & - & - & - & 67 & 225 & 67 & 203 & - & 76 \\
\hline - & 71 & 78 & 80 & 77 & 250 & 78,5 & 229 & 84 & - \\
\hline- & - & - & - & 89 & 275 & 92,5 & 254 & - & 102 \\
\hline 83 & 88 & 97 & 105 & 100 & 300 & 102 & 279 & - & - \\
\hline - & - & - & - & 111 & 325 & 111 & 304 & 125 & 120 \\
\hline- & - & - & - & 122 & 350 & 118 & 330 & - & - \\
\hline- & - & - & - & 134 & 375 & 129,5 & 356 & - & - \\
\hline 162 & 138 & 140 & 147 & 148 & 400 & 157 & 381 & - & - \\
\hline- & - & - & - & 158 & 425 & 176 & 406 & - & 181,5 \\
\hline- & - & - & - & 176 & 450 & 192 & 432 & - & - \\
\hline- & - & - & - & 190 & 475 & 213 & 457 & - & - \\
\hline- & - & - & - & 204 & 500 & 239 & 483 & - & - \\
\hline- & - & -- & - & 234 & 550 & 259 & 508 & 260 & 241 \\
\hline- & - & - & - & 265 & 600 & 288 & 559 & -- & - \\
\hline- & - & - & - & 301 & 650 & 324 & 609 & 355,5 & - \\
\hline- & - & - & - & 340 & 700 & - & - & - & - \\
\hline- & - & - & - & 380 & 750 & - & - & - & - \\
\hline- & - & - & - & 422 & 800 & 499,5 & 762 & - & - \\
\hline- & - & - & - & 518 & 900 & - & - & - & - \\
\hline - & - & - & - & 616 & 1000 & 689 & 914 & 724,5 & - \\
\hline- & - & - & - & - & - & 915,5 & 1067 & - & - \\
\hline & & & & & & 1008 & 1219 & - & - \\
\hline
\end{tabular}

*) nicht $125 \mathrm{~mm}$ sondern $120 \mathrm{~mm}$. Durchmesser. 
Schlusse eintretenden. Stössen vorzubeugen und die Belästigung durch Undichtwerden der Hähne zu verhindern. Trotz vielfacher Bemtihungen, die zum Theil sebr geistreich erdacht sind, ist es jedoch noch nicht gelungen, einen selbstthätig schliessenden Hahn, der keine Stösse in der Leitung erzeugt und allen anderen Anspriuchen genligt, zu erfinden. Trotzdem zeigen die Hähne von Frost, von Guest und Chrims, von John Aird, von Lambert, von Peet und wie die Namen alle heissen, bedeutende Fortschritte in der Construction der Hähne überhaupt, dieser so wichtigen Theile der Wasserleitungen, auf welche wir mit Befriedigung blicken kònnen und welche die Hoffnung rege erhalten, dass auch diese Aufgabe gelöst werden wird.

Ebenso sind die Fortschritte in der Construction der grösseren Absperrvorrichtungen in den letzten Jahrzehnten nicht unbedeutende gewesen.

Das Kegelventil zum Frsatz grosser Kegelbähne bei Wasserleitungen soll von einem Mechaniker Moulfarine in Paris erfunden sein und wird in einem 1831 erschienenen Werke uber Wasserleitungsrohre von Gottl. Meyer als etwas Neues bezeichnet. Trotzdem ist dasselbe bereits 1803 bei der neuen Wasserleitung in Philadelphia als Durchgangsventil benützt und es sind hier die Wasserschieber, ähnlich wie wir sie frliher benutzten, deren Schraubenspindeln jedoch ausserhalb des Gehäuses lagen und die zwei Muffenenden hatten, zuerst im Jahre 1822 zur Verwendung gekommen. Leider habe ich ihre Entstehung nicht weiter verfolgen können. Die Wasserschieber erhielten später eine in Innern liegende Spindel. Der Schieberkasten, zuerst aus zwei Theilen und einem I)eckel bestehend, wurde durch einen eintheiligen ersetzt und diesem später statt des rechteckigen ein elliptischer Querschnitt gegeben.

Der heute noch in London fast ausschliesslich in Anwendung befindliche Hydrant, der "Fire plug“, welcher dort in fast gleicher Form seit 1666 in Gebrauch ist, besteht aus einem in ein Spundloch des Leitungsrohres gesteckten Holzpflocke. 1803 wurde schon-in Philadelphia dafür ein mit einem Hebel zu öffnendes Ventil, welches auf einem senkrechten Rohre über Tage stand, bentitzt. Auch wendete man schon damals ein in der Erde stehendes Ventil von Leder mit Rothgusssitz als Hydrant an. Das Standrohr ging vertical in die Höhe und trug über Flur die seitliche Verschraubung für den Schlauch und in der Mitte auswärts eine Schraube, die die Ventilstange zum Oeffnen des Ventiles, welches durch den Wasserdruck geschlossen wurde, hinunterdrückte und dabei gleichzeitig eine auswärts angebrachte Stange 
in eine kleine, seitlich uber dem Ventile angebrachte Oeffnung zum Verschluss eintrieb, welche, wenn wieder geöffnet, die Selbstentwảsserung des Standrohres bewirkte. In Hamburg bestanden seit 1849 und bestehen die Hydranten noch aus einem am Hauptrohre angebrachten Schieber und es ist der Austritt desselben durch Rohrleitungen mit den an convenirenden Stellen angebrachten Verschraubungen verbunden. Berlin erhielt 1852 Hydrantenventile, neben denen tief in der Erde das lange transportabele Standrohr mittelst Bajonettverschluss aufgesetzt wurde, wälrend man in Altona 1859 sich eines kurzen Standrohres bediente und den Bajonettrerschluss direct unter das Strassenpflaster legte. Es wurde damit die schon eben erwähnte, in vielfachster Weise zu lösen versuchte Selbstentwässerung des ủber dem Ventile stehenden Rohres durch die allgemeinere Verbreitung dieser letzteren Construction von grosser Bedeutung. Die mit den Aufgrabungen zum Repariren undichter Ventile verbundenen Unannehmlichkeiten führten zu der Construction des weiten bis unter das Pflaster reichenden Rohres, durch welches man das Ventil herausziehen kann. Und dieses Rohr wurde in einigen Fällen zu einem ủber Terrain stehenden festen Standrohre, mit entsprechenden Schlauchverschraubungen versehen, verlängert.

Schon aus dem grauesten Alterthume haben wir Berichte tiber flies sende Brunnen, Fontainen und springende Strablen. Solche Anlagen sind stets mit grosser Auszeichnung behandelt, die sich in der Sorgfalt der Dekoration, wie sie in dem Reichthume der Ornamentik wenigen anderen Dingen zu Theil geworden, ausspricht. Diese Brunnen sind jedoch, wenigstens die künstlich hergestellten, niemals Gegenstand religiöser Verebrung gewesen, wenngleich "Feuer" und "Wasser" in den religiösen Cultus der Alten eingeschlossen waren und die symbolische Verehrung des Wassers mit fortschreitender Cultur immer mehr die des Feuers verdrängte. Aber diese Verehrung galt nur den aus Spalten und Klüftungen der Erde direct hervortretenden Quellen, deren Entstehung noch den meisten Griechen des klassischen Alterthums so geheimnissvoll erschien, dass sie die Stelle ihres Auftretens bald als Zugänge zur Unterwelt, bald als Verbindungsweg zum Inneren der Erde, schliesslich aber fast allgemein als diejenigen Orte bezeichneten, an welchen einst Deukalion's Fluth abgeflossen sei, als sich das Feste von dem Flüssigen geschieden habe. Der Umkreis solcher Erdspalten wurde als Sitz für Heiligthümer gewàhlt und durch daruber gebaute Tempel den Blicken der Unglaubigen entzogen. Das Orakel von Delphi befand sich an einem solchen Quell, ebenso die Tempel der Here zu Hierapolis, ferner 
Tempel in Athen, in Argos, in Troezen etc. Auch auf dem Comitium in Rom befand sich ein solcher Spalt, der mit einem mächtigen Steine, der Fluthstein genannt, verschlossen war, und bei anhaltender Dürre erflelite man die Hülfe der Götter, indem man den Stein in einer Procession durch die Stadt führte. Auch bei den Israeliten finden wir, wahrscheinlich von den Aegyptern mit hinübergenommen, die Heilighaltung der natürlichen Quellen, so der im Tempel des Salomon. Ferner finden wir bei allen Religionsformen der alten Welt den Abwaschungen besondere Wichtigkeit zugeschrieben und das Wasser als ein Symbol der Versöhnung aufgefasst. Nirgends aber begegnen wir der Verehrung der künstlich geschaffenen Ausflussstellen des Wassers, wenngleich sich ihnen, wie erwähnt, der Kunstsinn in hohem Maasse stets zugewendet hat.

Es war etwas gewöhnliches, das Rohr, welches das Wasser zuführte, in eine verzierte Säule einzuschliessen und die Rohröffnung, durch die das Wasser ausfloss, mit symbolischen Figuren zu schmücken; ja man legte die ganzen Rohre selbst in das Innere von Figuren. Man benützte dazu die Statuen von Männern, Frauen, Kindern, ferner die Figuren von Thieren, selbst von Vögeln und Fischen und liess aus einem Theile derselben das Wasser zum Ausflusse in ein Becken von. polirtem Marmor oder sonstigem kostspieligen Material gelangen. Auch liess man das Wasser in springenden Strahlen emporsteigen oder liess es von oben herab über künstliche Hindernisse in Form von Cascaden herabfallen.

Die Atmosphäre wurde durch solche Anlagen gekühlt und befeuchtet und das Auge erfreute sich nicht nur am Ganzen, sondern fand stets neue Unterhaltungen an den ewig sich ändernden Formen des bewegten Wassers. Der Geschmack an diesen Anlagen stammt jedenfalls aus dem Osten und ist entstanden aus dem Bedürfnisse der Bewässerung der Gartenanlagen und der Befeuchtung und Kühlung der Luft. Die dortigen Gärten wurden zu Zeiten als Speiseräume und selbst zum Schlafẹ benützt. Es waren solche Bewässerungsanlagen bei dem dortigen Klima ein wahres Bedürfniss. Fontainen und Wasserkünste werden wahrscheinlich schon in Babylon vorhanden gewesen sein.

In der Odyssee wird zweier Kunstleitungen im Garten des Alkinoos erwähnt. Der jüngere Plinius erzählt in der Beschreibung des Gartens seiner toscanischen Villa von einer Fontaine, deren Wasser, über die Ecken eines Marmorbeckens fliessend, zur Bewässerung der Blumen diente; eine andere Fontaine spritzte aus vielen kleinen Rohren Wasser aus, und es fiel dasselbe auf eine Cascade, Auge und Ohr erbauend, schäumend aus grosser Höhe in ein Marmorbecken hinunter. Auch 
im Speisezimmer des Plinius wird einer Fontaine erwähnt. Im hohen Lied Salamonis heisst es: „Wic ein Gartenbrunnen, wie ein Boru lebendigen Wassers, der vom Libanon fliesst."

Cato, der Censor, liess zur Strafe die Rohre abschneiden, durch die das Volk mit Wasser in den Häusern und Gärten versorgt wurde. Die Niederlage des Tarquinius wurde von Castor und Pollux überbracht, die sich an der Fontaine auf dem Marktplatze trafen.

Die Statuen des Juppiter Pluvius sowie die des ägyptischen Gottes Canopus wurden vielfach zur Verzierung solcher Fontainen benützt. Ihnen entquoll oft das Wasser aus einzelnen Stellen der Figur und mitunter auch aus allen möglichen Theilen des Körpers. Die Bruste weiblicher Figuren sind vielfach als Ausflussstellen benützt. In Pompeji, wo in fast jeder Strasse eine Fontaine vorgefunden ist, waren dieselben meistens mit Broncefiguren geschmuckt und es sind hier und in Herkulaneum Bilder von Fontainen mit bochspringenden Strahlen aufgefunden. In Pratolino ist eine Colossalstatue des Juppiter Pluvius in Mauerwerk ausgefuhrt, in deren Inneren sich verschiedene Zimmer befanden, unter anderen ein solches im Kopfe, welchem die Augenlócher als Fenster dienten. Von der Krone floss aus allen verschiedenen Stellen Wasser aus und rieselte fein zertheilt an der Figur herunter, was ihr bei Sonnenschein ein eigenthummliches Ansehen gab. Der Gott hatte die Hand auf den Kopf eines Lowen gelegt, aus dessien Maule sich gleichfalls das Wasser ergoss.

In älteren öffentlichen Gebäuden, sowie in der Nähe derselben und bei den Tempeln fand man im Osten stets Brunnen und Fontainen vor. In einer Beschreibung der Moschee von Adrianopel von 1624 heisst es, dass auf der Ost- und auf der Sudseite je 10 Leitungen mit Hälnen zum Waschen vor dem Betreten der heiligen Räume gewesen und lass auf einem Hofe im Innern sich unter der Fontaine 30 bis 40 solcher Hähne befanden. Auf dem Platze des Colosseums stand früher eine schöne verzierte Fontaine, Meta Sudans genannt, deren Bild durch die TitusMedaille erhalten ist. Die dieselbe bekrönende Statue des Juppiter schwitzte aus allen Theilen des Körpers Wasser aus, woher die Fontaine den Namen erhalten.

Nach einzelnen Nachrichten soll Brussel schon sehr fruh, vielleicht schon vor Rom, eine Wasserleitung besessen haben. 20 offentliche Brunnen, alle mit Statuen geschmuckt, befanden sich an den Ecken der Hauptstrassen. . Der Brunnen auf dem Gemüsemarkte, wo 4 Frauen sich das Wasser aus ihren Brüsten drücken, und der Manl- 
nekepis neben der Karmeliter-Kirche sind ja bekannte Figuren. Einer eigenthümlichen Fontaine des Michel Angelo mag hier noch erwähnt werden, welche aus der Statue einer Frau besteht, die Zeug auswringt und aus demselben so das Wasser zum Ausfluss gelangen lässt.

Die Leichtigkeit, das Wasser zu Bewegungszwecken zu verwenden, führte schon sehr früh dazu, damit Au tomaten durch Mechanismen in Bewegung zu setzen. Diese standen auf einem Piedestal, aus dem das Wasser ausfloss und in welchem der Mechanismus verborgen war. Man liess Männer Trompeten, blasen, Orgeln spielen, Vögel auf den Bäumen umberfliegen etc.

Die Reste solcher alten Wasserspiele haben sich am besten im modernen Italien erhalten. So heisst es in einer Beschreibung des Gartens zu Pratolino, dass der Eingang durch Tritonen geschützt war. Wenn man durch denselben eintrat, so fand man Strahlen, die aus Statuen hervortraten und andere, die aus den Bäumen und aus den Felswänden kamen. In einer Grotte, deren Dach und Wände aus Korallen und Perlen hergestellt war und 30000 Dukaten gekostet haben soll, befand sich eine auf einem Pfeiler stehende Wasseruhr. Der Gott Pan, welcher darin aufgestellt war, stiess einen melodischen Ton beim Anblick seiner Frau aus. In einer anderen Grotte setzte ein Engel eine Trompete an den Mund und blies darauf. Ein Clown reichte einer Schlange eine Schüssel mit Wasser; diese erhob den Kopf und trank es aus. Ferner war an einer Stelle eine Getrejdemühle, an einer anderen ein Papierstampfwerk in Bewegung. Auch waren Schmiede mit ihren Hämmern thätig und künstliche Vỏgel flogen zwitschernd auf den Bäumen umher. In einer Grotte kam Galatea, begleitet von zwei Nymphen, auf einem Meerwagen aus einem Thore, fuhr eine Zeit lang auf dem Wasser umher und verschwand dann wieder. Auf einem Teiche schwamm ein Delphin, der auf seinem Rücken eine nackte weibliche Figur trug, die von verschiedenen Figuren, die sich alle wie lebendige bewegten, umgeben war. An einer anderen Stelle befand sich ein Tisch für 15 Personen, in dessen Mitte sich ein springender Strahl erhob. Zwischen je zwei Plätzen quollen kleine Strahlen zum Kühlen des Weines hervor. An einer anderen Stelle trat die Samariterin aus einem Hause mit zwei Krugen, sie füllte sie am Brunnen und kehrte dann wieder zurück.

In den Gartenanlagen zu Chatworth befindet sich auf einem Teiche Neptun, von Nymphen umgeben, die zu jagen scheinen. Ferner ist hier ein Teich, in dem sich Seepferde bewegen. Auch ist daselbst ein 
kupferner Baum, aus dessen Blättern Regen herniederfällt. In einem Cypressenwalde wird von zwei Nymphen Wasser mit Krügen ausgegossen, welches auf einer Cascade hinabstlirzt. Es wird in einem Teiche von einer kunstlichen Rose aufgefangen, aus der es wieder in der Blattform dieser Blume aufsteigt.

Die Bäume scheinen sehr häufig als Ausgusspunkte für das Wasser benützt zu sein. Der Palmbaum von Bronce, der, dem Apollo geweiht, in einem Garten von Nikias aufgestellt war, hat wahrscheinlich auch als Fontaine gedient. Im Park zu Versailles, an dessen Wasserkinste ebenso wie an die des Gartens Frascati, an die auf der Wilhelmshöhe etc. hier nur erinnert werden mag, war früher ein Eichbaum, der nach allen Richtungen bin Wasser auswarf. Marcus Paulus erwähnt im 3. Jahrhundert des Gartens des alten Mannes vom Gebirge und beschreibt dabei eine Fontaine, die Milch, Wein und ein Gemisch von Honig und Wasser auswarf.

Ein im Jahre 916 von Constantinopel nach Bagdad geschickter Gesandter berichtete, dass er in der dortigen Audienzhalle einen grossen goldenen Baum fand, auf dessen $18 \mathrm{Z}$ weigen goldene und silberne Vögel sassen, die die Flügel bewegten und sangen.

In den römischen Theatern waren an den Wänden herum verdeckte Rohre angebracht, die ganz fein durchlochert waren, so dass das aus denselben ausspritzende $W$ asser auf die Zuschauer als fein zertheilter Nebel sich vertheilte und sie kuhlte und erfrischte. Das so zerstreute Wasser wurde mitunter mit den reichsten Parfüms wohlriechend gemacht. Es liess, nach erbaltenen Nachrichten, Hadrian zu Ehren seines Vorgängers Trajan das Publikum im Theater mit Wasser bethauen, welches durch Saffran und Balsam parfümirt war, und reiche Leute hinterliessen in ihren Testamenten oft grosse Summen für parfümirtes $W$ asser und furr die Apparate zu dessen Vertheilung. Die in den Theatern aufgestellten Statuen schwitzten ebenfalls nach den dem Publikum zugekehrten Seiten Parfüm aus. Sie waren hohl und mit eizer unendlichen Zabl kleiner Löcher versehen, denen durch Rohrleitungen das parfümirte Wasser zugeleitet wurde. In Pompeji ist eine Maueraufschrift aufgefunden, welche ein Thiergefecht und Athletenkämpfe anzeigt und dubei angiebt, dass mit wohlriechendem Wasser gespritzt werden würde.

Nero's Speisesaal in seinem goldenen Hause war auch mit solchen Thaurohren versehen. Hier konnte man aber nach Belieben Blumen oder parfümirtes Wasser regnen lassen. Bei Einem Feste wurden von 
ihm 100000 Kronen für parfümirtes Wasser verausgabt. Die Kühlung und Erfrischung der Luft in Wohnraumen und in den Gärten wurde im Osten vielfach dadurch angenehmer gemacht, dass man das Wasser fein zertheilt auf wirkliche Blumenbeete fallen liess, von denen es durch die Wärme verdunstet, als parfümirter Thau wieder emporstieg und die Luft nicht. nur kühlte und befeuchtete, sondern auch mit herrlichen Wohlgeruchen anfüllte.

Die Waterclosets, die wir als eine englische Erfindung anzusehen gewohnt sind, sind sehr alten Ursprungs: sie stammen jedenfalls aus dem alten Asien. Eglon, der König der Moabiter, hat nach dem Buche der Richter wahrscheinlich schon ein Closet mit Spülung besessen. Zur Zeit der Republik wurden dieselben nach Rom eingeführt. Aus späterer Zeit ist bekannt, dass die für die Kaiser bestimmten Closets sehr reich mit Marmor und Mosaik ausgeschmückt waren.

In einem solchen alten Closetraume, welcher noch erhalten ist, befindet sich eine Cisterne, von welcher aus Rohrleitungen mit Hähnen verschiedenen Sitzen zugefuhrt sind. Ein ähnlicher Baum ist in Pompeji in der Nähe eines Theaters entdeckt. Heliogabalus soll von Soldaten auf einem Closet getödtet sein. In der Nähe der Moscheen und der Tempel befiznden sich die Closets in grosser Zahl. Ihre Benützung im alten Rom, in Constantinopel, in Smyrna und auch wahrscheinlich in allen südlichen Städten war sehr ausgedehnt. In der Stadt Fez waren nach einem aus dem Jahue 1670 stammenden Reiseberichte rund um die Moschee 150 öffentliche Orte, jeder mit einem Hahne und einem Marmorbecken eingerichtet, nett und rein gescheuert und geputzt, nals ob die Orte für einen lieblicheren Zweck bestimmt wären “. Tavernier erwähnt aus Seraglio eines solchen, bei welchem das Loch durch eine Klappe, die durch eine Feder hochgedrückt wurde, geschlossen war, die sich aber sofort öfnete, wenn etwas darauffiel.

Unter der Regierung der Elisabeth von England wurden 1660 die Waterclosets von John Harrington aus Frankreich nach England eingefuhrt. Sie sind also keineswegs dort erfunden, wie fälschlich häufig angegeben wird, obwohl sie hier im Laufe der Zeit wesentliche Verbesserungen und Vervollkommnungen gefunden haben. Wenngleich unsere heutigen Jennings-Closets eine wesentlich andere Construction, als diese alten Closets hatten, besitzen, so ist doch die Wasserspülung für diesen Zweck, ebenso wie auch die Anwendung der Wasserverschlüsse, der s. g. Traps, eine sehr alte.

Dass die Abgabe von Wasser schon früh gegen Bezahlung statt- 
gefunden, ist bereits mitgetheilt und es lag nahe, die Zahlung nach dem Wasserquantum zu bemessen. Schon bei den römischen Leitungen ist daher zum Messen des Wassers das Messrohr, calix oder modulus genannt, benützt, sowie später in Paris eines ähnlichen Rohres, welches zum Messen des pouce d'ea u diente, erwähnt. Die im Laufe der Zeit angewendeten Constructionen von Kaliberhähnen, deren neueste wohl die 1871 dem Stone in Deptford und dem Chameroy in Frankreich patentirten sind, beruhen im Wesentlichen auf demselben Principe. Das Princip der Wasseruhren, deren schon Vitruv erwähnt und welche de Caus eingehend beschreilbt, ist auch für Wassermesser verwendbar und gewiss vielfach benützt, wie der von Rohlfs als in der Stadt Rhadames in Afrika jetzt noch im Gebrauch befindliche beschriebene Messer, der aus einem Topfe mit einem Loche im Bodẹn besteht, $G$ add us genavnt, dessen Steuerung und Zảhlwerk ein daneben stehender Knabe ist, zeigt.

Die englischen Patentlisten weisen den ersten Wassermesser im Jahre 1824 auf. Fs war dies ein Niederdruckmesser mit zwei Messgefassen, die sich abwechselnd füllten und durch Ventile abgelassen wurden. Der Erfinder war W. Pontifex. $1 \times 25$ erhielt Crosley ein Patent auf 2 Messer, von denen der cine aus Kippgefüssen, der andere aus einem rotirenden Zellenrade, ähnlıch dem der älteren Gasuhren, bestand. Das erste Patent auf einen Hochdruckmesser und zwar auf einen Kolbenmesser mit Vierweg-Hahn erhielt W. Bronton 1828. Der Kennedy-Messer wurde zuerst 1852 und darauf 1862 in verbesserter Form patentirt. Messer mit mehr uls 2 Cylindern wurden 1857 den Amerikanern Barden, Bockwood etc. und 1864 dem W. H. C. Voss patentirt. Ersterer hatte 3 oscillirende, letzterer 3 oder 4 um eine Achse herumliegende Cylinder. Der erste Messer, dessen Kolben keine Kolbenstange hatte, ist $1852 \mathrm{dem} \mathrm{Ch}$. Ritschie, und der einzige, dessen Kolben feststehend war, während das Messgefass sich bewegte, ist 1867 den H. Frost jun. und sen. patentirt. Den ersten Diaphragma-Messer hat sich 1836 S. B. Paterson patentiren lassen. Ein Messer mit oscillirendem Kolben ist zuerst dem Andrew Mac Nab 1841 und ein solcher mit rotirendem Kolben zuerst dem T. Moseley 1852 patentirt. J. Macintosh hat sich 1849 den ersten Messer, der auf dem Principe der Sackpumpen beruhte, patentiren lassen. Die Turbinenwassermesser beginnen 1851 mit dem Messer von Dunn, welcher Messer durch den Stoss des Wassers bewegt wurde und dem 1852 und 1853 der Taylor'sche Messer folgte. Der verbreitetste Messer, der von Siemens, ist zuerst 1852 patentirt und 1853, 56, 60 und 67 verbessert. Der erste Messer mit einer durch 
das Wasser bewegten Schraube ist 1850 von Tebay und der erste, dessen Flügelrad schraubenförmig gewundene Flügel hat, 1856 von Sturge und $18 \tilde{8} 8$ ron Loup und Koch benützt.

Wie zahlreich die Erfindungen auf dem Gebiete der Wassermesser sind, welche in dem Vorstehenden nur nach dem ersten Auftreten der verschiedenen Constructionsgedanken mitgetheilt wurden, ist hinreichend bekannt. Die Zahl der in England bis zum Jahre 1870 auf Wassermesser ertheilten Patente beläuft sich seit 1824 auf 134, also durchschnittlich pro Jahr auf 3. In den darauffolgenden 5 Jahren sind 64 Patente, nämlich 1871 deren 12, 1872 deren 8, 1873 deren 10, 1874 deren 19 und 1875 deren 15 Stuick genommen, und trotzdem auch später noch immer wieder neue Erfindungen aufgetaucht sind und noch ferner auftauchen werden, ist es bis heute noch nicht gelungen, einen Messer so zu construiren, dass er allen gerechten Anforderungen völlig gentigt.

Ich gehe nun zu dem dritten Theile der Specialgeschichte, nämlich zur kunstlichen $\mathrm{Hebung}$ des Wàssers über.

Die ersten künstlichen Mittel z'um Schöpfen des Wassers waren selbstverständlich Gefässe, die sich schon in den aller ältesten Zeiten, von den verschiedensten Materialien hergestellt, sowie in den verschiedensten Formen ausgebildet, vorfinden. Lag der Schöpfpunkt dı:s Wassers unter der Bodenfläche, so musste man zu dem Wasser hinabsteigen und that dies entweder durch einen seitlichen Erdeinschnitt oder legte bei grösserer Tiefe Treppen und Leitern an. Es finden sich bei allen Völkern des`Alterthums Brunnen bis zu grosser Tiefe, in denen man auf oft schönen kreisrunden Treppen hinabstieg. So stieg der Bibel nach Rebecca in den Brunnen hinab und füllte den Krug; dann kam sie wieder damit herauf zu Abrahams Knecht.

Wo man nicht zum Wasser hinabgelangen konnte, bediente man sich eines Gefässes und einer Schnur; es war dies damals das gewöhnliche Begleitzeug auf Reisen. Die Midianiter zogen den Joseph aus dem Brunnen, in den seine Brüder ihn geworfen, und die Samariterin antwortete Christus: „Herr, hast Du doch nichts, damit Du schöpfest, und der Brunnen ist tief." Dass man statt einer Schnur auch häufig eine Stange mit einem Haken am unteren Ende anwandte, ist gewiss. Auch ist schon im frühen Alterthume der Rolle erwähnt. Man bediente sich ihrer mit übergelegter Schnur dazu, ein an dem einen Ende derselben befestigtes, mit Wasser gefulltes Gefäss durch Menschen oder Thiere heraufzuziehen. Cleopatra rettete sich in einem Thurme 
durch eine solche Rolle vor dem Octavianus. Zur Erleichterung der Arbeit hängte man sehr bald zwei Gefässe, jedes an ein Ende der Schnur und liess das leer hinabgehende das Gewicht des gefüllten zum Theil ausgleichen.

Aus der Rolle entwickelte sich der $\mathrm{Haspel}$, dessen Achse von Menschen mittelst Kurbeln gedreht wurde. Die Chinesen benützten schon in den fruhesten Zeiten, ähnlich den in den Koblenzechen heute noch in Anwendung befiudlichen conischen Seiltrommeln, conische Haspelwellen bei tiefen Brunnen, um das Gewicht des langen Seiles bei einem Eimer gleichmässig 'zu vertheilen. Sie hängten den Eimer auch wohl an eine Rolle und liessen die beiden Enden der Schnur, welche, um die Rolle geschlungen, dieselbe trug, sich uber einen Haspel von verschiedener Dicke an beiden Enden aufwickeln. Die Rolle hob sich dann nur um die Differenz der Durchmesser, es war die Differentialwinde.

Durch die Anwendung von Zahnrädern, sowie durch auf die Achse gesteckte grosse Seilscheiben, an denen gezogen wurde, suchte man die Grösse der bewegenden Kraft ferner bedeutend zu reduciren, und es entwickelte sich aus der letzteren Anordnung das Tretrad, in dessen innerer Flache, und das Laufrad, auf dessen äusserem Umfange das ansteigende Gewicht die Bewegung hervorbrachte. Die Tret- und Laufräder haben in fruheren Zeiten zum Wasserschöpfen eine ungemeine Verbreitung gehabt. ' $/ u$ ihrer Bewegung wurden Menschen, Ochsen, Pferde, Maulthiere, Esel, Hunde, Ziegen und von den alten Gothen sogar Bàren verwendet. Durch conische Räder oder Rollen wurde die Bewegung der horizontalen Achse auch wohl auf eine verticale übertragen und es entwickelte sich so der Gojel und wenn statt der verticalen eine schräg geneigte Achse angebracht wurde, die Tretscheibe.

Die vorstehend angeführten Mechanismen wurden hauptsächlich zum Schöpfen des Wassers aus grösserer Tiefe für häusliche Zwecke angewendet. Viel zahlreicher ist aber im Alterthume die Klasse der maschinenartigen Einrichtungen, die zur Landesbewässerung sowohl in Asien als in anderen Theilen der Erde benutzt wurden. Nur mit ihrer Hulfe konnten, wie schon früher bemerkt, die Ebenen des Euphrats, des Ganges, des Nils und anderer grosser Flüsse so zahlreichen Bevölkerungen Nahrung verschaffen, und man sagt mit Recht: „Die orientalische Landescultur besteht hauptsächlich aus geeigneten Maschinen zum Heben des Wassers." Von den grossartigen Bauten zum Leiten 
und Sammeln des Wassers für diese Zwecke ist schon früher die Rede gewesen und es sollen hier nur die verschiedenen eigentlichen Beförderungseinrichtungen des Wassers besprochen werden.

Ein über den Rücken oder über die Schulter gelegtes Tragholz, an dessen Enden je ein Gefäss mit Wasser gebunden war, ist wohl die fruhheste Art des Wassertransportes gewesen, wie aus den ältesten Sculpturen der Aegypter hervorgeht, und in Hindustan bewässern heute noch die Eingebornen ihre Gärten in dieser Weise. Zum fortlaufenden Heben des Wassers auf geringe Höhe benützten die alten Aegypter und die Hindus den Schwingkorb, einen Korb, der an zwei Seilen befestigt war, welche zwei einander gegenüberstehende Personen unter Gesang schwenkten und der unten in das Wasser eintauchte und sich füllte und nach oben geboben entleert wurde. Auch in China und im Süden von Bengalen hat man diese anstrengende Art der Wasserförderung bis in die neueste Zeit noch vielfach beobachtet.

Eine der ältesten Maschinen zum Schöpfen, die speciell in Bengalen in Gebrauch war, wird wohl der Jantu gewesen sein, eine Rinne, die an dem einen Ende sich drehte, wälrend sie an dem anderen gehoben und gesenkt, das geschöpfte Wasser höher ausfliessen liess. Sie wurde auch wie ein Balancier in der Mitte drehbar angewendet und. es fand, dann hier der. Austritt des an beiden Enden eintretenden Wassers statt. An der Unterfläche der Eintrittsstelle befand sich auch wohl eine Klappe, die sich nur beim Eintauchen öffnete und sich dann schloss. Die Rinne wurde entweder mit den Händen gehoben oder auch am entgegengesetzten Ende mit den Füssen getreten. Auch hängte man zwei Rinnen mit ihren Ausgüssen nach der Mitte zu an einem zweiarmigen Schwingbaume auf und konnte durch daran angebrachte Stricke das Wasser bei geringerem Hube auf grossere Höhen fördern. Endlich fand auch ein System solcher zickzackförmig über einander angebrachter Rinnen, die an einem Gestelle pendelartig bewegt wurden, für noch grössere Höhen Verwendung. Hier mag auch noch die holländische Schau fel erwähnt werden, die mit einem langen Stiele versehen war und, an einem Gerüste pendelartig schwingend aufgehängt, von einer Person so geleitet wurde, dass sie unten sich mit Wasser füllte, welches oben ausgegossen wurde.

Die verbreitetste und vielleicht auch eine der ältesten Maschinen zum Wasserheben aus etwas grösserer Tiefe ist jedenfalls die Wippmaschine (Shaduf) gewesen. Sie bestand aus einem zweiarmigen Hebel, an dessen einem Ende der Wassereimer hing, während das 
andere Ende ein Gegengewicht trug, gerade so, wie sie heute wohl fast auf der ganzen Erde noch vielfach in Benützung ist, wó es sich um Hubhöhen bis zu $5 \mathrm{~m}$. handelt. In Aegypten wandte man, ebenso wie in Hindustan, dieselben in mehrerer Etagen über einander an, so dass jede Maschine das Wasser auf etwas mehr als $2 \mathrm{~m}$. Höhe hob. Dreissig, ja selbst bis funfzig derartiger Maschinen, so über einander aufgestellt, soll nichts ungewöhnliches gewesen sein. Von einer solcheu Hebestation aus Arabien wird berichtet, dass treppenförmig über einander 15 doppelte, also 30 einfache Wippmaschinen aufgestellt waren. In jeder Etage ging eine hinauf, wenn die andere herunter kam. Die Arbeiter, deren im Ganzen dafur 54 erforderlich waren, wechselten jede Stunde ab. Eine eigenthümliche Construction dieser Maschine, die in Hindustan sehr in Gebrauch ist, heisst P w otah. Der Arbeiter steht oben auf dem Balancier und bewirkt durch sein Hinaustreten über den Drehpunkt de Bewegung desselben.

Die späteren und vollkommeneren Maschinen zum Wasserheben verlieren sich zum Theil auch noch in sehr frühe Zeit und wir verdanken die Beschreibung der meisten derselben dem Vitruv, dem einzigen, der uns Nachrichten über Tympanon, Noria, Eimerkünste und Schnecken, sowie uber die Maschine des Ktesibius aus dem Alterthume hinterlassen hat.

Das Tympanon besteht aus einer Zahl un eine Achse radial gestellter Rinnen, deren innere offenen Euden sich in die hohle Achse ergiessen, während sie am Umfange das Wasser schöpfen; es ist also eine Vervielfältigung des Jantu. Eine mechanisch vollkommenere Construction dieses Rades ist Ende des vorigen Jahrhunderts von La Faye entwickelt, wobei sich das Wasser vertical und tangential zur Drehachse erhebt und es sind die Rinnen durch geeignet gekrümmte Rohre ersetzt. Eine andere Construction wendet gekrümmte Schaufeln an. Es sind solche Räder, durch Damptkraft betrieben, noch heute in Lincolnshire für Drainagezwecke in Benützung.

Die No ria besteht aus einer Zahl an dem Umfange eines Rades befestigter Gefässe; sie ist also eine rotirende Wippmaschine. Sie kann das Wasser bei gleichem Raddurchmesser fast doppelt so hoch als das Tympanon fordern. Die Chinesen machten dieselben fast ganz aus Bambusrohr und auch die Fórdergefässe waren von demselben Material. Letztere hatten circa 1,2 m. Länge bei 5 bis $8 \mathrm{~cm}$. Durchmesser und waren in solcher Neigung befestigt, dass sie sich unter Wasser füllten und erst oben nahe am Scheitel des Rades das 
Wasser ausgossen. Schöpfte die Noria oder das Tympanon aus einem Strome, so wurde das Rad qugleich mit Schaufeln versehen und als unterschlägiges Wasserrad ausgebaut. Die Chinesen baben solche Räder von $6 \mathrm{~m}$. bis $21 \mathrm{~m}$. Durchmesser ausgeführt und fördern mit einem solchen 150 bis $300 \mathrm{kbm}$. in 24 Stunden. Die römischen Norias wurden durch Treträder bewegt. Die ägyptischen Norias bestanden aus einem geschlossenen ringförmigen Raume, der durch radiale Schaufeln in eine Menge Abtheilungen getheilt war, in welche durch am äusseren Umfange befindliche Oeffnungen das Wasser eintrat und durch seitlich an dem Boden des inneren Umfanges angebrachte Oeffnungen dasselbe oben wieder ausgelassen wurde. In der Türkei, in Griechenland, in Spanien etc. hat man die Norias vielfach in der Weise hergestellt, dass man Thongefässe in entsprechender Neigung an einem Rade befestigte. Eine abweichende Construction ist die Persische Noria, bei welcher die Schöpfgefässe an dèm Rade um Zapfen drehbar aufgehängt und nur oben am Ausgusse durch eine entsprechende Einrichtung umgekippt und entleert werden. Sie hat den Vortheil, dass kein Wasser auf dem Wege zurückfällt und dass die verlorene Ausgusshöhe auf ein Minimum reducirt werden kanı. Diese Construction ist seit der 'Jeit der Römer sehr viel in Gebrauch gewesnn und ist auch heute noch vielfach in Benützung in der Schweiz, in Tirol uud in. England (seit 200 Jahren). Ferner wird sie in Frankreich gegenwärtig noch zur Landesbewässerung in Languedoc in grossartigem Maassstabe benüzt.

Die interessanteste Anwendung der Norias für städtische Wasserversorgung ist gewiss schon seit tausenden von Jahren bis auf die jüngste Zeit in Hamah, einer Stadt in Syrien, an dem reissenden Flusse Orontes gelegen, in Benutzung. Die Stadt ist zu beiden Seiten des Flusses gebaut. Die Räder werden durch das Wasser des Flusses getrieben und es sind circa 12 Stück solcher vorhanden. Das grösste derselben, Naoura el Mahommeyde genannt, soll $21 \mathrm{~m}$. Durchmesser haben. Das Wasser ergiesst sich aus den Rädern in einen steinernen Aquäduct, der auf leichten Bögen die Stadt durchzieht. Wo man zur Bewegung der Norias und der Tympanson keine Wasserkraft zur Verfügung hatte, hat man sie im Alterthume meistens durch Treträder mit Menschen oder mit Thieren in Bewegung gesetzt.

Die Eimerwerke sind die weitere Entwicklung der Idee des Schöpfgefässes mit der Schnur und dem Haspel, wie solche vorhin geschildert. Hängt man an eine über eine Trommel laufende Schnur oder Kette in gleichen Abständen eine Mengé Gefässe und schliesst 
die Schnur unten, so ist das Eimerwerk, in Aegypten Sakia genannt, fertig. Der grosse Vorzug dieser Maśchine und daher ihre umfangreiche Anwendung zu Bewässerungsarbeiten besteht darin, dass man damit jede beliebige Hubhöhe - im Falle der Noth durch Anwendung von zweien übereinander, wie es bei dem Josephsbrunnen der Fall war - erreichen kann. Der Nil ist ron seinen Quellen bis zu seinem Ausflusse an den Ufern entlang mit diesen Maschinen besetzt. Im oberen Aegypten und in Nubien trifft man sie in je $100 \mathrm{~m}$., ja an einigen Stellen sogar in $50 \mathrm{~m}$. Entfernung an. Für ein Eimerwerk war im Jahre $50 \mathrm{Mk}$., für eine Wippmaschine $25 \mathrm{Mk}$. Steuer zu zahlen, ein Beweis für die grössere Brauchbarkeit der ersteren. Während die Gefässe bei den Aegyptern aus Thon bestanden, die mittelst Schnüren zwischen zwei Stricken obne Ende angebunden waren, fertigten die Römer schon solche Maschinen mit Gefässen aus Messing, die 4 Liter fassten und an zwei eisernen Ketten aufgehängt waren, an. Nach Agricola wurden die Eimerwerke auch in deutschen Bergwerken verwendet. In Spanien, wo die Mauren den asiatischen Landbau einführten, fanden sie im Mittelalter bei den grossartigen Meliorationen umfassende Benützung. Auch finden wir sie mitunter bis zum 16. Jahrhundert in europäischen Städten zur Wasserversorgung angewendet und oftmals, namentlich in Holland, durch Windmühlen getrieben.

Wenngleich über die Wasserversorgung der hängenden Gärten der Semiramis in Babylon nur die Nachricht erbalten ist, dass Eine Maschine das Wasser aus dem Euphrat auf die $92 \mathrm{~m}$. hohen Wälle in ein Reservoir geschöpft hat, so kann es doch kaum zweifelhaft sein; dass dazu ein oder mehrere Eimerwerke verwendet sind; denn keine der anderen damals bekannten Maschinen würde diese Arbeit haben verrichten können. Bekannt ist es, dass die Eimerwerke auch zum Heben mancher anderer Körper Verwendung fanden. Sie sind jedoch auch umgekehrt als Motore in Benützung gekommen. 1668 wurde unter Colbert in den öffentlichen Gärten von Paris nach dem Plane von Francini ein doppeltes Eimerwerk in Betrieb gesetzt, dessen eine Kette durch das in einen Brunnen sich entleerende Ueberfallwasser eines Teiches in Bewegung gesetzt wurde, während die andere dadurch gleichfalls in Bewegung gesetzte Kette Wasser aus dem Teiche auf eine Anhöhe hob, von wo es als Wasserfall wieder hernieder fiel.

Die Wasserschnecke, deren Erfindung früher Archimedes zageschrieben wurde, während nach neueren Forschungen ihm nur die 
weitere Verbreitung derselben, die eigentliche Erfindung aber seinem Zeitgenossen und Freunde, dem Aegypter Conon von Alexandrien zufallen soll, wurde aus um eine hölzerne Spindel schraubenförmig gewundenen Bleirohren orler Lederschläuchen hergestellt. Es wurden auch in eine Spindel die Schraubenkanäle eingearbeitet uud der äussere Umfang wieder mit Latten geschlossen. Auch befestigte man auf einer Spindel in Form von Schraubengängen Bretter und liess sie sich in einem oben offenen festliegenden Troge (Wasserschraube) drehen oder schloss den Trog rund um die Schraube und drehte beide zusammen (Tonnenmühle) durch ein Tretrad oder auf andere Weise. Bei grösseren Förderhöhen wendete man mehrere solcher Schrauben über einander an. Auch gab man ihnen ebenso wie den Eimerwerken und den Norias ihre Bewegung dadurch, dass man die Schraube, die das Wasser auf eine grössere Höhe fördern sollte, weiter nach unten verlängerte und das Wasser aus grösserer Tiefe hob, wodurch man allerdings das Förderwasser auf grössere Höhe heben musste. Man liess aber dieses ursprünglich in grösserer Menge höher vorhandene Wasser durch eine zweite Schraube mit umgekehrter Steigung hinunter gehen, welche von geringerer Länge und von grösserem Durchmesser als die erstere, die ihr als Spindel diente, war und sie in Drehung versetzte. Derartige Combinationen von verschiedenen Schrauben auf einer Achse, deren eine die andere, die das Wasser hob, trieb, sind mehrfach ausgefuhrt.

Der Scheibenkünste erwähnt Vitruv nicht und sie sind ihm, sowie den Völkern, mit denen er und sein Land in Berührung kam, sehr wahrscheinlich unbekannt gewesen, obgleich ihre Entstehung aus den Eimerwerken sehr nahe liegt. Musste man dieselben stark geneigt und zu ihrer Unterstützung in einer Rinne laufend herstellen, so lag es ja nahe, die Gefässe durch Scheiben zu ersetzen und die Rinne in ein Rohr umzuwandeln, in dessen Innern sich das eine Ende der Kette mit den Scheiben bewegte, während das andere Ende aussen frei hinabglitt. Oder man konnte auch jede der Ketten in einem Rohre, gleiten lassen, die beide durch eine Scheidewand von einander getrennt waren. Es war das der erste Schritt zu unserer Kolbenpumpe. In China, welches als Vaterland dieser Scheibenkünste angesehen werden muss, sind sie nach späteren Forschungen seit unendlich langer Zeit und in grosser Zahl in Benützung gewesen. In der Regel stellte man die Leitungsrohre aus Brettern her und gab denselben oft einen quadratischen Querschnitt. Auch stellte man sie meistens nicht 
vertical, sondern gegen den Horizont geneigt auf und es wird als beste Neigung die unter $24^{\circ} 21^{\prime}$ bezeichnet. Noch heute besitzt fast jeder Bauer in China für den gewöhnlichen Gebrauch eine solche Scheibenkunst, die transportabel ist. Sie hat 15 bis $18 \mathrm{~cm}$. Durchmesser bei $2,5 \mathrm{~m}$. bis $3 \mathrm{~m}$. Länge und wird mit der Hand gedreht. Für die Kette ist an jedem Ende des Rohres zur Führung eine schmale Scheibe oder eine Rolle angebracht. Die Entfernung von zwei Scheiben wurde gleich der Breite genommen. Die Kette wurde bei allen kleineren Kunsten von Holz gemacht. Lederne Beutel oder ausgestopfte kugelförmige Kissen dienten als Scheiben. Auf der oberen Trommel legten sich die Scheiben zwischen Arme, um ein Gleiten der Kette zu verhindern. Das untere Ende wurde 0,5 m. tief ins Wasser gelegt.

Die Aehnlichkeit der Ketten mit den Polstern mit dem Rosenkranze verschafften diesen Künsten den Namen Paternosterwerke (in Frankreich $\mathrm{Chapelet).} \mathrm{In} \mathrm{Europa} \mathrm{konnten} \mathrm{sie} \mathrm{sich} \mathrm{trotz} \mathrm{vielfacher}$ Verwendung meistens keinen grossen Beifall erwerben, da ihre Bewegung in Folge zu grosser Reibung wegen schlechter Ausführung zu schwer war. Sie haben jedoch in Bergwerken, sowie namentlich auf Schiffen vielfach Verwendung gefunden. Belidor beschreibt eine solche Scheibenkunst, die im Hafen von Marseille in Benützung war. Im 17. Jahrhundert fuhrte jedes englische Kriegsschiff 3 gewöhnliche und 4 Kettenpumpen mit sich. 1768 erhielt ein Mr. Cole in England ein Patent auf eine Kettenpumpe für Schiffe, die bei einer Probe mit 4 Mann in $43^{1}, 2$ Secunden dasselbe leistete als eine alte Kettenpumpe mit 7 Mann in 76 Secunden. Dieselbe hatte eine eiserne Laschenkette, deren Glieder mit leicht lösbaren Keilen verbunden waren. Die Scheiben waren von dickem Leder, die zwischen zwei Platten von Eisen oder Messing eingeschlossen und in trockenem Zustande etwas kleiner als die Bohrung des Rohres, welches von Eisen oder Messing gemacht wurde, hergestellt waren. Im 16. Jahrhundert wurden die Kettenpumpen aus China von den Spaniern in Manilla und von den Holländern in Batavia eingeführt. 1796 brachte sie van Braam, der lange in China gelebt hatte, nach den vereinigten Staaten. Ebenso wie die anderen vorhin erwähnten Maschinen fand auch die Kettenpumpe Anwendung als Motor, indem man das Wasser umgekehrt hindurch gehen liess und es ist 1784 auf diese Anwendung in England ein Patent ertheilt.

Wenden wir uns nun zu dem verbreitetsten Wasserschöpfapparate, der Pumpe in ihren verschiedenen Constructionen.

Es ist unzweifelhaft, dass, die einfachen Saugepumpen ein hohes 
Alter haben, wenngleich nicht nachzuweisen ist, wer sie zuerst bentitzt hat. Die älteste Pumpe ist jedenfalls die Klystirspritze, welcher schon Herodot erwàhnt, nämlich ein Rohr mit massivem, dicht schliessendem Kolben ohne Ventile. Ihr folgte die Pumpe mit Ventilkolben, die eigentliche Hebepumpe, der Antlos der Griechen, die vielfach Verwendung fand. In einfachster Form war der Kolben aus einem Conus von Leder gebildet und das Kolbenrohr, in das Wasser gestellt, war oben offen und mit ènem seitlichen Ausflusse verseben. Eine weitere Verbesserung bewirkte man durch die Anbringung einer Klappe unten im Kolbenrobre, durch das Saugeventil. Die Griechen und Römer wandten solche Pumpen mit hölzernen gebohrten Stiefeln fast allgemein als Leckpumpen für die Schiffe an. Zu ihrer Herstellung existirte, was die Haufigkeit ibres Gebrauches beweist, eine eigene Klasse der Schiffszimmerleute. Und diesen ähnliche Schiffspumpen sind heute noch bei allen Völkern für die Kriegsschiffe und auch sonst im Gebrauch, mögen sie nun von Holz, Metall oder Eisen gemacht sein.

Die erste Nachricht tuber die eigentliche Druckpumpe mit massivem Kolben, bei welcher also das Wásser hoher als der Kolben durch eine geschlossene Leitung hinaufgedrückt wird, verdanken wir dem Vitruv, der ibre Erfindung dem Griéchen K tesibus (150 v. Chr.), einem Schüler des Hero, zuschreibt. Leider sind die sámmtlichen.Zeichnungen zum Werke des Vitruv verloren gegangen, so dass man uber die Construction dieser Pumpe nicht ganz im Klaren ist. Es ist auch hier, wie in allen ähnlichen Fällen, von verschiedenen Seiten angezweifelt, dass Ktesibus der wirkliche Erfinder sei. Die Pumpe bestand aus zwei Messingcylindern, die am Boden Klappen hatten und unten seitlich forkenförmig austretende kleine Rohre trugen, an denen oben gleichfalls Klappen befestigt waren und die in einen Bebälter, den Windkessel, mundeten, aus welchem ein Rohr, die Tuba, hervortrat, welches das Wasser auswarf. In den Cylindern bewegten sich Kolben auf und nieder. Diese Maschinen wurden als Feuerspritzen beniutzt. Sie sollen aber auch nach den Ansichten einiger Forscher zur Versorgung offentlicher Brunnen benützt sein; es würde also der Anfang centraler Versorgung mit kiutslicher Hebung aus dieser Zeit datiren, was jedoch schwer zu beweisen ist.

Die allgemeine Verwendung der Pumpen zu Feuerspritzen scheint sich lange Zeit auf die Klystirspritzen (engl. Squirts) beschränkt zu haben, wie aus vielen alten Abbildungen und Beschreibungen hervorgeht, und es fanden die Druckpumpen erst im 16. und 17. Jahrhundert 
allgemeinere Verwendung dafur. De Caus beschreibt eine solche mit einem Stiefel, welche auf einem Schlitten steht, aus dem Jahre 1615 und bezeichnet sie als in Deutschland vielfach zum Feuerlöschen verwendet. Die Benützung der Pumpen für Bergwerkszwecke ging rom sächsischen und böhmischen Erzgebirge aus. Nach Agricola sind hier $15 \overline{0} 0$ zuerst Saug- und Hebepumpen angewendet und es folgten ihnen später 1578 auch solche auf dem Harze. Die ersten Stangenkünste sind in dem böhmischen Silberbergwerke Joachimsthal nach Mittheilung von Calvör um diese Zeit gleichfalls in Benützung gewesen.

Von den Pumpen mit rotirenden Kolben, den Kapselrädern, finden wir zuerst die Pappenheimiana, die aus zwei zahnartig in einander greifenden Kolben besteht, und ferner Ruperts Wasserriegel, welcher aus einem excentrischen Kolben mit sich verschiebendem Schieber gebildet ist, im 17. Jahrhundert. Erstere soll 1593 von dem Franzosen Servière, letztere von dem englischen Prinzen Ruprecht (1609-1682) erfunden sein. Die Erfindung der Plungerkolben, auch Taucher-oder Monchskolben genannt, datirt vom Jalre 1674 und wir verdanken sie dem Englander Morland. Die erste und heute noch kaum tibertroffene doppeltwirkende Pumpe erfand 1716 der Franzose dé la Hire. Es ist dieses die bekannte Auordnung mit einem massiven Liederkolben und mit vier Ventilen, von denen zwei die Druckventile und zwei dic Saugventile sind. Zur Erreichung eines constanten Ausflusses des Wassers wurde 1732 von Demour die Centrifugalkraft benützt, und es entstanden damit die Centrifugalpumpen. Ein schräg gegen eine verticale Achse gestelltes Rohr wurde in Drehung versetzt und es entwickelte sich daraus schon in demselben Jahre ein in einem . cylindrischen Gehäuse gedrehtes Flugelrad, in dessen Mitte das Wasser eintreten und an dessen Umfange es radial ausfliessen sollte.

1746 erfand der Zinngieser Wirz in Zurich die nach ihm genannte Spiralpumpe, die aus einem um eine horizontale Achse in verticaler Ebene spiralförmig über einander aufgewickelten Rohre bestand, deren äusseres Ende, in das Wasser eintauchend, abwechselnd Wasser und Luft schöpfte, wenn die Achse gedreht wurde und deren inneres Ende, sich in eine hoble Achse ergiessend, aus einem fortgeleiteten Rohre stossweise Wasser ausfliessen liess. Diese Erfindung hat ebenso wie die folgende, die Höll'sche Luftsäulmaschine, jetzt kaum mehr als historisches Interesse. Letztere beruht auf der schon von Papín ausgesprochenen Idee, durch einen Motor Luft zu comprimiren und diese Luft als Transmission zu benützen, um damit Wasser zu fördern. 
Die Compression der Luft erfolgte bei der einzigen, 1753 auf dem Amaliaschacht bei Schemnitz in Ungarn aufgestellten Maschine dieser Construction in einem Cylinder, der abwechselnd mit Wasser gefullt wurde, und es drückte diese comprimirte Luft, durch eine Rohrleitung einem anderen Cylinder zugeführt, direct das in demselben enthaltene Wasser, welches durch ein Bodenventil eintrat, in Intervallen in die Hohe. Schon 1769 wurde die Maschine jedoch wieder ausser Benützung gestellt.

Im Jahre 1797 nahm Montgolfier am 3. November in Frankreich und in demselben Jahre Whaitehurs am 13. December in England auf ein und denselben Gegenstand, den hydraulischen Widder oder Stosśbeber, ein Patent. Die durch freien Ausfluss aus einem nur für den hydrostatischen Druck belasteten Ventile erlangte lebendige Kraft einer in einem Rohre sich bewegenden Wassermasse schliesst bei demselben dieses Ventil und öffnet ein zweites, welches in einen Windkessel mündet, von wo das Wasser unter Druck fortgeleitet wird. Hat das Wasser in dem Rohre seine Geschwindigkeit in Folge des in dem Windkessel herrschenden höheren Druckes verloren, so schliesst sich letzteres Ventil wieder, während das andere, nach Innen gehende sich wieder offnet und das Wasser von Neuem accelerint. In neuerer Zeit ist es mehrfach versucht, diesen Apparat fur ländliche $Z$ wecke wieder einzufuhren.

1785 construirte der Engländer Bramah eine Pumpe mit einem Kolben, der pendelartig in einem cylindrischen Gehäuse sich bewegte. Dieses Gehäuse war durch eine von der Mitte zum Rande gehende Querwand, sowie durch den Kolben in zwei Theile getheilt und trug auf dem Umfange zwei Saug- und zwei Druckventile. 1793 nahm er auf eine neue Anordnung solcher Pendelpumpen, welche für Feuerspritzen geeignet sein sollten, ein Patent, bei welcher die feste Scheidewand durch zwei dreieckförmig zusammenstossende und mit zwei Saugventilen versehene Wände ersetzt war und bei welchen der Kolben die Länge des Halbmessers des Gehäuses hatte. Dieser Kolben trug je ein zu jeder Seite des Drehpunktes liegendes Druckventil.

Eine eigenthümliche Anordnung einer doppeltwirkenden Pumpe ist die 1820 von Reichenbach für Augsburg gewählte, wo die vier Ventile von zwei einfachwirkenden, an den beiden Armen eines Balanciers hängenden Pumpen mit Liederkolben in einem Gehäuse vereinigt sind. 1828. führte Schitko eine ähnliche Disposition aus, bei der das Saugund Druckrohr in einer Verticalen uber einander liegen und die Pumpencylinder unten offen sind, während die Rohre, welche die Ver- 
bindung mit dem Ventilkasten herstellen, zwischen den Kolben und Stopfbuchsen einmulnden. 1836 fuhrte Althans eine besondere Construction, die Perspectivpumpe, aus, bei der der Ventilkolben sich in einem- aussen abgedrehten Rohre befindet, welches auf und ab gefuhrt wird, aussen in dem verlängerten Saugrohre sich bewegend und innen das Druckrohr umschliessend. Die Pumpe saugt bei dem Aufgange und drückt beim Auf- und Niedergange. Dieselbe Anordnung ist 1849 von Rittinger als einachsige Mönchkolbenhubpu m pe ausgeführt.

Die Idee solcher Differentialpumpen finden wir schon 1724 von Leupold beschrieben. In zwei Cylindern, von denen der obere einen halb so grossen Querschnitt als der untere hat, bewegen sich an einer Stange zwei Liederkolben und es ist zwischen beiden der Austritt des Druckrohres sowie unter dem grossen Cylinder das Saugventil angebracht. Der grosse Kolben ist ein Ventilkolben und der kleine ein massiver. Auf demselben Principe beruht die 1843 zuerst von Kirch weger ausgefuhrte Differentialpumpe, die einen beim Niedergange drückend wirkenden Plungerkolben und unter demselben, an derselben Stange befestigt, einen Ventilkolben von doppeltem Querschnitte hat, der beim Aufgange das ganze Quantum für einen Doppelhub ansaugt und das halbe Quantum fortdrückt. Dieselbe Anordnung ist ferner 1848 zuerst von Thomson fur Bristol in England ausgefulbrt und 1846 in Frankreich dem C. Faivre in Nantes patentilt. Ausser von diesen beiden wird die Priorität der Erfindung, die unzweifelhaft Kirchweger gebührt, von Farcot beansprucht und endlich auch noch Armstrong zugeschrieben.

Die Fijnje'sche oder Kasten pumpe, welche $184 \grave{o}$ zuerst ausgefuhrt wurde, unterscheidet sich von der de la Hire'schen nur dadurch, dass bei ihr ein selır grosser Ventilquerschnitt dadurch erreicht ist, dass der Pumpencylinder sich in einem viereckigen Kasten befindet, dessen getheilte Wande die Ventilöfnungen enthalten.

In den vierziger Jahren trat Repsold zuerst mit seiner Kapselpumpe hervor, die sich von der früher erwähnten Pappenheimiana dadurch unterscheidet, dass die beiden Kolben einzähnige Stirnräder sind. $18+8$ begann Appold mit der Herstellung brauchbarer Centrifugalpumpen, dem bald Gwy ne, Bessemer und vele Andere folgten. Ihrer compendiosen Auordnung der Ventile wegen mag hier auch die 1853 in Frankreich patentirte Japy-Pumpe, sowie die Californienpumpe von Hansbrow erwähnt werden, welche letztere zuerst 1862 
auf der Londoner Ausstellnng erschien. Eine sinnreiche Construction einer doppeltwirkenden Pumpe ist 1855 dem Amerikaner Vose in England patentirt. In zwei neben einander liegenden unten verbundenen Stiefeln bewegen sich in gleichem Sinne zwei Ventilkolben, deren einer sich nach unten, deren anderer sich nach oben öfnet. Ueber letzterem tritt das Druckrohr aus und über ersterem tritt das Saugrohr ein.

Belidor schon beschreibt eine Pumpenanordnung, ähnlich der, wie sie in neuester Zeit für das Wasserwerk in Magdeburg gewält ist. An einem Balancier hángen $z \mathfrak{u}$ beiden Seiten je eine einfachwirkende Pumpe mit Liederkolben, die so verbunden sind, dass das Druckrohr der einen als Saugrohr in die andere eintritt und von dieser aus das beiden gemeinschaftliche Druckrohr schliesslich fortführt, während erstere Pumpe mit dem gemeinschaftlichen Saugrohre verbunden ist.

Die mit Recht wachsende Vorliebe für die Plungerkolben führte Girard $185 \pm$ bei liegenden Pumpen zur Vereinigung von zwei einfachwirkenden Plungerpumpen durch einen verlangerten Plunger in zwei getrennten Stiefeln und damit zur Herstellung einer doppeltwirkenden Pumpe. Die gleichen Rücksichten haben mich bei stehenden Pumpen zur Aufstellung von zwei einfachwirkenden Plungerpumpen zu beiden Seiten eines Balanciers geführt, bei welcher Anordnung beide Pumpen ein gemeinschaftliches Saugrohr und ein gemeinschaftliches Druckrohr haben.

1860 ist von Armengaud eine Pumpe als Hubertspumpe beschrieben, bei welcher zwei Kolben mit Ventilen in einem Rohre sich durch Aufhängung an einer unter $180^{\circ}$ gekröpften Achse im entgegengesetzten Sinne bewegen. Dieselbe Einrichtung ist aber 1780 schon von dem Engländer Taylor in Southhampton mit dem Unterschiede ausgefuhrt, dass die beiden Kolbenstangen mit Zahnstangen versehen waren und diese durch ein gemeinschaftliches Getriebe in entgegengesetztem Sinne bewegt wurden. Ein um die Achse des Getriebes geschlungenes Seil wurde zur Bewegung hin- und hergezogen.

Eine eigenthumliche Construction einer doppeltwirkenden Pumpe ist endlich noch die der Bridgeport Manufacturing Company, welche seit 1867 bekannt ist. Die Kolbenstange ist hier zugleich das Druckrohr. An ihr befindet sich ein doppelter Ventilkolben. Zwischen beiden Theilen bewegt sich das gemeinschaftliche Ventil, den Kolben abwechselnd nach oben und unten schliessend. Für die obere, sowie für die untere Hälfte des Stiefels ist je ein Saugventil verhanden. 
Wenn auch nicht als Pumpen, so doch als dabei bentitzte Hulfsconstructionen, mögen hier noch die Nort on'schen Röhrenbrunnen, die gleichfalls aus Amerika stammen, Erwähnung finden, da sie, 1861 zuerst in grösserem Umfange benützt, eine sehr weite Verbreitung für Wasserversorgungen gefunden haben.

Ausser der zuerst von Giffard erfolgten Anwendung des Dampfstrahles zur Wasserfórderung durch Mitreissen und des auf ähnlichem Grundgedanken beruhenden Wasserschöpfapparates von $\mathrm{Nag}$ el \& $\mathrm{K}$ ä $\mathrm{mp}$ in Hamburg, der 1865 zuerst ausgeführt, wenn auch in seiner Grundidee nicht neu ist, muss hier der Vollständigkeit wegen noch der Geblä s e p u mpen erwähn't werden, deren Kolben aus einem Ledersack bestehen, der ausgedehnt und zusammengedrückt wird, und die seit unendlich langer Zeit in verschiedenster Form benützt sind. Ferner muss hier noch auf die zuerst auf der Pariser Ausstellung 1867 aufgetretenen Constructionen von Kapselrïdern von Root, Behrens und Dart aufmerksam gemacht werden. Endlich ist noch des Pulsometers von Hall als neuester Erfindung in Amerika zu gedenken, in welchem Lande der Erfindungsgeist in den letzten Jahren ungemein rege auf dem Gebieto der Wasserfordermaschinen gewesen ist, wie daraus hervorgeht, dass. in den vereinigten Staaten 1872155,1873 125, 1874132,1875115 , also in vier Jahren 527 Patente auf Pumpen ertheilt sind.

Im Vorstebenden durften wohl die sämmtlichen Wasserhebungsmaschinen und speciell die Pumpen in ihren Hauptzügen an dem Faden der Geschichte vorgeführt sein und es bliebe nur noch der umgekehrten Anwendung der Pumpen, nämlich nicht als Arbeitsmaschinen, sondern als Motoren, zu gedenken. Wir finden das Wasser schon in der Mitte des vorigen Jahrhunderts nicht nur von einem Kolben getrieben, sonclern einen Kolben treibend, bei den Wassersäulmaschinen in Benützung, gerade so wie wir die Umkehrung des Eimerwerkes, der Archimedes'schen Schnecke etc. im Vorstehenden erwähnt gefunden haben. 1753 wurde auf der Grube Carlsgnade eine kleine uñd 1761 eine grössere Wassersäulmaschine von Winterschmidt in Deutschland und 1765 eine solche von Westgarth in England aufgestellt. Derartige Maschinen fanden, namentlich nachdem sie 1808 von Reichenbach durch die Einfuhrung der Kolbenstatt der Hahnsteuerung, sowie durch viele andere Constructionen wesentlich verbessert waren, im Bergbau sehr ausgebreitete Anwendung. Um ihre Construction haben sich ferner Jordan auf dem hannoverschen Harze und Junker zu Huelgoat in der Bretagne in der Ver- 
vollkommnung von Reichenbach's Constructionen grosse Verdienste erworben.

Die weitere Entwicklungsperiode dieser Maschine beginnt mit dem Anfange der vierziger Jahre, wo die Engländer Taylor und Darling ton die Ventilsteuerung und manches Andere bei diesen Maschinen einfuhrten. 1846 wandte Armstrong solche Maschinen zuerst als Wasserdruckmaschinen*) an und erfand seine ktinstliche Druckwassersäule, den Accumulator. Mit dieser Zeit beginnt die zahlreiche. Bentitzung hydraulischer Aufzüge und sonstiger hydraulisch getriebener Bewegungsvorrichtungen. Der allerneuesten Zeit endlich gehort das Bestreben an, Wasserdruckmaschinen, fur das $\mathrm{Kleingew}$ erbe anzuwenden, die von den Wasserleitungen im Hause getrieben werden und Drehbewegungen erzeugen.

Die ersten derartigen Maschinen sind 1862 von $L$ e wis und von Ramsbotton ausgeführt. Die Maschine des ersteren war einer liegenden Dampfmaschine mit Schiebersteuerung völlig gleich, die jedoch an beiden Cylinderenden Windkessel hatte. Sie ist spater von George durch Anbringung eines Windkessels in der Druckleitung verbessert und 1867 von Coque dahin verandert, dass der Wassereintritt durch Schicber und der Austritt durch besondere grossere Ventile bewirkt wird. Die Maschine von Ramsbotton bestand aus zwei um ihre Mitte oscillirende Cylinder, deren Kolben die Kraft auf eine gekropfte Achse mit unter $90^{\circ}$ versetzten Kurbeln übertrugen. Später hat Armstrong solche Maschinen mit 3 schwingenden Cylindern angewendet.

Eine eigenthümliche Construction ist ferner die 1867 auf ler Pariser Ausstellung erschienene Perret'sche Maschine, bei welcher Kolben und Arbeitsrohr eine hin- und hergehende Bewegung in einer Doppelhülle ausfuhrten. Philipp Mayer's Expansionsmaschine, die 1873 erfunden und bei welcher eben so wie es schon Coque vorgeschlagen hatte, Luft zur Verminderung des Wasserstosses mit eillgeführt wurde, hat jedoch der 1871 von Schmidt in Zürich erfundenen Maschine, die später von Haag in Augsburg und von Wyss und Studer in Zürich nachgebaut ist, nicht gleichkommen könuen. Die Schmidt'sche Maschine ist jedenfalls die am weitesten verbreitetste. Sie hat einen liegenden oscillirenden Cylinder und ist doppeltwirkend. Die neuere Maschine von Wyss und Studer hat gleichfalls liegende oscillirende Cylinder, jedoch deren zwei und ebeuso hat die von.

*) 1795 wurde de liydraulische Presse von Bramah erfunden 
Kieffer und Engelmann zwei Cylinder, welche jedoch aufrecht stehen.

Vor mehreren Jahren tauchten auch in Paris Erfindungen auf, die die Benützung kleiner Girard-Turbinen für gleiche $Z$ wecke verfolgten, die sich jedoch ausser in den vereinigten Staaten kaum einer grösseren Verbreitung erfreut zu haben scheinen.

Zur Bewegung des verschiedenen Schöpfmaschinen fanden ausser den Menschen- und Thierkraften, die entweder durch ibr Gewicht oder durch Zug und Druck wirkten, bekanntlich Luft und Wasser und später Dampf Verwendung. In Nachfolgenden soll eine kurze Entwicklungsidee dieser Motoren zu geben versucht, sowie specieller auf deren Anwendung für städtische $W_{\text {asserversorgungen geschichtlich }}$ eingegangen werden.

Die Benutzung der bewegenden Kraft des Wassers und des Windes zum Betriebe der Wasserschöpfmaschinen ist sehr alt und es ist ja im Vorstehenden auch schon verschiedentlich darauf aufmerksam gemacht. Dic Verwendung dieser Triebkräfte scheint sich überhaupt anfanglich auf den $Z$ weck des Wasserförderns, sowie auf die Anwendung zum Mahlen von Getreide beschränkt zu haben. Nach Vitruv sind zur Zeit des Càsar (gest. 44 v. Chr.) in Rom schon Mühlen, durch Wasserrader getrieben, in Benützung gewesen. Es wird ferner berichtet, dass 536 n. Chr., als .Vitiges, der König der Ostgothen, Rom belagerte und dic Aquidlucte, deren Wasser auch zum Muhlenbetriebe lentutzt wurden, verstopftc, von Belisar; dem Feldherrn des Justinian, die Mïhlen auf der Tiber aufgestellt wurden und dass so die Schiffsmühlen entstanden. Aus Deutschland wird 379 von Ausonius berichtet, dass an der Mosel Marmormühlen durch Wasserräder bewegt wurden. Von Frankreich stammen die ersten Nachrichten uber Wassermühlen aus dem 6. Jahrhundert. Gregorius von Tours erwähnt derselben, als in der Stalt Dijon in Benlitzung gewesen. In Bühmen sollen die ersten Wassermühlen nach Wenzel Hager 718 angewendet sein und nach der Chronik des Wolterus hat 922 Kaiser Heinrich I. die Stadt Goslar auf den Platze, wo eine Wassermühle stand, erbaut.

Die altesten Nachrichten über die Anwendung von Windmühlen in Deutschland stammen aus dem Jahre 1105, sowie in England aus dem Jahre 1143. In Speyer soll zum Getreidemahlen 1393 die erste Windmühle und in Holland 1439 eine solche gleichfalls für diesen Zweck erbaut sein. In neuerer Zeit sind die Windmuhlen zu Entwässerungen und 
für Wasserförderungen eben so wie in älteren Zeiten, wenn auch in vervollkommneter Construction, vielfach verwendet.

Es liegt mir fern, die Ausbildung der Wasser- und Windräder hier geschichtlich zu verfolgen und ich will mich darauf beschränken, hier einiger der ältesten durch Wasserkraft bewegter Pumpwerke für Städte zu erwähnen.

. Die fruhesten Nachichten liegen mir über Augsburg vor, wo schon 1412 das Brunnenwerk am rothen Thore errichtet war, für welches 1416 ein grosser Wasserthurm erbaut ist. Die Erbauer beiler Werke werden in einem Gedichte besungen, das wie folgt lautet:

Leopold Karg zuerst das Wasser hat geleitet

Dass es in den Robren sich in ganzer Stadt verbreitet

Hans Felber zu der 7.ier und Nutzen unsrer Stadt

, Die Wasserkunst um viel verbessert und vermehret hat.

Das Brunnenwerk bei den sieben Kindeln in Augsburg ist 1450 erbaut und hatte urspringlich zwei über einander aufgestellte Arcbimedes'sche Schnecken als Hebemaschinen. Das Brunnenwerk am Vogelthore ist 1538 errichtet, und es ist hier die Betriebskraft durch ein eingebautes Wehr erlangt. 1609 ist vor dem Oblaterthore und vor dem Jakoberthore je ein mit Wasserkraft betriebenes Pumpwerk hergestellt.

In Braunschweig soll eine ähnliche Anlage auch schon im 15. Jahrhundert bestanden laben und in Läneburg wurde 1474 die Rathswasserkunst eroffnet. 1527 legte die Braucrgilde in Hannover ein Pumpwerk an, welches aus 6 messingenen Pumpenstiefeln bestanl, die von einer Daumwelle in Bewegung gesetzt uurden. Die Welle selbst wurde vòn einem Wasserrade getriebell. Hamhurg besass seit 1531 auch schon eine Wasserkunst, und da in Magdeburg 1631 das Wasserhebewerk der Stadt mit dieser selbst zerstört ist, so wird dasselbe wahrscheinlich auch schon im 16. Jahrhundert erbaut sein.

1580 wurde in Nürnberg das erste Pumpwerk, das Blausternwerk, errichtet. Ein vom Fischbach aus getrielenes Wasserrad bewegte 6 Pumpen, die das Wasser in 2 Reservoire drückten, welche auf einem der Mauerthürme aufgestellt waren. 1619 wurde in der Almosenmühle ein zweites solches Pumpwerk hergestellt, welches mittelst zweier Pumpen stündlich $\check{5}, 37 \mathrm{kbm}$. Wasser förderte. 1687 wurde das Nägeleinswasserwerk und etwas früher das in der Weidemühle errichtet, welche beide heute noch existiren. Von B remen liegt die Nachricht vor, dass dort schon im 17. Jahrhnndert ein derartiges Wasserhebewerk bestand. Das Wasser wurde durch eine auf einer Brücke befindlichen Pumpen- 
unlage, deren Betriebskraft ein Wasserrad war, in ein hoch aufgestelltes Reservoir gedrückt und von hier der Stadt zugeführt.

Aus derselben Zeit wird auch von der Stadt Toledo berichtet, dass ein durch Wasserkraft bewegtes Pumpwerk das Wasser des Tajo in ein auf einem Berge hergestelltes Reservoir förderte, von wo es durch Rohrleitungen zur Verwendung für städtische Zwecke gelangte.

Die alteste durch Wasserkraft getriebene Pumpenanlage in London stammt, wie schon früher mitgetheilt, aus dem Jahre 1582 und in Paris aus dem Jahre 1606. Die von Maurice unter der London Bridge errichtete erste Pumpstation hatte als Betriebskraft ein Ebbeund Fluthrad von $6,1 \mathrm{~m}$. Durchmesser und $4,2 \mathrm{~m}$. Breite, welches 2,2 Umdrehungen pro Minute maclite und mittelst von der Achse aus bewegter Hebel eine Zahl von 16 einfach wirkenden Druckpumpen mit massiven Kolben betrieb, die $180 \mathrm{~mm}$. Durchmesser und 1,4 m. Hub hatten. Das Wasser, $150 \mathrm{kbm}$. pro Stunde, wurde $36,5 \mathrm{~m}$. hoch in ein Reservoir gedrückt. Die Pompe Notre Dame in Paris, welche 1670 errichtet wurde, hatte zwei durch eine Stange verbundene Ventilkolben, die sich in zwei Stiefeln bewegten, von demen der eine, welcher oben offen und unter dem Boden eines Reservoires befestigt war, unten ein Saugventil und ein Saugrohr hatte. Der andere, welcher mit seinem unten offenen Ende in dem Reservoire stand, trug oben Druckventil und Druckrohr; es war also hier die Saug- und die Druckarbeit in zwei Pumpen getheilt.

Als Beweis der grossen Seltenheit solcher Anlagen auch noch in späteren Jahren mag erwähnt werden, dass 1751 aus England in einem geschichtlichen Werke mit grosser Bewunderung einer ,curious waterengine" erwähnt wird, die die Stadt Exter errichtet hatte. Der Bau hatte 1694 begonnen und bezweckte die Stadt mit Wasser zu versorgen. In den vereinigten Staaten von Amerika ist las erste städtische Wasserwerk 1762 nach dem Plane von Ch. Christenson in Bethleh em (Pa.) erbaut. Drei einfachwirkende Pumpen von $100 \mathrm{~mm}$. Durchmesser und $0,46 \mathrm{~m}$. Hub wurden durch ein unterschlägiges Wasserrad von $5,5 \mathrm{~m}$. Durchmesser uıd $0,6 \mathrm{~m}$. Breite bewegt und hoben das Wasser anfänglich auf $22 \mathrm{~m}$., später auf $35 \mathrm{~m}$. Höhe. Das Werk ist bis 1832 in Benützung gewesen und es wurden die Druckrobre, die ursprünglich von Holz waren, 1789 durch solche von Blei und 1813 durch solche von Gusseisen ersetzt.

Es mögen hier noch zwei durch Wasserräder betriebene Pumpwerke etwas näher beschrieben werden, wenngleich sie nicht städti- 
schen, sondern nur fürstlichen Luxuszwecken gedient haben. Sie geben aber ein Bild des Ingenieurwesens unserer Branche in jener Zeit, wie es hubscher kaum zu finden ist.

Die wunderbarste und in ihrer Art einzige Pumpenanlage, die wohl je geschaffen ist, war die in Marly bei Paris für die Versorgung der Gärten von Versailles mit Seinewasser. Dieselbe ist nach den von einem Hollànder Ranneken entworfenen Plänen mit einem Kostenaufwande von circa 10 Milliopen Mark 1682 ausgeführt. Das Reservoir, in welches das Wasser zu heben war, lag circa 5 Kilom. von der Pumpstation entfernt und $162,5 \mathrm{~m}$. höher als der Fluss. Zur Erlangung der Betriebskraft wurde die Seine durch einen Damm aufgestaut und in der ganzen Breite durch Pfeiler in 14 Kammern getheilt, in deren jeder ein unterschlägiges Wasserrad von $12 \mathrm{~m}$. Durchmesser aufgestellt wurde. An den beiden Enden der Achsen von jedem dieser Räder befanden sich Krummzapfen, die eine Menge schwingender Hebel und Ketten in Bewegung setzten, durch welche die Kolbenstangen von im Ganzen circa 250 Saug- und Druckpumpen getrieben wurden. Die Pumpen waren in drei verschiedenen Abtheilungen aufgestellt. Die erste Abtheilung befand sich neben dem Flusse und enthielt 64 Stück, welche durch 6 Räder getrie'en wurden. Sie sogen das Wasser durch kurze Saugrohre aus dem Flusse an und drückten es durch eiserne Rohre auf den Berg, wo es sich in ein Reservoir ergoss, welches $51,7 \mathrm{~m}$. hoch uber dem Flusse hergestellt war. Aus demselben entnahm es die zweite Abtheilung von 79 Pumpen und beförderte es in ein zweites, 56,4 m. höher angelegtes Reservoir. Aus diesem endlich entnahm es die dritte Abtheilung von 82 Pumpen und beforderte es $54,4 \mathrm{~m}$. hoch in das eigentliche Hochreservoir. Diese Anordnung machte es nöthig, die bewegende Kraft für 79 Pumpen auf $2000 \mathrm{~m}$. Entfernung und $52 \mathrm{~m}$. Höhe und für 82 Pumpen auf $5000 \mathrm{~m}$. Entfernung und $108 \mathrm{~m}$. Höhe zu übertragen, was oberirdisch durch Gestänge, Hebel, Kreuze, Ketten etc. geschah und der Anlage nach Ewbank den Titel "A monument of ignorance" eingebracht hat. Der Verlust durch die Uebertragung der Arbeit ist, vielleicht ein bischen zu hoch, auf 95\% veranschlagt und nach einer 1815 erschienenen Beschreibung soll das Gerassel und Gekrächze, wenn die Anlage im Gange war, schlimmer gewesen sein, als wenn eine Menge schwer beladener Wagen einen Berg hinabrollen, bei denen noch niemals Schmiere angewendet gewesen ist.

Ausser den 225 erwähnten Pumpen waren noch circa 25 andere 
vorhanden, die zum Anfullen etc. der anderen dienten. Die unteren Pumpen hatten massive Kolben, in' deren Stiefel unten seitlich ein Rohr einmündete, in welchem sich übereinander die beiden Ventile, aus Lederklappen bestehend, befanden. Die oberen Pumpen standen mit unten offenen Pumpenstiefeln in den betreffenden Reservoiren; sie hatten Ventilkolben und uber denselben liegende Druckventile. Die Kolbenstange jeder Pumpe trat unten aus dem Stiefel heraus und wurde durch zwei seitlich den Stiefel umfassende Stangen bewegt. Der Wasserverlust durch die 225 undichten Kolben und die 450 sicher nicht ganz dicht schliessenden Ventile muss ein ganz enormer gewesen sein.

1738 wurde der Versuch gemacht, das Wasser allein mit ilen untersten Pumpen auf die ganze Höle zu fördern. Derselbe gelang; aber da man die Betrielskraft der anderen Wasserräder nicht mit dafür benützen konnte, so wurden die Maschinen zu sehr angestrengt und der Versuch wurde daher wieder aufgegeben. Eine 1775 gemachte Probe, mit den unteren Pumpen gleich in das zweite Reservoir zu pumpen, gelang gleichfalls. Aber es zeigten sich im Laufe der Zeit sehr viele Rohre dem stïrkeren Drucke nicht entsprechend, so dass man auch diesen Versuch aufgab und zu den ersten Einrichtungen zurückkehrte, bis endlich die ganze Anlage unter Napoleon III. 1859 aufgegeben und durch eine Dampfmaschinenanlage von 65 Pferdekräften rrsetzt wurde, dic $1500 \mathrm{kbm}$. Wasser direct $162 \mathrm{~m}$. hoch fördert.

Die andere Pumpenanlage, deren hier gedacht werdelı soll, ist die, welche die Fontainen und Wasserkünste in Her renhausen bej Hannover versorgte und unter Georg I. 1718 bis 1721 von dem englischen Architekten Benson gemeinschaftlich mit den Architekten Andrews und Cleves erbaut ist. Durch eine Stauschleuse wurde die Leine $3,5 \mathrm{~m}$. hoch zur Erlangung der nöthigen Betriebskraft aufgestaut und fünf untersrhlägige Wasserrärler von $10 \mathrm{~m}$. Durchmesser und 2,5 m Breite eingebaut, deren $1 \mathrm{~m}$. starke und $12 \mathrm{~m}$. lange Holzwellen abwechselnd je um 2,2 m. in der Richtung der Achsen versetzt waren. Zwischen je 2 Ridern befand sich ein lichter Raum von $5,5 \mathrm{~m}$. Breite. Von je einem der 10 Wellenausläufe wurden 4 einfachwirkende Pumpen mit hölzernen Plungern von $300 \mathrm{~mm}$. Durchmesser und $2 \mathrm{~m}$. Höhe bewegt, welche in diesem Raume ganz unter dem Wasserstande des Flusses aufgestellt waren. Es waren also im Ganzen 40 Pumpen vorhanden, von denen je 4 Stück eine Gruppe bildeten und ein gemeinschaftliches Druckrohr hatten Im Ganzen waren demnach 10 Druckrohre angelegt. Jede 
Pumpe hatte ihr Saug- und ibr Druckrentil. Die Stempel von je 2 benachbarten Pumpen waren durch eine Kette mit einander verbunden, so dass durch den Triebapparat der eine Stempel gehoben und der andere niedergedrückt wurde. Durch einen eigenthümlichen Mechanismus, ein Kehrrad, wurde die Bewegung für 8 Pumpen so regulirt, dass sie sämmtlich gegeneinander versetzt und mit Pausen arbeiteten, wodurch eine so grosse Gleichförmigkeit in der Bewegung des Wassers erzielt wurde, dass die Fontainen, direct aus den Leitungen gespeist, nur geringe Schwankungen in der Strablhöhe zeigten. Die 10 Druckrohre vereinigten sich zuerst zu drei und dann zu zwei Rohren, letztere von je $300 \mathrm{~mm}$. Durchmesser, und gingen schliesslich zu einem einzigen liohre von $400 \mathrm{~mm}$. Durchmesser über, welches, wie früher mitgetheilt, aus Blei bestand und $50 \mathrm{~mm}$. Wandstärke hatte. Die Anlage ist 1860 nach den Plänen des Baurath Hagen in Hannover umgebaut und daraus ein durch Poncelet-Räder getriebenes herrliches Pumpwerk geschaffen, dessen Beschreibung später noch eingehend erfolgen wird.

Wenden wir uns nun zur Benützung des Wasserdampfes zum Heben des Wassers, so ist in erster Linie zu beachten, dass die Dampfmaschinen, deren unendliche Bedeutnng hier wohl keiner weiteren Auseinandersetzung bedarf, ihre Entstehung dem Bedürfnisse verdankten, das Wasşer theils zu Zwecken der Beseitigung, theils zu Zwecken der Verwendung künstlich zu heben, und es ist daher wohl natürlich, wenn ich auf die Entstehung der Wärmebenutzung zum Wasserheben hier etwas näher eingehe.

Die Benützung der Wärme zum Heben des Wassers ist sehr alt. Schon die ägyptischen Priester verstanden es, die Wärme der Sonne zu verwenden, um ihren Götzen, mit denen sie die Menge.des Volkes beherrschten, Stimmen zu entlocken und Bewegungen zu ertheilen. Der Heronsbrunnen, der Sonne ausgesetzt, erzeugt einen springenden Strahl. De Caus beschreibt eine hierauf beruhende Einrichtung, die an heissen Orten in Italien und Spanien vielfach in Bentitzung war und aus 4 Kupferbehältern von $0,3 \mathrm{~m}$. im Quadrat und $0,2 \mathrm{~m}$. Höhe bestand, aus denen, mit Wasser und Luft gefüllt, durch die Wärme der Sonne das Wasser mittelst entsprechender Rohrleitungen in einem Strahle austrat. Die Wirkung der Sonne wurde auch durch Anbringen von Brenngläsern auf oder vor den Kästen vergrössert.

Die erste Anwendung des Feuers zum Heben des Wassers wird wohl auf den Altären stattgefunden hāben, die ja im Alterthume häufig als Laboratorien und physikalische Cabinete dienten, um Wunder da- 
mit zu verrichten. Eins der ältesten uns darüber überkommenen Bilder ist folgendes. In ein auf einem Altare brennendes $F$ euer giessen zwéi danebenstehende Statuen Wasser aus. Sie sind mit Rohren mit dem unter dem Altare befindlichen, mit Luft und Wasser, gefüllten Behälter verbunden, aus, dem das Wasser durch das obere Feuer ausgetrieben wird.

Die Expansivkraft des Wasserdampfes, von welchem man zum Kochen und Baden schon früh Gebrauch gemacht hat, fand zuerst in den Windblàsern, Eolipilen, Verwendung. Diese werden von Vitruv als in gewöhnlichem Gebrauche befindlich bezeichnet. Es waren das bohle Kugeln von Eisen, Kupfer, Bronze etc., in welchen sich eine feine Oeffnung befand. Mit Wasser, und zwar oft mit wohlriechendem, gefüllt, wurden sie auf ein Feuer gelegt und bliesen den Dampf aus. Sie fanden auch practische Verwendung sowohl als Gebläse, als auch zum Lóschen des Schadenfeuers. Ferner bediente man sich ihrer auch im Kriege, wozu sie entweder mit brennbaren Flüssigkeiten gefüllt waren oder nur als Bomben wirkten.

Hero beschreibt schon zwei Eolipilen, die die beiden Grundideen der Benützung der bewegenden $\mathrm{Kraft}$ des Dampfes aussprechen. Bei dem einen wird eine Kugel von dem ausströmenden Dampfe getragen; das andere, zwischen zwei Punkten aufgehängt und mit zwei Austritts-Oeffnungen versehen, dreht sich um eine Achse, durch die Reaction des austretenden Dampfes getrieben.

Es ist als sicher erwiesen anzunehmen, dass man im Alterthume sehr wohl die Expansivkraft des Wasserdampfes kannte und mit Dämpfen auch umzugehen verstand, wenngleich die Benützung derselben als bewegende Kraft späteren Zeiten vorbehalten war.

Der erste Vorschlag zu dieser Benützung geht von dem Italiener Branca (1629) aus, der ein Eolipil gegen die Schaufeln eines Rades blasen liess und die Bewegung des Rades durch Räderübersetzung zur Erzeugung nutzlicher Arbeit umwandeln wollte. Denn der Vorschlag, den de Ca u s 1615 zum Heben des Wassers durch Dampf machte, nämlich in ein auf Feuer gestelltes, verschlossenes und mit Wasser gefullttes Gefäss ein Rohr bis nahe auf den Boden zu führen und oben ein Stick über die Decke emporragend aufzustellen, ist nach der Beschreibung in dem Spiritualium des Hero (120 v. Chr.) kaum als etwas Neues zu betrachten. Ebensowenig konnte der Zeit die Erfindung des Porta, die er 1606 in seinem Werke, ebenfalls Spiritualium genannt, mitgetheilt, auf Neuheit Anspruch machen; denn sie besteht aus einem unteren, 
auf dem Feuer stehenden Gefässe, von dessen Decke ein Rohr oben in ein zweites gleichfalls geschlossenes, aber höher stehendes Gefäss einmündet, das, mit Wasser gefüllt, durch ein über die Decke hinausragendes Rohr zum Ausspritzen gelangte.

1630 erhielt David Ramseye in England ein Patent "to raise water from low pitts by fire" und ferner "to raise water from low plaies and mynes and coal pitts by a new waine never yet in use". Das ist jedoch das einzige, was von dieser Erfindung bekannt ist. Ebensowenig weiss man etwas Näheres über eine, 1651 in einer anonymen englischen Druckschrift "Invention of engines of motion lately brought to perfection" angektundigte Maschine, die zu aller nur denkbaren Arbeit Verwendung finden sollte. Durch den Erfinder der Luftpumpe, 0 tto v. Gericke, fand der Grundgedanke unserer heutigen Kolbenmaschine 1654, den ersten praktischen und geistigen Ausdruck. Der Marquis v. Worcester (gest. 1667) gab in seinem Werke „A Century of the Names and Scantlings of such Inventions as at present I can call to mind to have tried and perfected etc.", welches 1663 erschienen ist, unter Nr. 68 die Beschreibung eines bewunderungswürdigen und kräftigen Mittels, das Wasser durch das Feuer nicht durch Ziehen oder Aufsaugen, sondern durch den Druck auf jede Höhe zu bringen, $n$ fire water works" von ihm genannt. Die undeutliche Beschreibung und der Mangel einer Zeichnung hat zu einer Menge Unklarheiten und Meinungsverschiedenheiten uber den Werth dieser Maschine gefürt. Unter Nr. 100 spricht er ferner von einem' "Waterwork for furnishing cities with abundance of water, though never to high seated" und es scheint nach einem Berichte in dem ,Journale des Como von Medici“ aus der Mitte des 17. Jahrhunderts, dass neben Somerset House in London eine Maschine zum Wasserheben von Worcester ausgefüht und in Thatigkeit gesetzt gewesen ist, wenngleich auch hier Angaben über die Art und den Umfang ihres Betriebes fehlen.

Die erste bestimmte Idee für unsere heutige Kolbenmaschine scheint Papin 1690 ausgesprochen zu haben, wenngleich von Moreland aus dem Jahre 1683 ähnliche Mittheilungen vorliegen. Die Maschine von Savery, welche 1698 in England patentirt wurde, die hydraulische Dampfmaschine genannt, bei welcher der Dampf ohne Vermittlung eines Kolbens das Wasser fortdrückte und bei der die durch die Condensation des Dampfes erzeugte Luftleere das Wasser ansog, führte, mit der Maschine von Papin verbunden, 1711 zu der Ne wcomen'schen Maschine, die atmosphärische genannt, weil bei ihr der Dampf nur zur Erzeugung 
der Luftleere unter einem Kolben benutzt wurde und die eigentlich treibende Kraft der Atmosphàrendruck war. 1712 war eine solche Maschine von $550 \mathrm{~mm}$. Cylinderdurchmesser zum Wasserpumpen auf einer Grube in Warwickshire in Benützung und 1720 stellte der Engländer Potter eine solche für Bergwerkszwecke in der Gegend von Königsbèrg in Ungarn auf.

Wenngleich in den folgenden Jahren S meaton und manche Andere sich um weitere Verbesserungen auf diesem Felde verdient machten, so war es doch dem genialen Schotten James Wátt (geb. $1736 \mathrm{~d}$. 19. Jan., gest. 1819 d. 15. Aug.) vorbehalten, die Dampfmaschine so zu crfinden, zu verbessern und auszuführen, dass wir in ihm iliren eigentlichsten Erfinder verehren, der damit den Grund zu einer Culturrevolution gelegt, wie sie auf der Welt noch nicht dagewesen ist. Naturlich kann es nicht meine Absicht sein, hier die einzelnen Watt'schen Erfindungen, sowie die seiner zahlreichen Nachfolger weiter aufzuzahlen; ich verweise dafur' vielnehr auf Ruhlmann's allgemeine Maschinenlehre.

Wahrscheinlich wurde die erste Dampfmaschine, die dauernd fur eine städtische Wasserversorgung in Betrieb blieb, 1761 in London bei London Bridge in Benutzung genommen. Es war eine Newcomen'sche Maschine und sie diente bei dem Fluthwechsel, sowie bei niedrigem Wasserstande als Aushülfe zum Wasserpumpen für die Wasserräder des dortigen Pumpwerkes. Eine Gesellschaft „The Governor and Company of Undertakers for raising Thames Water in York Buildings", die 1691 zur Versorgung eines Theiles von London gebildet war und 2700 Häuser in Piccadilly, Whitehall und Covent Garden mit Wasser versorgte, bediente sich schon früher des Dampfes zum Heben des Wassers, da sie nach einer von 1725 datirten Notiz eine solche Maschine als "chargable" bei Seite gelegt und sich, wie mitgetheilt wird, wieder wie vorher der Pferde zum Pumpen bediente. Die Pumpe der letzteren Pumpmaschine bestand aus einem Plungerkolben, der bohl gegossen und mit Blei ausgefüllt war und später noch durch aufgelegte Bleigewichte beschwert wurde. Er drückte das Wasser durch sein eigenes Gewicht fort, während er, mit einer Kette an den einen Arm des Balanciers einer Newcomen'schen Maschine aufgehängt, von dieser gehoben wurde.

1787 stellten Boulton und Watt eine Maschine fur die New River W. W. Company von 60 Pferdekräften auf. Sie hatte einen Cylinder von $1371 \mathrm{~mm}$. Durchmesser und arbeitete mit 0,57 Kilo Dampfdruck p. $\square \mathrm{cm}$. Sie trieb 2 Pumpen, von denen die eine $736 \mathrm{~mm}$. Durch- 
messer und die andere $508 \mathrm{~mm}$. Durchmesser hatte. Im folgenden Jahre stellten dieselben Fabrikanten einè zweite solche Maschine auf und es wurden damit, nąch den Hubzählern berechnet, im Jahre 1072148 kbm. Wasser gehoben. 1807 stellten Boulton und Watt für die in diesem Jahre gegründete East London W. W. Comp. in Old Ford die erste rotirende Maschine auf.

1811 wurde von derselben Firma eine 24 pferdige einfachwirkende Maschine bei Deptford auf dem jetzigen Terrain der Kent W. W. Comp. aufgestellt. Sie war mit einem Balancier und einem Schwungrade versehen. Der Cylinder hatte $914 \mathrm{~mm}$. Durchmesser und der Kolben $2,4+\mathrm{m}$. Hub. Sie trieb 2 Pumpen, deren eine, für eine niedere Druckzone bestimmt, $428 \mathrm{~mm}$. Durchmesser und 2,44 m. Hub hatte und deren andere, für eine höhere Druckzone bestinmt, $343 \mathrm{~mm}$. Durchmesser und 1,22 m. Hub hatte. Die Maschine wurde 1844 einer grösseren Reparartur unterworfen und ist heute noch in Betrieb. 1824 stellte die Kent W. W. Comp. bei Deptford eine der vorigen ähnliche, aber doppeltwirkende Maschine auf. Im Jahre 1876 dienten zur Wasserversorgung Londons 118 Dampfmascbinen, jede im Durchschnitt von über 116 Pferdekräften.

Die erste grössere Anwendung von Dampfmaschinen für stadtische Wasserversorgungen im fruheren De utschland wird wahrscheinlich die bei der Kaiser Ferdinands-Leitung in $\mathrm{W}$ ie $\mathrm{n}$ gewesen sein, welche 1836 bis 1840 erbaut wurde. Es waren hier 2 Watt'sche Niederdruckmaschinen in Benützung, die später durch Woolf'sche Maschinen ersetzt sind.

In Paris wurden die ersten Versuche, Wasser mit Dampfkraft für die Stadt zu pumpen, schon 1735 gemacht. Sie scheiterten jedoch an der Unkenntniss der Ausführung und Behandlung der Maschinen. 1782 wurde dort aber, wie schon fruher erwähnt, eine Dampfmaschine für diesen Zweck in dauernde Benutzung genommen. Von den dort heute noch in Gebrauch befindlichen, mit Dampfkraft betriebenen Wasserstationen ist die alteste Maschine die zu Gros Caillou.

Aus Amerika stehen mir zwei geschichtliche Notizen zur Verfúgung, die eine von New York und die andere von Philadelphia, welche ich hier, und namentlich die letztere etwas ausführlicher, folgen lasse.

Schon 1741 fasste die Stadt New - York den Beschluss, ein städtisches Wasserwerk zu bauen, und übertrug Ch. Colles die Anfertigung der Pläne. Die Fertigstellung des Entwurfes verzögerte sich bis 1785 und wurde dann aufgegeben. Es bildete sich daun 1797 die Manbattan 
Company zur Wasserversorgung dieser Stadt. Das Wasser wurde aus Brunnen entnommen und durch 3 oder 4, durch Pferde bewegte Pumpen $12 \mathrm{~m}$. hoch gedrückt. Dasselbe wurde einem Reservoire, im Park an der Stelle, wo sich jetzt die Post befindet, gelegen, zugeführt. 1804 wurde für diesen Betrieb eine Dampfmaschine genau nach dem Systeme Boulton und Watt aufgestellt. Zwei Kessel, der eine von Holz, ähnlich dem bei Philadelphia später zu beschreibenden, und der andere aus schmiedeeisernen Platten zusammengesetzt, lieferten den Dampf zum Betriebe der Pumpen, die an Krummzapfen aufgehängt waren. Das Schwungrad war durch ein Planetenrad bewegt. Diese Anlage ist, ausser verschiedenen anderen späteren zu gleichem Zwecke hergestellten, im Betriebe geblieben, bis der Craton-Aquäduct, zu dessen Bau die Idee 1834 auftauchte und der 1837 begonnen und $18+2$ von Johu Jervis vollendet war, der Benützung übergeben wurde.

Die erste Anlage zur Versorgung von Philadelphia mit Wasser, welches mit Dampfkraft gehoben wurde, ist von Fr. Graff und Latrobe fur Rechnung der Stadt 1799 im Bau begonnen und 1801 in Betrieb gesetzt. Sie bestand aus zwei verschiedenen, fast ganz gleichen Pumpstationen, die eine zu Centre Square, die andere in Chestnut Street am Schuylkill-Flusse. Die Maschinen sind in den Sobo Works in der Nahe von Newark (so genannt nach dem bekannten Werke von Boulton und Watt) von N. J. Rosevelt erbaut und geliurten mit zu den ersten Dampfmaschinen, die in Amerika in Thätigkeit waren. Sie sind bis 1815 in Betrieb gewesen und es ist das kreisrunde, thurmartige Gebäude der Centrc Square-Station, in welchem die Reservoire und die Maschinen aufgestellt waren, erst seit 1827 beseitigt. Dasselbe hatte $10,7 \mathrm{~m}$. im Licluten Durchmesser und es waren in demselben $12,2 \mathrm{~m}$. hoch zwei hölzerne Bottiche von zusammen $80 \mathrm{kbm}$. Fassungsraum als Reservoire aufgestellt.

Die Maschine der Centre-Square-Station war eine Balanciermaschine mit einem Schwungrade von anfänglich $4,88 \mathrm{~m}$, und später $6,10 \mathrm{~m}$. Durchmesser und die Pumpe eine doppeltwirkende de la Hire'sche mit Klappenventilen. Es wurde ihr das Wasser durch einen Tunnel von der Schuylkill-Station aus, die dasselbe aus dem Flusse entnahm, zugeführt. Die Pumpe der Centre-Square-Station hatte $457 \mathrm{~mm}$. und die der Schuylkill-Station $44 \check{~} \mathrm{~mm}$. Durchmesser; beide Pumpenkolben hatten ebenso wie die Dampfkolben, deren Durchmesser bei ersterer Station $813 \mathrm{~mm}$. und bei letzterer $978 \mathrm{~mm}$. betrug, einen $\mathrm{Hub}$ von $1,83 \mathrm{~m}$. Die Dampfcylinder waren aus zwei Theilen gegossen, mit 
Kupfer verbunden und der Stoss durch einen $450 \mathrm{~mm}$. breiten schmiedeeisernen Ring armirt. Die Förderhöhe beider Maschínen zusammen, d. i. vom niedrigen Wasserstande im Flusse bis zum Ausgusse in die Reservoire, hetrug üher $28 \mathrm{~m}$. Für den rohen Guşs des grösseren Dampfcylinders wurden 37500 Kilo Fisen verwendet. Bei beiden Maschinen sind die Balanciers, die Arme und die Achsen der Schwungräder, die Schwungradlager-Träger, die Kalt- und Warmwasser-Cisternen, sowie die Kalt- und Warmwasser-Pumpen von Holz hergestellt gewesen.

Der erste Kessel der Schuylkill-Station bestand aus einem bölzernen Kasten von 4,270 m. Länge, von $2,745 \mathrm{~m}$. Breite und von $2,745 \mathrm{~m}$. Höhe im Lichten gemessen. Er war aus $127 \mathrm{~mm}$. dicken Fichtenholzbohlen zusammengesetzt, mit 4 Rahmen von Eichenholz von $254 \mathrm{~mm}$. Quadratseite im Querschnitt umgeben und mit eisernen Anker'n von $32 \mathrm{~mm}$. Durchmesser verbolzt. In diesem Kasten befand sich eine eiserne Feuerbüchse, welche $3,81 \mathrm{~m}$. lang, $1,83 \mathrm{~m}$ breit und $0,56 \mathrm{~m}$. hoch war und durch 6 , die Decke und den Boden durchbrechende Rohre von $368 \mathrm{~mm}$. Durchmesser und durch 2 solche von $305 \mathrm{~mm}$. Durchmesser für die Wassercirculation getheilt wurde. Die Verbrennungsgase gingen oberhalb der Feuerbüchse durch ein ovales Rohr von hinten nach vorn und dann von vorn nach hinten zurück, wo sie in den Kamin eingefuhrt wurdeu. Der Rost war $0,915 \mathrm{~m}$. lang und $1,525 \mathrm{~m}$. breit, hatte also $1,39 \square \mathrm{m}$. Fläche, während die Heizfläche des Kessels $33,44 \square \mathrm{m}$. betrug. Ursprünglich war die ganze Feuerbüchse von Gusseisen; spater ist sie, zuerst mit Ausnahme der Rohre, durch eine solche aus Blech ersetzt und zuletzt sind auch die Rohre von Blech hergestellt. Die Bleche dazu wurden aus England bezogen, da man sie dort schon in der Grösse von $97 \mathrm{~cm}$. mal $81 \mathrm{~cm}$. walzen konnte, während die amerikanischen Bleche zu jener Zeit als grösstes Maass $91 \mathrm{~cm}$. mal $46 \mathrm{~cm}$. (unbeschnitten) hatten.

Beide Maschinen wurden dem Lieferanten für die Summe von $126000 \mathrm{Mk}$. übertragen, sollen-ihm aber selbst $324206 \mathrm{Mk}$. gekostet haben. Bei angestellten Versuchen uber die Leistung der Maschinen hat in 24 Stunden bei 16 Umdrehungen pro Minute die grössere Maschine $5619,4 \mathrm{kbm}$. Wasser $11,88 \mathrm{~m}$. hoch bei einem Kohlenconsum von 3171,0 Kilo und die kleinere $3660,8 \mathrm{kbm}$. $15,54 \mathrm{~m}$. hoch bei einem Kohlenconsum von 2491,5 Kilo gehoben. Als Kohle wurde solche von Virginia benützt und es betrug der Dampfdruck 0,176 Kilo pro $\square \mathrm{cm}$. E's giebt das $66755172 \mathrm{~m}$. Kilo resp. $56888832 \mathrm{~m}$. Kilo im Ganzen oder pro Kilo verbrauchte Kohlen $21051 \mathrm{~m}$. Kilo resp. $22833 \mathrm{~m}$. Kilo and 
pro effective Pferdekraft pro Stunde einen Kohlenverbrauch von 12,8 Kilò resp. 10,9 Kilo.

Die hölzernen Kessel wurden später durch gusseiserne Kofferkessel ersetzt.

Erwähnt werden mag noch, dass die Pumpen anfänglich keine Windkessel hatten. Man brachte jedoch spätér, 1810, für die Pumpe der Centre-Square-Station einen solchen in dem Druckrohre an, welches $457 \mathrm{~mm}$. Durchmesser hatte, weil die Maschine ohne Windkessel nicht mehr als 11 bis 12 Umdrehungen machen konnte, ohne die heftigsten Stösse zu erzeugen. Die Betriebskosten der beiden Stationen haben 1809 für die Schuylkill-Maschine 26268,31 Mk. und fur die CentreSquare-Maschine 31722,05 Mk., zusammen also 57990,36 Mk. betragen.

Am 7. Sept. 1815 begann die Versorgung der Stadt von Fairmount aus, 1,5 Kilom. von der Stadt entfernt gelegen, gleichfalls aus dem Schuylkill-Flusse. Das Wasser wurde durch 2 Dampfmaschinen einem Reservoire von $97 \mathrm{~m}$. Lànge, $51 \mathrm{~m}$. Breite und $3,05 \mathrm{~m}$. Tiefe zugeführt, welches $30 \mathrm{~m}$. hoch über dem Flusse und $17 \mathrm{~m}$. über dem höchsten Punkte der Stadt lag. Die erste hier benutze Maschine war den vorhin beschriebenen ahnlich; sie hatte jedoch einen Balancier und ein Schwungrad von Gusseisen. Die Dimensionen der Maschine waren folgende: Dampfcylinder $1108 \mathrm{~mm}$. Durchmesser, 1,829 m. Hub.; Balancier zweitheilig 7,238 m. lang; Pumpe doppeltwirkend $508 \mathrm{~mm}$. Durchmesser, 1,829 nt. Hub; Forderhöhe des Wassers 30,54 m. Der Dampfkessel war von Gusseisen. Er kostete 378 Mk. pro' 1000 Kilo, während der Dampfcylinder mit $672 \mathrm{Mk}$., der Balancier mit $504 \mathrm{Mk}$. und das Schwungrad mit Achse mit $420 \mathrm{Mk}$. pro 1000 Kilo bezahlt wurde. Die ganze Maschine stellte sich auf $228232 \mathrm{Mk}$. Ursprünglich arbeitete sie mit 0,176 Kilo Dampfdruck pro $\square \mathrm{cm}$.; später wurde der Druck aber auf 0,28 Kilo pro $\square \mathrm{cm}$. erhöht. Die Maschine ist mit dem gusseisernen Kessel bis 1822 in Betrieb gewesen und ausser Betrieb gesetzt, weil für den .Pumpenbetrieb von der Zeit ab Wasserkraft angewendet wurde.

Auf der Fairmount-Station wurde ferner die erste grosse Hochdruckmaschine von Evans aufgestellt. Sie hatte einen Dampfcylinder von $508 \mathrm{~mm}$. Durchmesser und 1,524 m. Hub und trieb mittelst eines hölzernen Balanciers eine doppeltwirkende Pumpe von gleichem Durchmesser und Hub wie der Dampfcylinder. Die Kessel waren von Schmiedeeisen. Es waren deren 4 Stück von $686 \mathrm{~mm}$. Durchmesser und $8,230 \mathrm{~m}$. Länge, die zeitweise Dampf bis zu 15,46 Kilo Pressung 
erzeugten, vorbanden. Bei einer am 15. Mai 1817 vorgenommenen Probe arbeitete die Maschine mit 22 Umdrehungen pro Minute und es konnten die Kessel den Dampf druck auf 13,64 bis 14,06 Kilo pro $\square \mathrm{cm}$. halten. Zweimal, 1818 und 1821, fanden Kesselexplosionen statt; bei ersterer verloren 3 Menschen das Leben. Diese Maschine wurde, ebenso wie bei der anderen bemerkt, durch Auwendung der Wasserkraft verdrängt und es wurden schliesslich beide Maschinen 1832 abgebrochen. Jetzt verrichten ihre Arbeit drei mächtige Jonval -Turbinen, die mit Räderubersetzung je zwei liegende doppeltwirkende Pumpen betreiben, von denen später die Rede sein wird.

Ich will die geschichtliche Einleitung damit zum Abschluss bringrn, dass ich noch durch einige Zahlen zeige, was im Verlaufe dieses Jahrhunderts auf dem Gebiete der städtischen Wasserversorgungen im Allgemeinen geleistet ist.

In Lond on wurden $18763_{/ 4}^{9 / 4}$ Millionen Einwohner mit täglich über $600000 \mathrm{kbm}$. Wasser durch fast 5000 Kilom. lange Hauptleitungen, denen das Wasser durch mittelst Dampfkraft betriebene Pumpmaschinen von fast 14000 Pferdekräften zugefuhrt wurde, versorgt. Ueber $226000000 \mathrm{Mk}$. waren auf die verschiedenen Anlagen, die, wenn auch nur in geringem Umfange, zum Theil in das vorige Jabrhundert mit hineingreifen, verwendet.

Für verschiedene andere Städte Eng lands mit 41/2 Millionen Einwohnern, giebt eine früher von mir gemachte, allerdings diese Anlagen wicht erschópfende Aufstellung ein tägliches Wasserquantum von über $700000 \mathrm{kbm}$. mit einem Anlagecapitale von fast $200000000 \mathrm{Mk}$.

In den vereinigten $\mathrm{Sta}$ aten sind im Laufe dieses Jahrhunderts für die Versorgung von 50 grossen Stadten $500000000 \mathrm{Mk}$. und von 250 kleineren Städten und Orten $230000000 \mathrm{Mk}$. ausgegeben. ,

In $\mathrm{Par}$ is wurden 1874 täglich $245000 \mathrm{kbm}$. Wasser für die Bedürfnisse von 1850000 Einwohnern durch ein Rohrnetz von $1370 \mathrm{Kilom}$. Länge vertheilt, und es hat von 1861 bis 1874 die Stadt $8000000 \mathrm{Mk}$. auf neue Anlagen verwendet.

Der Aufwand für städtische Wasserversorgungen betrug in den letzten 30 Jahren, soweit meine Nachrichten reichen, in DeutschOesterreich circa $50000000 \mathrm{Mk}$. und-in der Schweiz $10000000 \mathrm{Mk}$.

In Deutschland sind seit 1849 in 143 Städten, deren jede mehr als 5000 Einwohner hatte, Anlagen zur Wasserversorgung für im Ganzen 5 Millionen Menschen mit einem Kostenaufwande von circa 